\title{
ESCAPE FROM MIDDLE INCOME TRAP: AN EXPORT STRUCTURE APPROACH TO THE CASE OF POLAND ${ }^{1}$
}

Poland, although a few years ago was indicated among the countries that were in danger of falling into the middle income trap, nowadays in most studies is counted among the rich countries. Poland was examined in this article as a successful case of "escaping from middle income trap". This article searched for the keys to the success story of Poland among its trade patterns. In the analysis the author used the product space approach first developed by Hidalgo et al. (2007), and added to it market analysis, mainly using the growth-share matrix of the Boston Consulting Group, first formulated by Henderson (1970). The results show that Poland is achieving a healthy transformation towards medium technology automotive and engineering products and some high technology products. To improve its position in world markets, Poland should also carefully examine the market structure of its exports.

Keywords: product space, Poland, growth-share matrix, export structure

JEL Classification: F14, C60

DOI: $10.15611 /$ aoe.2021.2.07

\section{INTRODUCTION}

Achieving high growth rates is one of the most important aims of governments throughout the world. Although many countries reach very high growth rates from time to time, sustaining high growth is not a common occurrence. A middle income country, aiming to become a rich country, should reach high growth rates and sustain it for long periods of time, but this is usually not easy for many such countries.

The middle income trap (MIT), as a concept, was first introduced by Gill and Kharas (2007): "Middle-income countries, it is argued, are squeezed between the low-wage poor-country competitors that dominate in mature

\footnotetext{
* The Republic of Turkey Ministry of Trade, Ankara, Turkey. The views expressed in this article are those of the author and not binding for the Republic of Turkey Ministry of Trade. ${ }^{1}$ This study was funded by The Scientific and Technological Research Council of Turkey; grant number 2219.
} 
industries and the rich-country innovators that dominate in industries undergoing rapid technological change" (Gill and Kharas, 2007, p. 5).

The literature on the definition of the middle income trap can be divided into two: those perceiving the trap as growth slowdowns (Hausmann, Pritchett and Rodrik 2005; Eichengreen, Park and Shin 2013; Felipe, Abdon and Kumar 2012; Berg 2012; Aiyar 2013), and those emphasising the catching-up problems (Paus 2009; Ohno 2009; Woo 2012; Jankowska et al. 2012). The former offer a threshold GDP per capita level at which high growth rates of developing countries usually slow down and thus fall into the middle income trap. The latter use a high income country, usually the USA, as the benchmark and define middle income trap countries as those with GDP per capita levels at a certain percentage of that of the high income country for long periods of time. As of 2010, 88 countries out of 123 have per capita incomes below $30 \%$ of the USA; moreover, during 1985-2010, the gap increased for about half of the countries (Aiyar et al. 2013).

Felipe et al. (2012) defined four income categories in terms of PPP adjusted per capital income basis as: i) low income: below $\$ 2000$, ii) lower-middle income: \$2000-\$7250, iii) upper-middle income: \$7250-11750, and iv) high income: above $\$ 11750$. Descriptive statistics on data show that on average it takes 28 years for a lower middle income country to join the group of higher middle income countries, and it takes 14 years for a higher middle income country to become a high income country. Felipe et al. (2012) considered the countries remaining in their groups for more than these averages as being in the middle income trap. According to the analysis by Felipe et al. (2012), on this basis, as of 2010, 35 out of the 52 middle income countries were in the middle income trap (MIT). Being trapped in lower middle income is more likely, as out of the 35 MIT countries, 30 were in the lower middle income trap and 5 in the upper-middle income trap. Among the remaining 17 middle income countries which were not in the trap, 8 were at risk of falling into it, 3 into the lower income trap, and 5 into the upper middle income trap (Felipe et al., 2012, p. 25).

Ito (2017) explained the results of his panel data growth convergence analysis for East Asian countries: “...in Asia there are three convergence paths: low income, middle income, and high income. Economies can and do jump from one convergence path to another by pursuing reforms and stimulating innovation.... the middle-income trap is understood as a result of failing to make the jump from the middle-income convergence path to the high-income convergence path. Hence, growth convergence results in a steady 
state that is lower than the steady state of the advanced economies (or the US)" (Ito 2017; p. 4, p. 19).

The aim of this article was to examine a country which is deemed to be a rich country by some, and still a developing country (although a successful one at the edge of high income) by others, such as Poland. The author examined Poland's case focusing on its export structure, and aimed to see whether the export basket of the country is changing in line with the way that the middle income trap literature expects. After obtaining a current picture of the export basket, the author offered some policy advice to improve it, in order to reach higher levels of development and competitiveness.

\section{LITERATURE REVIEW}

One of the most frequently cited causes of the difference between growth rates of countries are productivity differences (Jankowska et al. 2012; Aiyar et al. 2013; Rodrik 2011; Y1lmaz 2016). According to Aiyar et al. (2013), in the success of Asian countries, the contribution of a robust total factor productivity (TFP) growth is important and accounted for more than half of the GDP growth in Taiwan and China. Kohli and Mukherjee (2011) stated that countries that achieve high-income levels do so by quickly converging their total factor productivity to global best practices.

The Commission on Growth and Development (2008) emphasised the importance of dedication by policy makers, public investment in health, education and infrastructure, economic policies allowing 'creative destruction', and commitment to equality of opportunities in reaching a high income level. Eichengreen et al. (2013) concluded that "slowdowns are less likely in countries where the population has a relatively high level of secondary and tertiary education and where high-technology products account for a relatively large share of exports..." (Eichengreen et al. 2013, p. 2).

There is an extensive literature on the effects of the export structure on the level of the economic development of a country. The level of sophistication of production and the export basket of a country are the most frequently named determinants of whether a middle income country graduates to a high income level or falls into the middle income trap. To be able to escape it, most studies emphasise the importance of the structural transformation of production and the export basket of a country from low value added, low technology activities to high technology activities, and the country's production of its own technology and innovative products rather than copying them from elsewhere. According to Lucas (1988), "a growth miracle sustained for a period of decades thus must involve the continual introduction of new goods, not merely 
continual learning on a fixed set of goods." Similarly, Michalski (2018) pointed out: "the essence of the middle-income trap is that an economic system smoothly adopts foreign technologies, which induces better productivity of labour and relatively higher wages, but is incapable of creating its own innovations" (Michalski 2018; p. 407).

Zhu, He and Zhou (2017) differentiated regional diversification patterns into two: path-dependent and path-breaking. Developing countries, to be able to reach developed countries' level should make path-breaking diversifications into higher value added industries. Path dependencies exist due to fact that countries can more easily diversify into products that are technologically proximal, in which case, for many developing countries there may not be higher value added and higher technology products that the country can easily jump to, hence the country can get locked into the existing products and technologies. On the other hand, path-breaking requires radical innovations against technological discontinuities. The authors searched for the determinants of such path-breaking diversifications and suggested that extra-regional linkages and internal innovation are important factors determining it, thus emphasising the role of economic and institutional factors in jumping from one point to another in the product space.

According to Rodrik (2011), the convergence gap between developed and developing countries has not closed for many developing countries. Convergence is not an automatic process, it depends on specific policies and institutional arrangements that are usually hard to identify and implement. For convergence, the structural transformation of the economy from low to high productivity activities, and to more diversified production, is necessary. When an economy achieves this and begins to be a producer of high value added, high technology products, it is on the way up. According to Rodrik, such a structural transformation usually cannot be achieved by unassisted market forces, and the active participation of governments is necessary.

Paus (2009) compared China and Latin American countries in terms of the middle income trap and mentioned that, although China currently has a lower level of per capita GDP than LA countries, its export basket is similar to that of a much higher income country, and thus China is in a better position confronted with the middle income trap. Paus (2009) thought that this was largely due to wise government policies applied by China to ensure structural transformation.

Kanchoochat and Intarakumnerd (2014) in their survey of middle income trap, also emphasised the importance of the sophistication level of the production and export structure of the country to escape the middle income trap. The authors classified the policy advice in the literature to avoid MIT into 
three: i) those emphasising the role of achieving proper education and institutions thus giving the state a minimum role, ii) those emphasising the role of export composition and comparative advantage, usually seeing the state as a facilitator, iii) those emphasising the role of innovative technologies and suggesting that state should have an active role in enhancing capability accumulation, industrial upgrading and the production of higher technology products.

There are also studies questioning the very existence of a middle income trap. Examining the literature on the subject, Wade (2016) said that there is not enough evidence to conclude that there is a middle income trap, and that the countries in middle income levels are more prone to growth slowdowns in comparison to low or high income countries. However, he also observed that "if we use the idea in a looser and more metaphorical sense to mean that countries in a broad middle-income band (divided into lower and upper-middle) have a higher probability of experiencing sharp slowdowns and sustained lower than average growth for a decade or more than either low or high-income countries, it is 'real enough' to be taken seriously by national policy makers and international development organizations" (Wade 2016, p. 27)

Ye and Robertson (2016) developed a test of whether a country was in a middle income trap or not and concluded that according to the test results there was little evidence of MIT, as only seven countries happened to be candidates for MIT out of the 46 middle income countries. The test depended on time series analysis of the growth path of countries relative to a rich reference country, "specifically, a necessary condition for country $i$ to be in a MIT is that the expected value, or long term forecast, of $i$ 's per-capita income relative to the reference country is time invariant and lies within the middleincome band" (Ye and Robertson 2016, p. 175). They classified the country in MIT if its growth rate prematurely converged before its income reached the level of rich reference country (the US in their analysis).

Bulman, Eden and Nguyen (2017) also questioned the existence of a middle income trap, suggesting that there is not enough evidence that middle income countries are more likely to stagnate than countries at other income levels. The authors ran growth regressions of low and middle income countries and their results did not support the common theoretical MIT view that innovation and human capital accumulation are more important growth factors for middle income countries than low income countries. However, they concluded that there are different policy choices and different growth fundamentals between successful middle income countries who "escaped to high income" and who continued to be in middle income status, namely higher 
TFP growth, faster transformation from agriculture to industry, higher export shares, lower inflation and decreases in inequality and dependency ratios (Bulman et al. 2017).

This article examined Poland's export structure as a successful case of escaping or near- escaping from the middle income trap in the very recent past. Felipe et al. (2012) listed Poland among those countries that are not in the middle income trap but can fall into it if they cannot achieve high growth rates. Yet the authors also made the observation that, "at the rates their income per capita is growing, Poland can make it to high income in 2013". On the other hand, as of 2011, according to the World Bank criteria, Poland was included among the high income countries. Thus, the country represents an interesting threshold case of falling into the middle income trap versus reaching high income status.

According to the World Bank (2017), reforms of the transition from communism was important for Poland's success. Poland improved the institutions, especially the rule of law, the property rights, democratic accountability, and basic market institutions, whilst EU accession and membership reinforced the process. The country achieved stability and resilience as a result of sound macroeconomic policies, ensured competition in the domestic market and successfully connected to global and regional markets (World Bank 2017). Wojnicka-Sycz (2018) considered the transformation of Poland from a command economy to a market economy as a huge success, stressing that Poland has one of the lowest levels of unemployment in the EU, the annual average growth rate in 1995-2016 was $4.1 \%$, and in 2015 GDP in terms of purchasing power was $250 \%$ higher than its 1990 level.

Poland modernized its production base and achieved high growth rates, especially in recent years. The country has valuable natural resources, a welldeveloped network of environmentally protected areas, a stable macroeconomic situation, a fast growing economy and an increasing education level of its work force (Bialek and Oleksiuk 2016). Poland has strong economic and investment ties with Germany and other high income EU countries, serving as a cheap, high quality production platform for them (Orenstein 2014).

Felipe et al. (2010) calculated the index of opportunities of developed and developing countries based on their capability to undergo structural transformation. They analysed countries based on four dimensions of characteristics of their export basket: sophistication, diversification, standardness and the possibility for exporting with comparative advantage over other products. The authors described Poland as one of the most successful in all these criteria and third after China and India in the overall index. 
Hare (2019) concluded that "Poland's transition experience remains one of the most impressive in the region, and the country's income level did catch up significantly with the EU average, though many observers still find the rate and extent of this catch up quite disappointing" (Hare 2019, p. 219).

Poland is naturally not without problems; the country struggles to close the productivity gap with more developed EU member states, there are frequent changes in legislation, the level of innovativeness is unsatisfactory, the share of high and medium technology products in production and exports are low, and there is a relatively high risk of poverty and social exclusion (Bialek and Oleksiuk 2016). According to the study, the country will most likely fell into the middle income trap.

Michalski (2018), examining the technology structure of Polish production and exports, concluded that the Polish economy is still severely exposed to threat of MIT, providing evidence that there is a trade surplus in resources and labour-intensive products, and low-tech and medium-tech products using old technologies. On the other hand, Poland has a trade deficit in high-tech products. The country attracted foreign investment, but multinational companies seem to be uninterested in developing a skills base of Polish workers. Poland is unable to commercialize the outcomes of its domestic innovative efforts, which is a typical syndrome of the middle income trap (Michalski 2018).

Hence, it seems that there is no consensus in the literature on whether the country is in MIT or not. Poland is an interesting threshold case, with some successes and some problems common to many upper middle income countries. Since the export structures of countries are very important determinants of their income level, and many studies on MIT indicated the importance of the sophistication level of exports, this author focused on the export structure of Poland.

This article tested the hypothesis that a middle income country, to be able to escape MIT and to reach high income status, has to change its export structure to include more sophisticated products. High growth performance goes in tandem with the successful transformation in export structure. To test this hypothesis, Poland is an important case in point; is it is a large middle income country that has just passed to high income status from some points of view, or has it not yet passed that threshold but is close to it? Still both points of view agree that Poland has experienced an important transformation in its economic structure and experienced high growth rates for a long time. The author's hypothesis is that this must reflect on the transformation of Poland's export structure towards a higher level of sophistication. By observing the growth performance Poland experienced in recent decades and the related 
literature on the subject, the hypothesis is that the export basket of Poland must have changed from lower value added, primary and resource based products to higher value added, more sophisticated, medium or high technology products.

The main contribution of the article is combining the product space analysis methodology developed by Hidalgo et al. (2007) with the market analysis methodology developed by the Boston Consulting Group (1970), and revealed comparative advantage methodology developed by Balassa (1986). This enables to obtain a more complete picture of the existing diversification and sophistication level, and the future possibilities of Poland's export basket, both taking into consideration the ease of diversification of its existing capabilities and the situation of the products that country may want to diversify in the world markets. This complete picture enables both a clearer thinking on deciding to which higher sophistication sectors in terms of ease of transformation to diversify to, and at the same time creates a sharper view on whether it will be worth diversifying into these products in terms of market structure. An important question is: is it a market with growth potential, and will there be possibilities to gain competitive advantage?. Even if Poland successfully diversifies into producing a higher sophistication product, if it cannot sell that product competitively in world markets or the market of the product is declining globally, that diversification achievement will not benefit Poland much in terms of its economic growth. Therefore, in formulating development policies, product space analysis always needs to be combined with market analysis. Later, based on results of the author's analysis, strategies are suggested for Poland's diversification.

\section{METHODOLOGY}

\subsection{Product space}

The sophistication level of products is seen to be a major determinant of the income level of countries, thus it is important to measure it. Traditionally, technology classifications were used to measure sophistication level. The technology intensity of the industries is judged using various criteria like $R \& D$ as a share of sales, employment share of scientists and engineers in total or R\&D employment, number of patents taken by industry, and technology embodied in the inputs used by the industry (Lall et al.2005). The classifications often also use technical experts' knowledge of technologies and rankings (Lall et al. 2005). Yet technology classification has some disadvantages; first of all it is often done at a quite aggregate level, usually two digit classifications, 
therefore many different technology levels of products under such a classification are ignored.

In particular, after fragmentation of production, some parts of products are produced in different countries, so, although a developing country may be just assembling a high-tech product with its cheap labour advantage, since it seems to be the exporter of the product in trade statistics, the country's export structure appears to be sophisticated. In order to be able to differentiate this, process information in addition to product information is required, which is missing (Lall et al. 2005). Another problem with technology classifications is that it ignores the quality differences between countries producing products that are seemingly under the same technology classification. Moreover, technology analysis requires industry data which are not commonly available for all countries and at detailed levels; on the other hand, trade data are much more available for a large number of countries, at very detailed levels (Lall et al. 2005).

Kaplinsky and Paulino (2005) examined unit price changes in products as an indicator of technology and innovation content, under the assumption that rising unit prices reflect growing product innovation and/or margins protected by entry barriers. The authors suggested evaluating unit price changes together with market share changes, such a combination of rising unit prices and rising market shares may indicate the existence of product rents and a appropriate path of innovation. However, a deficiency of using unit prices as an indicator of technology is that it makes the strong assumption that all changes in unit prices of industries are due to technological changes and innovation, and other factors that can affect unit prices such as demand changes, non-technological barriers to entry, process innovation, fragmentation of value chain, and policy based trade distortions either do not have an important effect on unit prices, or their effects are equal in all industries (Lall et al. 2005). Henn, et al. (2015) developed estimates of export quality by estimating a reduced form of unit price and import equations, thus removing from unit prices the effects of the income level of exporter and importer (to account for cost differences) and distance (exports to distant destinations are tilted towards higher priced goods, due to higher shipping costs). The authors also calculated 'quality ladders' as an indicator of the country's position in the quality upgrading potential of products.

The study by Lall et al. (2005) was among the first to use an outcome based measure of technology levels of the products, based on the idea that "an export is more sophisticated the higher the average income of its exporter" (Lall et al. 2005 , p. 5). The sophistication index of a product is calculated as the weighted average of incomes of exporters of that product, the weights being each 
country's share of world exports. The logic is that high income countries export products that can be competitive with high wages, for which technology is usually a necessary factor, among others like advanced marketing, design, packaging and branding skills, logistics and proximity advantages, fragmentability of production processes, information and familiarity with export markets, existence of natural resources, infrastructure (especially ICT) and value chain organization (Lall et al., 2005). In index technology this is an important factor, but its role cannot be differentiated from the role of other factors (Lall et al., 2005).

To assess industry relatedness, Neffke et al. (2011) used a co-occurrence based measure, i.e. "revealed relatedness", using plant level micro data. The revealed relatedness index was based on the ratio in which different industries exist in the portfolios of same manufacturing plants. If two industries happen to be together frequently in the same plant, it is usually due to the fact that the production processes of one generate economies of scope for one another; the same machinery and employees with similar skills can be employed in the production capacity of both industries. The high degree of variety among related industries in the region and inter-industry trade linkages with other regions increase knowledge spillovers, learning opportunities, and thus the diversification possibilities of firms to new industries (Neffke et al. 2011).

Poland is a country newly graduating to a high income level. This study firstly analysed the export structure of Poland using various indices suggested in the literature, and tried to provide a picture of the degree of sophistication and competitiveness of its export products. Next, some policy advice was offered to improve the export product base to reach higher levels of sophistication and competitiveness.

In recent years the product space approach has been developed and brought an original and insightful understanding to the subject. This study also adopted the product space approach and calculated the indices suggested in the literature, details of which are shown below.

The first article on product space was by Hidalgo et al. (2007), according to which the growth of economies depends on their upgrading of the products they make and export. To manufacture new products, the necessary technology, capital, institutions and skills are adapted from the existing ones, and some are nearer to those that will be newly produced and some are further away, in a hypothetical 'product space', where some parts are denser, and some sparser. Highly sophisticated products are placed in the dense parts of the product space with more connections, and low-sophistication products are placed in the periphery of the product space with more distance to the sophisticated products. The development level of a country was determined to a large extent 
by its ability to move from the periphery to the dense core by travelling the distance between the less sophisticated products and the more sophisticated ones. This is an outcome based on the measure of similarity of product; rather than looking at the physical similarities between products or their inputs, the similarity measure is based on trading outcomes (Abdon and Felipe 2011).

One of the important aspects of the product space approach is that it takes into consideration the path dependency created by the current structure of export products, as not all products have the same potential to create longterm growth. Specializing in higher value added goods will bring higher economic growth (Record et al. 2010). Traditional trade theories such as Ricardo or Hecksher-Ohlin, implicitly assume that it is most efficient for the country to specialize and export in line with its factor endowments, while the long-term growth implications of this are ignored.

According to Hidalgo et al. (2007) and Hidalgo and Hausmann (2011), the new products that a country develops depend substantially on the capabilities already available in that country. The authors aimed to link countries with the capabilities they have, and the products to capabilities they require. They questioned the Dixit-Stiglitz assumptions (Dixit and Stiglitz 1977) that the cost of product development is independent of any characteristics of the product, and the independence of the relationship between a particular product and the previous productive history of a country. As the authors emphasise, the cost of developing a regional jet aircraft cannot be the same for a country who produces only raw cocoa and coffee than for a country who developed transcontinental aircraft and the combustion engine.

According to Hidalgo and Hausman (2011), products use combinations of potentially many non-tradable capabilities as inputs. Products differ in the variety of capabilities they require, and countries differ in their posession of various capabilites. The authors defined the "quiescence trap", namely countries with few capabilities will find it difficult to produce new products, for example if a complex product requires 30 different capabilities and a poor country has 10 capabilities, even if it develops, 5,10 , or 15 new capabilities, it will not be able to make that product. On the other hand, a rich country with 25 capabilities out of the required 30, would have the incentive to develop 5 new capabilities and produce the output. This meaning that countries with few abilities have less incentive to develop new capabilities, and thus small initial differences between countries in terms of capability endowments would be amplified over time (Hidalgo and Hausman 2011).

Hausman and Klinger (2006) pointed out that product space is not smooth and countinous, rather in some areas it is dense, and in some areas it is quite sparse. The density of the area in the product space near the area of a country 
which has a comparative advantage is very important in the structural transformation of that country.

Hidalgo et al. (2007) defined the proximity of the products as "the minimum of the pairwise conditional probabilities of a country exporting a good, given that it exports another":

$$
\phi_{i, j}=\min \left\{P\left(R C A x_{i} \mid R C A x_{j}\right), P\left(R C A x_{j} \mid R C A x_{i}\right)\right\} .
$$

Thus, RCA is Balassa's (1986) definition of revealed comparative advantage calculated as the share of the product in a country's export basket relative to the product's share in total world exports.

To test whether countries produce new products that are nearer to the existing product structure, Hidalgo et al. (2007) calculated density as the average proximity of a new potential product $j \mathrm{j}$ to a country's current product structure:

$$
\omega_{j}^{k}=\frac{\sum_{i} x_{i} \phi_{i j}}{\sum_{i} \phi_{i j}}
$$

Here, $x_{i}=1$ if $R C A_{k i}>1$, that is, to find the average proximity of new product $j$ to the current production structure of the country, the authors added proximity of product $j$ to the products $i$ that the country can produce with comparative advantage, and divided it with the total proximity of the new product to all the other products.

Abdon et al. (2010) ranked 5,107 products and 124 countries in terms of product complexity. According to these calculations, chemicals and allied industries, electrical machinery, plastics, rubber, metal products and transportation are the most complex products; they are at the same time located in a densely connected core, with many nearby products. The least complex product groups of footwear/headgear, textiles, vegetable products, raw hides, skins, leather and furs, foodstuffs, animal and animal products are in the periphery of the product space, in less connected areas. Thus, it is more difficult for the countries producing least complex products to achieve development by transiting to higher value added nearby products. As expected, the major exporters of high complexity products are high income countries and the major exporters of low complexity products are low income countries.

Changing the line of the product, and entering a new industry, is difficult especially for the leading companies, as the process involves many fixed costs in terms of securing requisite inputs, infrastructure needs, research and 
development capabilities, regulatory services, workforce with relevant experience, geographic location, production technology, distribution channels etc. These costs increase with the distance between existing production techno-logies and those planned to be produced. Once these costs are incurred, it becomes a public good, and the firms that follow can more easily operate in the industry without incurring these fixed costs (Hausman and Klinger 2006).

There is a market failure of a public goods kind, potential innovators cannot internalize the benefit of entering into new product lines to the next generations or to other existing industries. There could even be stagnation in the process of structural transformation if there are no goods at the right distance sufficiently attractive for any of the companies to pay for the fixed adjustment cost. The nearby goods may be downscaled (have a lower price than the current good) and upscaled goods may be too far away. Thus, there is a need for regulation from the viewpoint of a social planner with a longer time horizon, even inter-generational horizon, therefore government intervention is necessary (Hausman and Klinger 2006).

For pertinent case studies using the product space approach, one can refer to Abdon and Felipe (2011), Fortunato et al. (2015), Record et al. (2010), Cruz and Ricker (2012), Violata and Davidsons (2008), Bayudan-Decaycuy (2012) and Kali et al. (2013).

Hausmann et al. (2007) measured the sophistication of export products and the sophistication level of the export basket of a country, using the PRODY and EXPY concepts. The PRODY of a product is the weighted average of the GDP per capita of the countries exporting these products, where the weights are the RCA of the country for that product. The EXPY of a country is the average PRODY of the export basket of the country. There have been criticisms about how successful PRODY and EXPY are in measuring the degree of sophistication, for instance some low-tech products seem to be sophisticated just because many developed nations produce them (e.g. bacon and ham) and PRODY and EXPY do not take into consideration quality differences (World Bank 2014). PRODY and EXPY ignore value chains, and which phase of production is performed in which country; a high-tech product may seem to have low sophistication just because its final assembly is carried out in a developing country and exported from it (the World Bank, 2014). PRODY and EXPY also ignore global demand for the products; if a country tries to diversify to a high PRODY product, there is no guarantee that it will find enough demand for that product. Therefore, sophistication analyses should always go hand-in-hand with market analysis. This study tried to do this by adding market information to sophistication analyses. 
To answer these problems with PRODY and EXPY, Hidalgo and Hausmann (2009), Hausmann and Hidalgo (2011) defined ubiquity indices. This study also calculated the ubiquity of each product using the formula given by Hidalgo and Hausmann (2009). Adjacency matrix $M_{c p}$ was defined by Hidalgo and Hausmann (2009) as taking $M_{c p}=1$ if country c is a significant exporter of product $\mathrm{p}$ and taking the value of 0 if otherwise. The authors defined a significant exporter as having an RCA value greater than 1. Balassa's (1964) definition of RCA was used: the ratio of the export share of the product in the country's total exports to the share of the product in the global markets. Then, to calculate the indices about diversification of the countries and the ubiquity level of their products, the authors used an iterative method they called "the method of reflections", and characterized the countries through vector $k_{c}=\left(k_{c, 0}, k_{c, 1}, k_{c, 2}, \ldots, k_{c, N}\right)$, and the products by vector $k_{p}=\left(k_{p, 0}, k_{p, 1}, k_{p, 2}, \ldots, k_{p, N}\right)$.

Here, $k_{c, 0}$ and $k_{p, 0}$ are defined in the equations below, where $k_{c, 0}$ represents the level of diversification of a country (the number of products exported by that country with comparative advantage), whilst $k_{p, 0}$ the ubiquity of a product (the number of countries exporting that product with comparative advantage):

$$
\begin{aligned}
& k_{c, 0}=\sum_{p} M_{c p} \\
& k_{p, 0}=\sum_{c} M_{c p}
\end{aligned}
$$

Other variables of the vectors were calculated, using the method of reflections:

$$
\begin{aligned}
& k_{c, N}=\frac{1}{k_{c, 0}} \sum_{p} M_{c p} k_{p, N-1} \\
& k_{p, N}=\frac{1}{k_{p, 0}} \sum_{c} M_{c p} k_{c, N-1}
\end{aligned}
$$

The generalized measures of diversification of the countries were shown by the even variables of the country vector $k_{c}=\left(k_{c, 0}, k_{c, 1}, k_{c, 2}, \ldots ., k_{c N}\right)$, and the generalized measures of ubiquity of their exports by the odd variables of that vector. The product vector's even variables $k_{p}=\left(k_{p, 0}, k_{p, 1}, k_{p, 2}, \ldots, k_{p, N}\right)$ represent the product's ubiquity and the ubiquity of other related products, whereas the odd variables show the diversification of the countries exporting those products (Hidalgo and Hausmann 2009, p. 10571). The values of $k_{p, N}$ and $k_{c, N}$ converge to mean as $\mathrm{N}$ increase. After enough iterations, the rankings of the variables remain unchanged (Hidalgo and Hausmann 2009).

Hidalgo and Hausmann (2009) described the interpretation of the first two levels of these indices as below: 
Table 1

Descriptions of Ubiquity and Diversification Measures

\begin{tabular}{l|l}
\hline \multicolumn{1}{c|}{ Definition } & \multicolumn{1}{c}{ Description } \\
\hline$k_{c, 0}$ & Number of products exported by country c (competitively) \\
\hline & How many products are exported by country c? \\
\hline$k_{p, 0}$ & Number of countries exporting product $\mathrm{p}$ (competitively). \\
\hline$k_{c, 1}$ & How many countries export product $\mathrm{p} ?$ \\
\hline & Average ubiquity of the products exported by country c. \\
\hline$k_{p, 1}$ & How common are the products exported by country c? \\
\hline & Average diversification of the countries exporting product $\mathrm{p}$. \\
\hline
\end{tabular}

Source: Hidalgo and Hausmann (2009).

\subsection{Market and competitiveness analysis}

As mentioned previously, product space analysis should be combined with market analysis to be able to perceive the complete picture and to formulate better policies.

This study added market share, revealed comparative advantage and the Growth-Share Matrix analysis to better understand the sectoral export performance and competitiveness of Poland.

To calculate the RCA of Poland and other countries, the study used the Balassa (1986) method, where $\mathrm{c}$ denotes the country and i denotes the product:

$$
\operatorname{RCA}(\mathrm{c}, \mathrm{i})=\frac{\operatorname{Exports}(\mathrm{c}, \mathrm{i}) / \text { Total Exports }(\mathrm{c})}{\text { Total World Exports }(\mathrm{i}) / \text { Total World Exports }}
$$

The RCA (Revealed Comparative Advantage) of a country in a product is measured by the product's share in total exports of that country, over the product's share in total world exports. If the index is greater than 1 , it means that the country exports more of that product in proportion to its total exports than the world average; thus more successful in that product than the world average. Hence, 1 is usually used as the threshold indicator of a country having comparative advantage in the export of that good.

The Growth-Share Matrix was developed by B. Henderson of the Boston Consulting Group at the beginning of the 1970s as a planning model for the firm and activity portfolios of holdings, and afterwards was used widely by many companies in their decision-making processes. According to Reeves et al. (2015), in the late 1970s and early 1980s about half of all the Fortune 500 
companies used the BCG matrix, which helps companies to evaluate the performance of their business unit regarding the dimensions of market share and growth rate.

Table 2

BCG Growth-Share Matrix

\begin{tabular}{l|c|c|c}
\hline \multirow{3}{*}{$\begin{array}{l}\text { Annual Rate } \\
\text { of Market }\end{array}$} & & \multicolumn{2}{|c}{ Relative Market Share } \\
\cline { 2 - 4 } Growth & & High & Low \\
\cline { 2 - 4 } & High & Stars & Question Marks \\
\cline { 2 - 4 } & Low & Cash Cows & Dogs \\
\hline
\end{tabular}

Source: Henderson (1970).

According to Henderson (1970), a holding company, if it wants to be successful, should have a portfolio of products with different growth rates and market shares. To be able to have a high market share, investment must be made. Since in high share markets companies have higher margins, these markets can provide cash flow to the company. The growth of the market reflects the attractiveness of the industry, and relative market share shows the competitive advantage. Each product has its own life cycle and companies have products at various levels of this life cycle; managing different risks and returns and forming a balanced portfolio of activities are important for companies (Ioana et al. 2009).

According to Reeves et al. (2015), in today's world, market share is not a sufficient indicator of competitiveness; in rapidly changing environments the ability to adapt to changing circumstances or shaping them, become new drivers of competitive advantage.

This concept can be applied to countries as well. They are competing in the world markets with their products, and for some products the world markets are growing at a high rate, while for some at a low rate. The BCG GrowthShare Matrix can also guide countries in shaping their export products portfolio.

The BCG Growth-Share Matrix comprises four components: stars, cash cows, question marks and dogs.

Stars: These are sectors with high potential. Since the companies' market share is high, earnings are high, and at the same time, since the market growth is notable, so is expenditure. In the future, the growth rate of the market will decline and the sector will serve as a cash cow to firm/country if the firm/ country can keep up its high share. If the leader position is lost, the sector may become a dog. Star sectors are important to the firm/country, every firm/ country needs to have some. 
Cash cows: These are sectors with low growth rates where the firm/country has a high market share. Since the firm/country is the market leader, it earns more than necessary to remain in the market. Excess cash milked from the cash cows can be invested in stars. Usually firms/countries think that investing in their capacity is not worthwhile in these sectors since the sector does not have a future.

Dogs (or pets): Both the sector's growth rate is low and the firm/country has a low share in it. Since the potential of the sector is low, the firm/country should not invest in it. Since its market share is also low, it does not generate much money either. The firm/country should exit from the sector in time when it becomes unable to generate enough money to break even in the sector.

Question Marks: Since the sector is growing fast, investment is necessary, on the other hand, since the market share of the firm/country is low, the sector does not generate enough money. The sector can grow better in the future, thus, if the firm/country invests in it and gain a market share, it can become a star. However, there is a risk of the low or declining growth of the sector in the future, in which case the investment may be wasted. Careful planning and forecasting is important to decide whether it is worth making large enough investments so as to make the company become the market leader in the sector.

\section{RESULTS AND INTERPRETATION}

In this section the export structure of Poland is evaluated. For this purpose, $k_{c}$ of Poland and $k_{p}$ of products it exported were analysed and product space analyses were combined with market share and competitiveness analysis.

The data were SITC Rev. 3 classification 4-digit product level data taken from the UN Comtrade database. In nearly all studies in the literature, 4-digit level is preferred due to being both detailed enough to make the necessary product analysis, and plain enough to be able to formulate sectoral policies.

In Appendix Table A1, the kc20 ranking of countries, and in Appendix Table A2 the kc19 rankings of the countries for 2015 and 1995 are shown. Each iteration of the method of reflections refines the ranking and usually the rankings converge in 18-20 iterations which leads to better interpretations (Hidalgo and Hausmann 2009; Abdon et al. 2010). Thus this analysis was based on 19 and 20 iterations for both the kc and kp indices. The even variables of kc represent the diversification of countries, and the odd variables represent the ubiquity of their exports. The even variables of kp represent the product's ubiquity and the odd variables of $\mathrm{kp}$ represent the diversification of the countries exporting these products. 
According to the kc20 rankings, as of 2015 the most diversified countries were Japan, Switzerland and Taiwan. Poland was $35^{\text {th }}$ in the ranking of 150 countries, while Iraq, Afghanistan, Sudan and Angola were the least diversified countries. In 1995 the top ranking was more or less similar. The USA's fall from $8^{\text {th }}$ rank to $13^{\text {th }}$ place attracted attention. Poland dropped from $31^{\text {th }}$ position to $35^{\text {th }}$ in the past 21 years.

The kc19 of a country, being an odd number, represents the average ubiquity of the products exported by country c, i.e. how common are the products exported by the country. Thus an increasing number means that the country has a comparative advantage in the products competitively exported by many countries. Table A2 gives the scores in ascending order.

In 2015 the countries that are exporting the least ubiquitous products were Iraq, Japan, Switzerland, Taiwan, South Korea and Singapore; those producing the most common products were Afghanistan, Sudan, Ethiopia, the Maldives and Guinea. Poland was 37th, while in 1995 the country's ranking was 32 . Another significant change in ranking was the fall of the USA - from being $8^{\text {th }}$ in 1995 to $14^{\text {th }}$ in 2015 . The situation of Iraq is interesting in that in 2015 the country was exporting the least ubiquitous products, well above the high income countries. The reason was that, although the country can export only four products with comparative advantage, being the only exporter of product 2114 (goatskins) with an RCA greater than 1 globally, its export basket's average ubiquity dropped significantly. This is one of the indicators that ubiquity does not always mean high technology or high sophistication. Therefore this study again emphasises the importance of making product space analyses together with unit price and market analyses.

In Table A3, Poland's kc20 score is compared to that of some countries that became high income after 1990, those that are upper middle income and not yet in the middle income trap, and the countries that are in the middle income trap according to the classification of Felipe et al. (2012). Mauritius, Chile, Argentina, Greece, Portugal and Spain are less diversified than Poland, despite being high income countries. Among those that are upper middle income and not yet in the middle income trap, all the countries except for China, Thailand, Hungary and Mexico have less diversification than Poland. Among countries in MIT, only Malaysia is more diversified than Poland.

Table A4 shows product rankings for each product, kp20, and technology classification. In 2015, the kp19 and kp20 rankings were very similar, so this study used kp20. Since it is an even reflection, kp20 represents ubiquity of the products. The technology classification was taken from UNCTAD, defined on the SITC Rev. 3, 3-digit products. The UNCTAD, basing its calculations on Lall (2000), classified commodities into 11 categories: i) Primary products, 
ii) Resource-based manufactures: agro-based, iii) Resource-based manufactures: other, iv) Low technology manufactures: textile, garment and footwear, v) Low technology manufactures: other products, vi) Medium technology manufactures: automotive, vii) Medium technology manufactures: process, viii) Medium technology manufactures: engineering, xi) High technology manufactures: electronic and electrical, $\mathrm{x}$ ) High technology manufactures: other, xi) Unclassified products (UNCTAD 2017).

As expected, the most ubiquitous products were primary products or resource based products, but the least ubiquitous products were not high-tech, except for 8719 , liquid crystal devices. There is even one primary product, goat skins, due to fact that only one country can produce it with comparative advantage. Thus, for a middle income developing country, wanting to diversify to higher value added products and increase sophistication of its export basket, the ubiquity of the products cannot be the only guide.

In Table A5 the rankings of high technology products (according to UNCTAD classification) are given (since classification is in 3 digits, as an approximation, the rank of the average for the 4-digit sectors in the respective 3-digit ones are taken); the rankings of high technology products in terms of their ubiquity were not very high.

\subsection{Revealed Comparative Advantage Analysis of Poland's exports}

In Table A6, for 2015 and 1995, Poland's 40 export products that have the highest RCA are given. It should be noted that many of the highest RCA and highest export share products are still either primary, agro-resource based or low-tech. The only high technology product in Poland's first 40 RCA is "7611 Television receivers" with a considerable RCA of 5.44.

On the other hand, as of 2015, Poland has a considerable RCA in some medium technology sectors, like "7753 Dishwashing machines of the household type", "7751 Household-type laundry equipment, n.e.s., whether or not electrical", "5832 Monofilament of polymers of vinyl chloride", "5534 Preparations for oral or dental hygiene, including denture fixative pastes and powders", "5812 Tubes, pipes and hoses, rigid", "7831 Motor vehicles for the transport of ten or more persons, including the driver","7932 Ships, boats and other vessels". The average kp20 rank of the top 40 products in Poland is the highest RCA of 568, which is around the world average.

In nearly all sectors, Poland improved its RCA considerably. The sectors whose RCA increased most are "451 Rye, unmilled", "353 Fish (including fillets), smoked, whether or not cooked before or during the smoking process", "7753 Dishwashing machines of the household type" and "7751 Household- 
type laundry equipment, n.e.s., whether or not electrical". In particular, in medium tech engineering products i.e. dishwashing machines and laundry equipment, Poland gained a sizeable RCA of 16.4 and 14.3 respectively from virtually non-existent exports.

Among the highest 40 RCA products, since 1995, RCA declined in 11 sectors. Except for "7932 Ships, boats and other vessels", all are either primary products or resource based agro or low-tech products; thus it can be said that the decline of RCA in these products is part of a healthy transformation process towards higher technology products.

In Table A7, Poland's RCA in high technology sectors as of 2015, in comparison to 1995, are given. Among those, as of 2015, Poland has an RCA higher than one in eleven sectors, "7611 Television receivers, colour", "7782 Electric filament or discharge lamps", "7523 Digital processing units", "7128 Parts for the turbines of subgroup 712.1", "7783 Electrical equipment, n.e.s., for internal combustion engines and vehicles; parts thereof", "7189 Engines and motors, n.e.s. (e.g. wind engines and hot air engines) parts of these", "7781 Batteries and electric accumulators, and parts thereof", "7169 Parts, n.e.s., suitable for use solely or principally with the machines falling within group 716", "7162 Motors (other than motors of an output not exceeding 37.5 W) and generators, direct current", "7163 Motors (other than motors of an output not exceeding $37.5 \mathrm{~W}$ ) and generators, alternating current", and "7711 Transformers, electrical".

In three high technology sectors, as of 2015, Poland had nearly zero exports, "7925 Spacecraft (including satellites) and spacecraft launch vehicles", "7591 Parts and accessories of the photocopying and thermocopying apparatus 751.3”, "7521 Analogue or hybrid (analogue-digital) data-processing machines".

In nearly all high technology sectors, there were notable increases in RCA. The sectors in which Poland increased its RCA the most between 1995 and 2015 were:"7611 Television receivers, colour","7523 Digital processing units","7128 Parts for the turbines of subgroup 712.1","7783 Electrical equipment, n.e.s., for internal combustion engines and vehicles; parts thereof" "7781 Batteries and electric accumulators, and parts thereof" and "7162 Motors (other than motors of an output not exceeding $37.5 \mathrm{~W}$ ) and generators, direct current". In all these sectors, Poland had nearly no RCA in 1995. This shows the successful transformation of Poland, at least in some sectors, towards high technology products.

The sectors which, although having RCA above 1 in 1995, lost out most in their RCA between 1995 and 2015, were "7761 Television picture tubes, cathode-ray" and "5423 Medicaments containing alkaloids or derivatives 
thereof but not containing hormones". There was also a considerable RCA decline in "5413 Antibiotics, not put up as medicaments of group 542"and "5415 Hormones, natural or reproduced by synthesis; derivatives thereof".

Table A8 lists the first 50 products with highest share in world exports and Poland's RCA and export share in them in 2015. They are mainly high tech products and medium tech automotive and medium tech engineering products.

In three of the high share, high technology products, Poland has considerable market power, "7611 Television receivers, colour", "7932 Ships, boats and other vessels (other than pleasure craft, tugs, pusher craft, special-purpose vessels and vessels for breaking up)"and "7523 Digital processing units, whether or not presented with the rest of a system". In "7712 Other electric power machinery; parts of the electric power machinery of group 771" also, Poland has an RCA close to 1 .

In nearly all of the highest world share medium tech automotive products, Poland has competitive power. In "7843 Other parts and accessories of the motor vehicles of groups 722, 781, 782 and 783" and "7821 Motor vehicles for the transport of goods", Poland has of RCAs 2.34 and 1.23, respectively. In "7812 Motor vehicles for the transport of persons, n.e.s.", also the RCA is not low, at 0.74 .

There are 10 medium technology engineering products in the world's highest 50 export share sectors and in 6 of them Poland has an RCA greater than 1: "7731 Insulated (including enamelled or anodized) wire, cable (including co-axial cable) and other insulated electric conductors", "7139 Parts, n.e.s, for the internal combustion piston engines of subgroups 713.2, 713.3 and 713.8", "7149 Parts of the engines and motors of heading 714.41 and subgroup 714.8", "7726 Boards, panels (including numerical control panels)", "8131 Lamps and lighting fittings (including searchlights and spotlights), n.e.s." and "7478 Taps, cocks, valves and similar appliances, n.e.s.".

There are 2 medium technology processing products in the world's highest 50 export share sectors, "5822 Other plates, sheets, film, foil and strip, of plastics, non-cellular and not reinforce" and "5989 Chemical products and preparations, n.e.s."; Poland had an RCA of 1.42 in the first one, and 0.83 in the second one.

Analysis of the export structure of the country using RCA and product space approaches showed that Poland is achieving a healthy transformation towards medium technology automotive and engineering products and high technology products. The country already gained comparative advantage in a number of high technology and medium technology products that have a high share in world trade. The products from Poland which lost RCA since 1995 
are mostly primary, resource based and low technology products. Thus, there is a transformation in the production and export structure of the country, and this transformation is probably one of the most important factors that contributed to Poland's escape (or near escape, according to some) the middle income trap and become a high income country.

\subsection{BCG Growth-Share Matrix Analysis of Poland's exports}

Table A9 presents the world's highest growing 50 sectors between 2005 and 2015, their average increase in world trade share, Poland's share in the world exports of that product, the technology classification of the product, the kp20 ranking of the product (from least to most ubiquitous) and BCG classification for Poland ${ }^{2}$. The products whose world market share grew fastest were "5416 Glycosides; glands or other organs and their extracts", "8973 Jewellery of gold, silver or platinum group metals (except watches and watchcases)", "3431 Natural gas, liquefied" and "7522 Digital automatic dataprocessing machines". Among the top 100 highest growing sectors, 10 are high technology electronic, 9 high technology other, 13 medium technology engineering, 9 medium technology processing, 9 low technology textile, 13 low technology other, 18 primary products, 7 agro-based resources, 11 resource based other, and 1 is unclassified (paintings, drawings).

Among the 993 sectors Poland export, 175 are stars and 285 are question marks. Among the 50 highest growing sectors, just 17 are stars for Poland, the others are question marks, which means that Poland has a high market share in 17 high growth sectors, while in others a low market share. Among the star sectors of Poland, only 2 are high technology electronic, "7783 Electrical equipment, n.e.s., for internal combustion engines and vehicles; parts thereof" and "7181 Batteries and electric accumulators, and parts thereof". Among these stars 4 are medium technology engineering, 4 are primary products, 3 are low tech-other, 2 are medium technology processing, 1 is resource based agro and 1 is low tech-textile. Among Poland's stars, "7783 Electrical equipment, n.e.s." (kp20 rank 122) is the least ubiquitous, followed by "7478Taps, cocks, valves and similar appliances, n.e.s." and "7726 Boards, panels (including numerical control panels), consoles, desks, cabinets and other bases". The average kp20 ranking of Poland's stars was 521, so ubiquity of the star products of the country is around the world average.

Among the 175 cash cows of Poland, the first 40 in terms of share of Poland in world exports of the sector are given in Table A10. Out of these, 11 are

\footnotetext{
2 The author regards Poland as having a high share in a market if it has a market share greater than 1.07 , i.e. Poland's total exports share in world exports.
} 
resource based agro (mostly wood and wood products), 9 are primary products (mostly meat, copper, zinc, tin), 4 are medium-tech engineering (dishwashers, laundry equipment, ships, refrigerators), 4 are low-tech other (candles, envelopes, wooden furniture), 3 are resource-based other (coke, glass, wool based products), 3 are high-tech electronic (televisions, lamps, digital processing units), 2 is medium-tech processing (monofilaments and tubes, pipes, hoses), 1 is medium-tech automotive (motor vehicles) and 1 is low-tech textile (leather articles). Poland is a country with rich forest resources and some mines. The country has also competitive advantage in many consumer electronics products. Although, the world trade share of these products is declining, Poland can still take advantage of its market power in these sectors and use the cash generated from exports in these sectors to improve the sophistication of its export basket.

Among the 993 sectors in which Poland has exports, 358 are dogs. The top $40 \mathrm{dog}$ sectors in terms of share of Poland in world exports in the sector are given in Table A11. Since in both these sectors, the world market share is declining and Poland has a low market share, they are not worth further investment. The country should divest itself of these sectors when they stop generating enough cash and use the resources in faster growing sectors of global economy. Out of these sectors, 11 are low technology, 6 resource-based, 3 primary, 18 medium technology and just 2 are high-tech sectors.

Out of the 993 sectors in which Poland has exports, 285 are question marks. The top 40 question mark sectors in terms of share of Poland in world exports of the sector are given in Table A12, of which 8 are resource-based and primary, 17 medium technology, 14 low technology, and just one "7712- Other electric power machinery; parts of the electric power machinery of group 771 ", is a high-tech sector. Poland should examine these sectors in detail, and try to predict future growth potential of the sectors, the big exporters in world markets, the probability of gaining a sizeable share from them in the world markets if it invests, and how much investment will be necessary to gain the high share and will the expected future revenues be worth it.

In Table A13 densities, i.e. average proximity, of high technology products to the country's current product structure were calculated for Poland, using the definition by Hidalgo et al. (2007):

Hidalgo et al. (2007) calculate density as average proximity of a new potential product $\mathrm{j}$ to a country's current product structure:

$$
\omega_{j}^{k}=\frac{\sum_{i} x_{i} \phi_{i j}}{\sum_{i} \phi_{i j}}
$$


Here, $x_{i}=1$ if $R C A_{k i}>1$, i.e. to find the average proximity of new product $j$ to the current production structure of the country, the authors added the proximity of $j$ to the products $i$ that country can produce with comparative advantage, and then divided it to the total proximity of the new product to all the other products.

In Table A13, the average proximities of biggest world trade share products to Poland's current product structure are given for 2015 and 1995, respectively. Among the 100 highest world trade share products, Poland has a comparative advantage in 39 of them. All of these are stars or cash cows. Among them, 5 are high technology products : "7611 Television receivers, colour","7932 Ships, boats and other vessels (other than pleasure craft, tugs, pusher craft, special-purpose vessels and vessels for breaking up)","7523 Digital processing units, whether or not presented with the rest of a system", "7783 Electrical equipment, n.e.s., for internal combustion engines and vehicles; parts thereof" and "7781 Batteries and electric accumulators, and parts thereof"; 8 products are low technology, 18 are medium technology and 8 are primary or resource based.

Out of the remaining 61 in which Poland does not have RCA, the first 5 products that are closest to Poland's exports structure are primary or low tech goods like fruits, some garments and footwear. The sixth is " 5429 Medicaments n.e.s", which is high technology and Poland's RCA in that sector, although lower than 1 , is fairly good at 0.69 . Thus there can be opportunities for Poland in this sector, in 1995 the RCA of Poland in that sector was 0.89 . The reasons for this decline should be further explored. In 17th place there is another high technology sector, "8746-Automatic regulating or controlling instruments and apparatus", but this is a dog sector for Poland, meaning low market share in a non-growing market. Thus, whether the diversification into that sector is worthwhile or not should be investigated; RCA increased from 0.17 in 1995 to 0.79 in 2015. In 20th, 23th and 29th places there are high-tech sectors of respectively, "7929 Parts, n.e.s. (not including tyres, engines and electrical parts), of the goods of group 792", "7712 Other electric power machinery; parts of the electric power machinery of group 771" and "7788 Electrical machinery and equipment, n.e.s.". The first two are question mark sectors and the last is a dog. Hence the first two may be worth investing in, especially 7712 , whose RCA is already close to 1 , namely 0.92 , and reached that point from 0.44 in 1995 . The RCA of 7929 is also not very low at 0.45 , so there is already some capacity there and it may be worth further investment. There has been also a very significant improvement in RCA since 1995 from 0.08 to 0.45 . Out of the 61 products for which Poland does not have competitive power, 23 are high technology. The high technology products which are 
furthest from the existing production structure of Poland are: "7763 Diodes, transistors and similar semiconductor devices; photosensitive semiconductor devices", "8719 Liquid crystal devices, n.e.s.; lasers (other than laser diodes); other optical appliances and instruments, n.e.s." and "7764 Electronic integrated circuits and microassemblies". Even though these products are distant, there is a considerable improvement in RCA in sector 7763, namely between 1995 and 2015 from 0.04 to 0.4 . These results show Poland's capacity to build new capabilities even in some far-placed high technology products.

In nearly all products, Poland's export structure increased its proximity, i.e. its export structure has become nearer to the highest world trade share products. The sectors in which Poland is increasing its proximity the most are:"7139 Parts, n.e.s, for the internal combustion piston engines of subgroups 713.2, 713.3 and 713.8", "7523 Digital processing units, whether or not presented with the rest of a system", "7726 Boards, panels (including numerical control panels)", "7638 Sound-recording and other sound-reproducing apparatus; video-recording or reproducing apparatus" and "7611 Television receivers, colour". Out of the first five sectors which increased their proximity the most, two are high technology electronic products: "7523 Digital processing units, whether or not presented with the rest of a system" and "7611 Television receivers, colour", and the others are medium technology engineering products. All of the first five are cash cows except for "7726 Boards, panels (including numerical control panels)", which is a star sector.

The proximity of Poland's exports decreased in 6 of the 100 highest world trade share products : "3212 Other coal", "7239 Parts, n.e.s., of the machinery of group 723", "8453 Jerseys, pullovers, cardigans, waistcoats and similar articles, knitted or crocheted", "8442 Suits, ensembles, jackets, blazers, dresses, skirts, divided skirts, trousers, bib and brace overalls, breeches and shorts" "8414 Trousers, bib and brace overalls, breeches and shorts" and "8514 Other footwear with uppers of leather or composition leather". Among these sectors only "7239 Parts, n.e.s., of the machinery of group 723" is a medium technology engineering product. Coal is a primary product and all the others are low technology textile products. This is another indication that Poland's export structure is becoming distanced from lower value added products and is getting closer to medium technology engineering and automotive products and even to some high technology products.

Graphs A1 and A2 (taken from Atlas Media) show how much more connected Poland's export structure became in the product space between 1995 and 2015. Graph A3 and Graph A4 show tree maps of the export structure of Poland between 1995 and 2015. The decreased share of primary products like coal, copper, clothing and the increasing share of medium and high technology products like cars and electronic products are apparent. 


\section{CONCLUSION}

The transition from being a middle income country to becoming a rich country requires high growth rates sustained for long periods of time, but usually this is not easy for many middle income countries, 'trapped' into middle income for a long time before becoming a rich country. The "middle income trap" concept was first introduced by Gill and Kharas (2007), and afterwards its various definitions and an extensive literature on the subject were developed.

Poland's case is interesting in that, although the country has been indicated among those that are in danger of falling into middle income trap a few years ago, nowadays most studies list it among rich countries. Thus Poland's case was examined in this article as a successful escape (or at the very least, a near escape) from MIT.

Although in the literature many factors that cause MIT were examined and various policy proposals were prepared for middle income countries, the level of sophistication of production and the export basket of a country is one of the most frequently stated determinants of whether a middle income country graduates into a high income level or falls into a middle income trap. To be able to escape the latter, nearly all studies emphasise the importance of the structural transformation of production and the export basket of a country from low value added, low technology activities to high technology activities, and producing its own technology and innovative products rather than copying them from elsewhere.

For this reason, this article searched for keys to the success story of Poland among its trade patterns. In analysis the author used the product space approach first developed by Hidalgo et al. (2007), and added market analysis, mainly using the revealed comparative advantage of Balassa (1986) and the GrowthShare Matrix of Boston Consulting Group, first formulated by Henderson (1970).

One of the important aspects of the product space approach is that it takes into consideration the path dependencies created by the current structure of export products as not all products have the same potential to create long term growth. To produce new goods, the necessary technology, capital, institutions and skills are adapted from the existing products and some are nearer to the newly produced and some are further away in a hypothetical 'product space'. However, this approach lacks the market aspect. Analysis of sophistication of a country's exports should always go hand-in-hand with market analysis, otherwise a middle income country aiming to reach competitiveness in high value added, high technology goods may not find enough demand for its products in the world markets. 
This article combines a market analysis technique frequently used by holding companies with the product space approach. According to the GrowthShare Matrix approach of Henderson (1970), a company, if wants to be successful, should have a portfolio of products with different growth rates and market shares. To be able to obtain a high market share, investment must be carried out. Yet, since in high share markets firms have higher margins, these markets can provide them with cash flow. In this article the analysis was conducted for the export portfolio of Poland.

Product space and market analyses show that in nearly all sectors, between 1995 and 2015, Poland improved its RCA considerably, especially in mediumtech engineering products. Nearly all of the products which experienced a decline in RCA were either primary products or agro-based resources or lowtech products. Thus, it can be said that the change of RCA of the products in the export basket is part of the healthy transformation process towards higher technology products.

In the high technology sectors, as of 2015, Poland had an RCA greater than 1 in 11 sectors. Moreover, in nearly all the high technology sectors, there were significant increases in RCA. In three of the high-tech sectors with a large share in global trade, Poland has considerable market power, and in nearly all of the world's highest medium tech automotive products, Poland has a competitive power.

Among the 100 highest world trade share products, Poland has comparative advantage in 39 of them, 5 of which are high technology products. Out of the 993 sectors of Poland's export, 175 are stars, 285 are question marks, 175 are cash cows and 358 dogs. The author made policy suggestions taking into consideration the global market share of these products and their technology classification. Poland should consider further investment in its high technology star sectors in which it has a high market share and the world market for the product is also fast-growing. There are a lot of dog sectors with a low world market growth rate and in which Poland has a low share, hence the country should consider moving resources from these sectors into the sectors with better prospects.

When the proximity of Poland's export structure is compared in terms of its proximity to the highest world trade share products between 1995 and 2015, it was observed that Poland's export structure is moving far away from lower value added products and getting closer to medium technology engineering and automotive products, and even to some high-tech products.

To sum up, analyses of Poland's export structure using the product space approach showed that Poland is achieving a healthy transformation towards medium technology automotive and engineering products and some high technology products. It has already gained comparative advantage in a number 
of high technology and medium technology products that have a high share in world trade. The products where Poland lost RCA since 1995 are mostly primary, resource based and low technology products. Thus, there is a transformation in the production and export structure, which is probably one of the most important factors that gave Poland the edge in escaping from MIT and becoming a high income country. To improve its position in world markets, Poland should also carefully examine the market structure of its exports. It may be time for divesting of some dog sectors and using resources to continue the transformation to higher technology star sectors. Poland should also examine the prospects in question mark sectors and evaluate whether it will worth investing in some of them. In planning the transformation of its export structure, the country should take into consideration the fact that investing in the sectors closest to its current export structure (in terms of proximity calculations) would be more cost efficient.

The analyses in this article confirmed the initial hypothesis to a great extent. Poland, throughout its development experience, has achieved a certain transformation towards increasing the sophistication level of its export basket, which was diversified into higher value added medium-high technology sectors, and continues to diversify its export structure towards high technology sectors. This suggests that Poland is on the correct path to escape the middle income trap, if it has not done so already. The contribution of this article was to combine export sophistication analysis with market analysis, which is missing in product space analysis. Market analysis combined with product space analysis can guide government policies for various sectors, enabling Poland to explore higher sophistication products that it can easily diversify into, given its existing capabilities, and products which also have growth potential in world markets so that it will be worth effort .

In the future, the scope of the article can be extended into micro analysis. Poland, in planning to which sectors/products it wants to diversify, should first examine the macro analysis performed here, as well as product space, market share/growth potential and RCA analysis. Then it should explore more deeply how to help its firms produce these products to establish and gain competitiveness in world markets. The microanalysis of firm level data becomes important here. The analysis of the microeconomic foundations of macroeconomics became especially popular in recent decades as company level data become increasingly available and the processing capabilities of the software has increased. Indeed, examining the microeconomic foundations of macroeconomics facilitated better understanding of the dynamics behind macroeconomics. The microeconomic analysis of the structure of the existing firms, their capabilities, the transformations needed to able to produce higher value added, diversified products will be also necessary. This analysis will 
help the government to formulate policies to address educational needs of the employees, to provide the necessary infrastructure and public goods, and to provide coordination and the necessary guidance for businesses.

Another aspect to explore in future work is domestic content and value chain analysis. Value chains are becoming important in world production and trade. A country can transform its export basket towards higher value added products by taking part in global value chains, but if its part in the value chain is in low value added sections of the production process, any gains from it will be limited. Poland has established strong links with global value chains, but domestic content in exports of many medium-high and high technology sectors is declining (Michalski 2018). Domestic content analysis and how to increase domestic value added of the country in the value chains are important future possible areas of study, in order to formulate better development policies for the Polish economy.

\section{REFERENCES}

Abdon, A., Felipe, J., The Product Space: What Does It Say About the Opportunities for Growth and Structural Transformation in Sub-Saharan Africa?, Levy Economics Institute Working Paper No. 670, 2011.

Abdon, A., Bacate, M, Felipe, J., Kumar, U., Product Complexity and Economic Development, Levy Economics Institute of Bard College, Working Paper No. 616, 2010.

Aiyar, S., Duval, R., Puy, D., Wu, Y., Zhang, L., Growth Slowdowns and Middle-Income Trap. IMF Working Paper, WP/13/71, 2013.

Balassa, B., Comparative advantage in manufactured goods: A reappraisal, Review of Economics and Statistics, 68(2), pp. 315-319, 1986.

Bayudan-Decaycuy, C., The Philippine Export Portfolio in the Product Space: Potentials, Possibilities and Policy Challenges, Economics Bulletin, 32(1), pp. 59-66, 2012.

Berg, A., Ostry, J. D., Zettlemeyer, J., What makes growth sustained?, Journal of Development Economics, 98, pp. 149-166, 2012.

Białek J., Oleksiuk A., The socio-economic effects of Poland's membership in the European Union and the challenges of the middle-income trap, Journal of International Studies, 9(1), pp. 130-143, 2016.

Bulman, D., Eden, M., Nguyen, H., Transitioning from low-income growth to high-income growth: is there a middle-income trap?, Journal of the Asia Pacific Economy, 22(1), pp. 5-28, 2017.

Commission on Growth and Development, The Growth Report Strategies for Sustained Growth and Inclusive Development. The World Bank, Washington DC, 2008.

Cruz, J. D. L., Ricker, D., Product Space Analysis of the Exports of Brazil, US International Trade Commission Office of Economics Working Paper, No. 2012-06A, 2012.

Dixit, A. K., Stiglitz, E. J., Monopolistic Competition and Optimum Product Diversity, American Economic Review, 67(3), pp. 297-308, 1977. 
Eichengreen, B., Donghyun, P., Kwanho, S., Growth Slowdowns Redux: New Evidence on the Middle-Income Trap, NBER Working Paper No. 18673, 2013.

Felipe, J, Abdon, A., Kumar, U., Tracking the Middle-income Trap: What Is It, Who Is in It, and Why?, Levy Economics Institute of Bard College Working Papers No. 715, 2012.

Felipe, J, Abdon, A., Kumar, U., As You Saw So Shall You Reap: From Capabilities to Opportunities. Levy Economics Institute of Bard College Working Papers No. 613, 2010.

Fortunato, P., Razo, C., Vrolijk, K., Operationalizing The Product Space: A Road Map To Export Diversification, UNCTAD Discussion Papers, No. 219, 2015.

Hausmann, R., Hwang, J., Rodrik, D., What you export matters, Journal of Economic Growth, 12(1), pp. 1-25, 2007.

Hausmann, R., Klinger, B., Structural Transformation and Patterns of Comparative Advantage in the Product Space, Center for International Development at Harvard University Working Paper No. 128, 2006.

Hare, P., Growth and Development - Catching Up, Acta Oeconomica, Vol. 69 (S1), pp. 215 240, 2019.

Henderson, B. The Product Portfolio. https:/www.bcgperspectives.com/content/classics/ strategy_the_product_portfolio/(Accessed 16/02/2016), 1970.

Henn, C., Papageorgiou, C., Spatafora, N., Export Quality in Advanced and Developing Economies: Evidence from a New Dataset, World Trade Organization Working Paper ERSD-2015-02, 2015.

Hidalgo, C., Hausmann, R., The Building Blocks of Economic Complexity. Proceedings of the National Academy of Sciences 106(26), pp. 10570-10575, 2009.

Hidalgo, C., Klinger, B. Barabasi, A.-L., Hausmann, R., The Product Space Conditions the Development of Nations, Science 317, pp. 482-487, 2007.

Hausmann, R., Hidalgo, C., The Network Structure of Economic Output, Journal of Economic Growth, 16, pp. 309-342, 2011.

Hausmann, R., Pritchett, L., Rodrik, D., Growth Accelerations, Journal of Economic Growth 10, pp. 303-329, 2005.

Hidalgo, C., The Dynamics of Economic Complexity and the Product Space over a 42 year period. CID Working Paper No. 189, 2009.

Ioana, A., Mirea, V., Balescu, C., Analysis of Service Quality Management in the Materials Industry Using the BCG Matrix Method, Amfiteatru 270 Economic, 11(26), pp. 270-276, 2009.

Ito, T., Growth Convergence and the Middle-Income Trap, Asian Development Review, Vol. 34, No. 1, pp. 1-27, 2017.

Jankowska, A., Nagengast, A., Perea, J. R., The Product Space and the Middle Income Trap: Comparing Asian and Latin American Experiences, OECD Development Centre, Working Paper No. 311, 2012.

Kali, R, Reyes, J., McGee, J., Shirrell, S., Growth Networks, Journal of Development Economics, 101, pp. 216-227, 2013.

Kanchoochat, V., Intarakumnerd, P., Tigers Trapped: Tracing the Middle-income Trap through the East and Southeast Asian Experience, Berlin Working Papers on Money, Finance, Trade and Development, Working Paper No. 04/2014.

Kaplinsky, R., Santos Paulino, A., Innovation and competitiveness: Trends in unit prices in global trade, Oxford Development Studies, 33(3-4), pp. 333-355, 2005. 
Kohli, A. H., Mukherjee, N., Potential Costs to Asia of the Middle Income Trap, Global Journal of Emerging Market Economies, 3(3), pp. 291-311, 2011.

Lall, S., Weiss, J., Zhang, J., The 'Sophistication' of Exports: A New Measure of Product Characteristics, Manila: Asian Development Bank Institute Discussion Paper No. 23, 2005.

Lall, S., The technological structure and performance of developing country manufactured exports, 1985-98, Oxford Development Studies, 28(3), pp. 337-369, 2000.

Lucas, R. E., On the Mechanics of Economic-Development, Journal of Monetary Economics, 22(1), pp. 3-42, 1988.

Michalski, B., Looking for evidence of the middle-income trap. The case of Polish trade in high-tech goods with Germany, Post-Communist Economies, 30(3), pp. 405-420, 2018.

Neffke, F., Henning, M., Boschma, R., How do regions diversify over time? Industry relatedness and the development of new growth paths in regions, Economic Geography, 87(3), pp. 237265, 2011.

Ohno, K., Avoiding the Middle-Income Trap Renovating Industrial Policy Formulation in Vietnam, ASEAN Economic Bulletin, 26 (1), pp. 25-43, 2009.

Paus, E., The Rise of China: Implications for Latin American Development, Development Policy Review, 27(4), pp. 419-456, 2009.

Record, R., Nghardsaysone, K., Xay, P., Road, N., Lao PDR Development Report 2010 Natural Resource Management for Sustainable Development, World Bank Background Paper, Export Dynamics and Diversification in Lao PDR: An analysis of the product space, 2010.

Reeves, M., Moose, S., Venema, T., BCG Classics Revisited: The Growth Share Matrix. https:// www.bcgperspectives.com/content/articles/corporate_strategy_portfolio_management strategic_planning_growth_share_matrix_bcg_classics_revisited/(Accessed 16/02/2016), 2014.

Rodrik, D., The Future of Economic Convergence, NBER Working Paper No. 17400, 2011.

Vitola, K., Davidsons, G., Structural Transformation of Exports in A Product Space Model, Lavijas Banka Working Paper, 4, 2008.

Wade, R. H., The role of the state in escaping the middle-income trap: The case for smart industrial policy, METU Studies in Development, 43 (April), pp. 21-42, 2016.

Wojnicka-Sycz, E., The Successful Transition to a Knowledge-Based Development Path of a Less-Developed Region, Growth and Change, 49(3), pp. 569-589, 2018.

Woo, J., Technological Upgrading in China and India: What Do We Know?, OECD Development Centre Working Papers 308, OECD Publishing, 2012.

World Bank, Lessons from Poland, Insights for Poland: A Sustainable and Inclusive Transition To High Income Status. World Bank, Washington, DC, https://openknowledge.worldbank. org/handle/10986/28960, 2017.

Ye, L., Robertson, P. E., On the Existence of a Middle-Income Trap, Economic Record, 92(297), pp. 173-189, 2016.

Y1lmaz, G., Labor Productivity in the Middle Income Trap and the Graduated Countries, Central Bank Review, 16, pp. 73-83, 2016.

Zhu, S., He., C., Zhou, Y., How to jump further and catch up? Path-breaking in an uneven industry space, Journal of Economic Geography, 17(3), 2017.

Received: July 2019, revised: March 2021 


\section{APPENDIX}

Table A1

kc20 scores of countries

\begin{tabular}{|c|c|c|}
\hline Ranking & kc20-1995 & Country \\
\hline 1 & 221.256719 & Japan \\
\hline 2 & 221.256605 & Germany \\
\hline 3 & 221.256602 & Sweden \\
\hline 4 & 221.256596 & Switzerland \\
\hline 5 & 221.25653 & Austria \\
\hline 6 & 221.256526 & Finland \\
\hline 7 & 221.256513 & UK \\
\hline 8 & 221.256469 & USA \\
\hline 9 & 221.256447 & France \\
\hline 10 & 221.256439 & Italy \\
\hline$\ldots$ & $\ldots$ & $\ldots$ \\
\hline$\ldots$ & $\ldots$ & $\ldots$ \\
\hline 31 & 221.256250 & Poland \\
\hline$\ldots$ & $\ldots$ & $\ldots$ \\
\hline$\ldots$ & $\ldots$ & $\ldots$ \\
\hline 114 & 221.255903 & Burkina Faso \\
\hline 115 & 221.255887 & Malawi \\
\hline 116 & 221.255862 & Uganda \\
\hline 117 & 221.255862 & Niger \\
\hline 118 & 221.255855 & Madagascar \\
\hline 119 & 221.255839 & Burundi \\
\hline 120 & 221.255822 & Kiribati \\
\hline 121 & 221.25582 & Maldives \\
\hline 122 & 221.255809 & Sudan \\
\hline 123 & 221.255757 & Ethiopia \\
\hline
\end{tabular}

\begin{tabular}{|c|c|c|}
\hline Ranking & kc20-2015 & Country \\
\hline 1 & 219.573618 & Japan \\
\hline 2 & 219.5736 & Switzerland \\
\hline 3 & 219.573579 & Taiwan \\
\hline 4 & 219.573567 & South Korea \\
\hline 5 & 219.573562 & Singapore \\
\hline 6 & 219.573557 & Germany \\
\hline 7 & 219.573519 & Sweden \\
\hline 8 & 219.573505 & Finland \\
\hline 9 & 219.573503 & Austria \\
\hline 10 & 219.573497 & Czech Rep. \\
\hline$\ldots$ & $\ldots$ & $\ldots$ \\
\hline$\ldots$ & $\ldots$ & $\ldots$ \\
\hline 35 & 219.573413 & Poland \\
\hline$\ldots$ & $\ldots$ & $\ldots$ \\
\hline$\ldots$ & $\ldots$ & $\ldots$ \\
\hline 141 & 219.573162 & Greenland \\
\hline 142 & 219.57316 & Nicaragua \\
\hline 143 & 219.573153 & Guinea \\
\hline 144 & 219.573153 & Mongolia \\
\hline 145 & 219.573135 & Maldives \\
\hline 146 & 219.573121 & Ethiopia \\
\hline 147 & 219.573116 & Angola \\
\hline 148 & 219.573078 & Sudan \\
\hline 149 & 219.573077 & Afghanistan \\
\hline 150 & 219.571673 & Iraq \\
\hline
\end{tabular}

Source: calculations done by author using trade statistics of UN Comtrade. 
Table A2

kc19 scores of countries

\begin{tabular}{|c|c|c|}
\hline Ranking & kc19-1995 & Country \\
\hline 1 & 21.45424479 & Japan \\
\hline 2 & 21.45425969 & Germany \\
\hline 3 & 21.45426018 & Sweden \\
\hline 4 & 21.45426081 & Switzerland \\
\hline 5 & 21.45426935 & Austria \\
\hline 6 & 21.4542699 & Finland \\
\hline 7 & 21.45427151 & UK \\
\hline 8 & 21.45427713 & USA \\
\hline 9 & 21.45428004 & France \\
\hline 10 & 21.45428102 & Italy \\
\hline$\cdots$ & $\ldots$ & $\cdots$ \\
\hline$\cdots$ & $\ldots$ & $\ldots$ \\
\hline 32 & 21.45430540 & Poland \\
\hline$\cdots$ & $\cdots$ & $\ldots$ \\
\hline$\cdots$ & $\ldots$ & $\ldots$ \\
\hline 114 & 21.45434999 & Burkina Faso \\
\hline 115 & 21.45435187 & Malawi \\
\hline 116 & 21.4543552 & Uganda \\
\hline 117 & 21.45435524 & Niger \\
\hline 118 & 21.45435605 & Madagascar \\
\hline 119 & 21.45435808 & Burundi \\
\hline 120 & 21.45436004 & Kiribati \\
\hline 121 & 21.45436056 & Maldives \\
\hline 122 & 21.45436204 & Sudan \\
\hline 123 & 21.45436875 & Ethiopia \\
\hline
\end{tabular}

\begin{tabular}{|c|c|c|}
\hline Ranking & kc19-2015 & Country \\
\hline 1 & 26.48923069 & Iraq \\
\hline 2 & 26.48925522 & Japan \\
\hline 3 & 26.48925782 & Switzerland \\
\hline 4 & 26.48926190 & Taiwan \\
\hline 5 & 26.48926366 & South Korea \\
\hline 6 & 26.48926417 & Singapore \\
\hline 7 & 26.48926501 & Germany \\
\hline 8 & 26.48927074 & Sweden \\
\hline 9 & 26.48927288 & Finland \\
\hline 10 & 26.48927349 & Austria \\
\hline$\ldots$ & $\ldots$ & $\ldots$ \\
\hline .. & $\ldots$ & $\ldots$ \\
\hline 37 & 26.48928788 & Poland \\
\hline$\ldots$ & $\ldots$ & $\ldots$ \\
\hline$\ldots$ & $\ldots$ & $\ldots$ \\
\hline 141 & 26.48932547 & Angola \\
\hline 142 & 26.48932639 & Ecuador \\
\hline 143 & 26.4893271 & Greenland \\
\hline 144 & 26.48932732 & Mongolia \\
\hline 145 & 26.48932776 & Nicaragua \\
\hline 146 & 26.48932848 & Guinea \\
\hline 147 & 26.48933144 & Maldives \\
\hline 148 & 26.48933383 & Ethiopia \\
\hline 149 & 26.48933658 & Sudan \\
\hline 150 & 26.48934033 & Afghanistan \\
\hline
\end{tabular}

Source: calculations done by author using trade statistics of UN Comtrade. 
Table A3

Country comparisons of $\mathrm{kc} 20$

\begin{tabular}{|c|c|c|c|}
\hline \multicolumn{2}{|c|}{$\begin{array}{l}\text { Countries which became high income after } \\
1990\end{array}$} & \multicolumn{2}{|c|}{$\begin{array}{l}\text { Countries that are Upper Middle Income } \\
\text { and not yet in the Middle Income Trap }\end{array}$} \\
\hline & Rank in kc20 2015 & & Rank in kc20 2015 \\
\hline S. Korea & 4 & Turkey & 55 \\
\hline Taiwan & 3 & China & 31 \\
\hline Greece & 73 & Thailand & 27 \\
\hline Ireland & 29 & Bulgaria & 52 \\
\hline Portugal & 50 & Hungary & 15 \\
\hline Spain & 45 & Poland & 35 \\
\hline Argentina & 87 & Costa Rica & 66 \\
\hline Chile & 93 & Mexico & 33 \\
\hline Mauritius & 97 & Oman & 99 \\
\hline \multicolumn{4}{|c|}{ Countries in the Upper Middle Income Trap } \\
\hline & & \multicolumn{2}{|c|}{ Rank in kc20_2015 } \\
\hline Malaysia & & \multicolumn{2}{|c|}{28} \\
\hline Uruguay & & \multicolumn{2}{|c|}{80} \\
\hline Saudi Arabia & & \multicolumn{2}{|c|}{42} \\
\hline
\end{tabular}

Source: Felipe et al. (2012). 


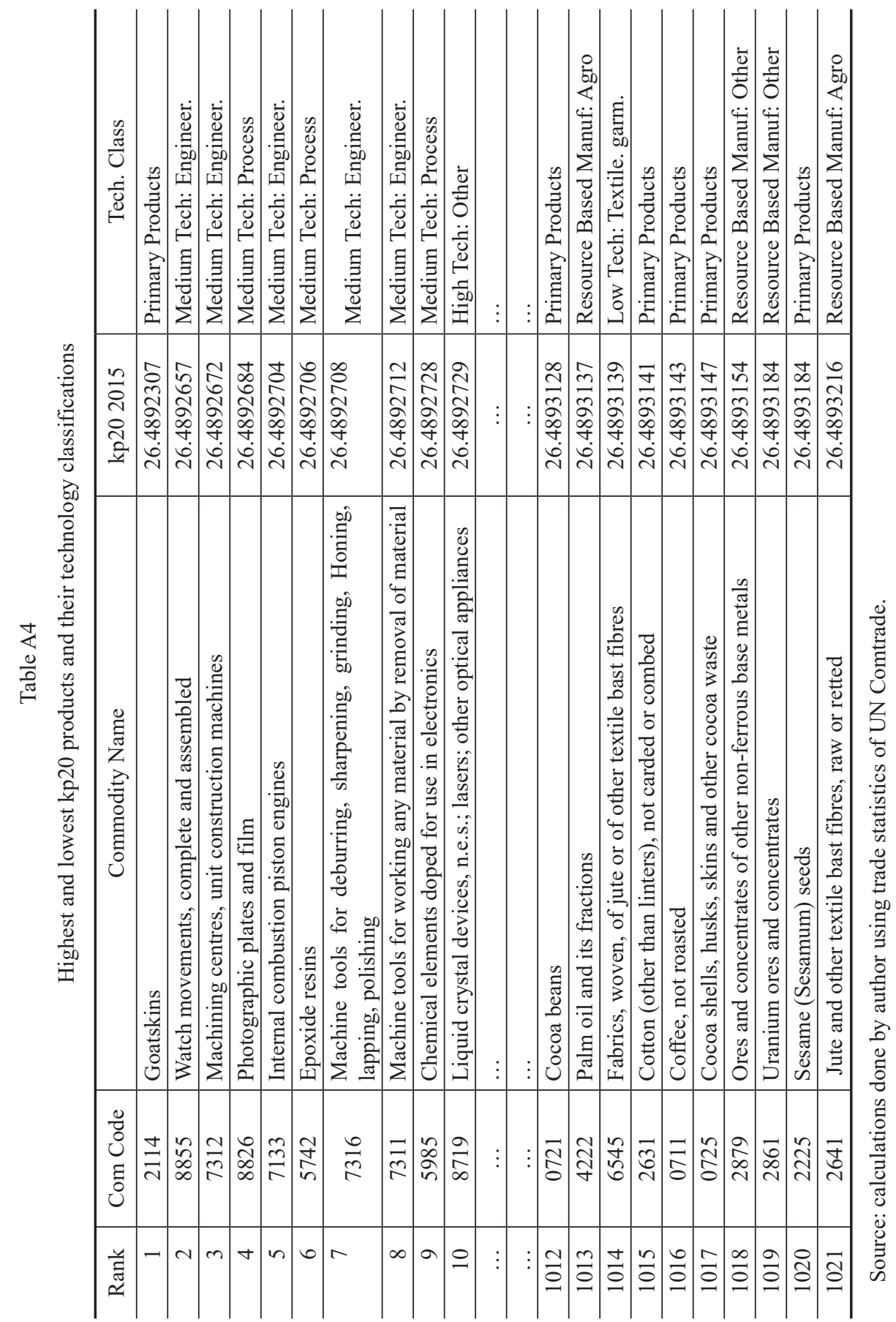


Table A5

High technology products and their kp20 rank

\begin{tabular}{c|l|c}
\hline Com Code & \multicolumn{1}{|c}{ Commodity Name } & Rank (kp20) \\
\hline 716 & Rotating electric plant \& parts thereof, n.e.s. & 324 \\
\hline 718 & Other power generating machinery \& parts, n.e.s. & 289 \\
\hline 751 & Office machines & 341 \\
\hline 752 & Automatic data processing machines, n.e.s. & 305 \\
\hline 759 & Parts, accessories for machines of groups 751, 752 & 431 \\
\hline 761 & Television receivers, whether or not combined & 686 \\
\hline 764 & Telecommunication equipment, n.e.s.; \& parts, n.e.s. & 336 \\
\hline 771 & Electric power machinery, and parts thereof & 387 \\
\hline 774 & Electro-diagnostic appa. for medical sciences, etc. & 97 \\
\hline 776 & Cathode valves \& tubes & 225 \\
\hline 778 & Electrical machinery \& apparatus, n.e.s. & 206 \\
\hline 525 & Radio-actives and associated materials & 365 \\
\hline 541 & Medicinal and pharmaceutical products, excluding 542 & 247 \\
\hline 542 & Medicaments (incl. veterinary medicaments) & 350 \\
\hline 712 & Steam turbines \& other vapour turbin., parts, n.e.s. & 151 \\
\hline 792 & Aircraft \& associated equipment; spacecraft, etc. & 425 \\
\hline 871 & Optical instruments \& apparatus, n.e.s. & 87 \\
\hline 874 & Measuring, analysing \& controlling apparatus, n.e.s. & 145 \\
\hline 881 & Photographic apparatus \& equipment, n.e.s. & 360 \\
\hline
\end{tabular}

Source: calculations done by author using trade statistics of UN Comtrade. 


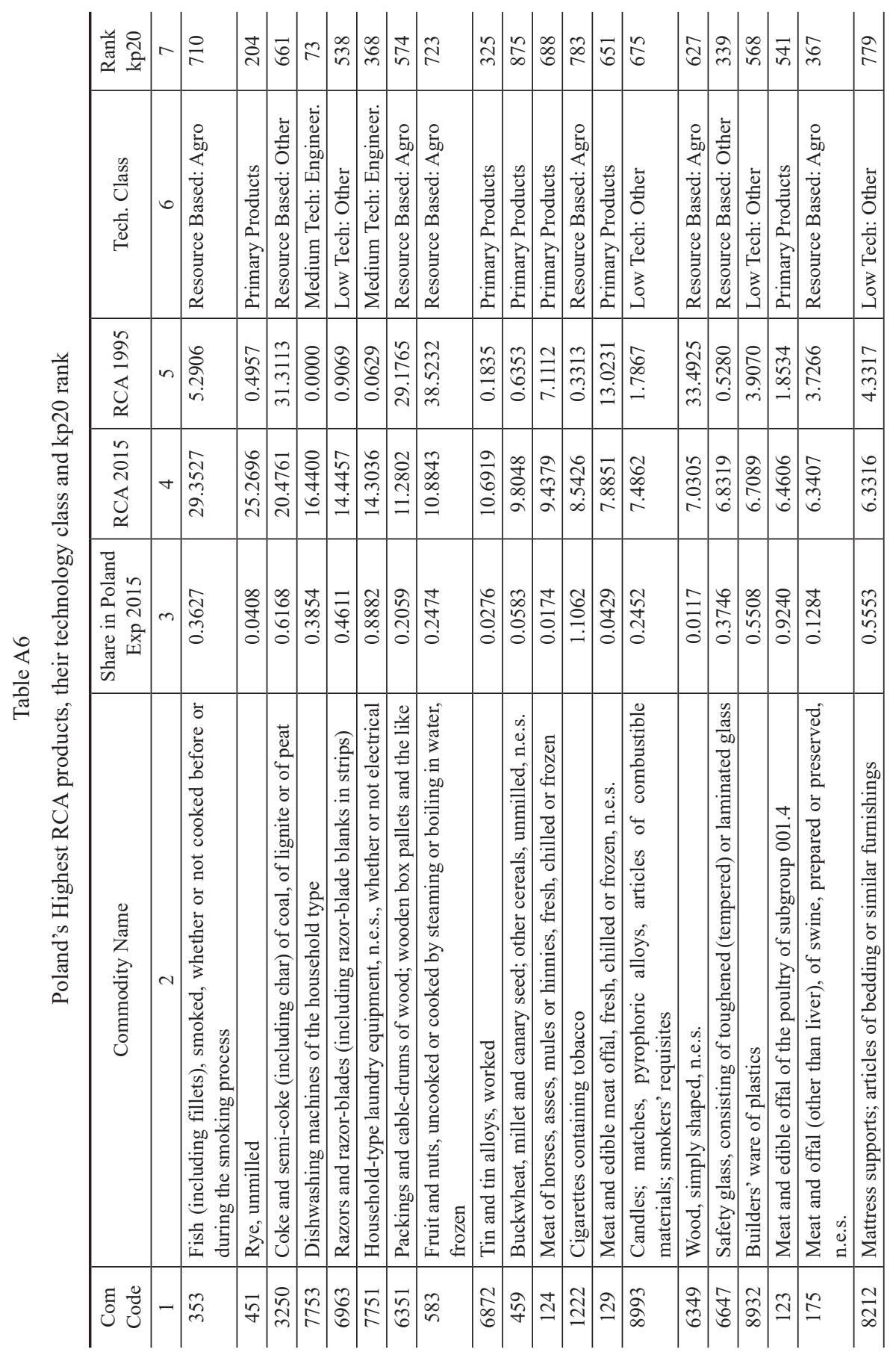




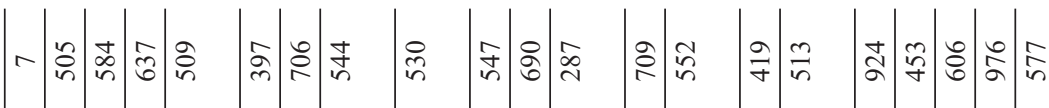

\begin{tabular}{|c|c|c|c|c|c|c|c|c|c|c|c|c|c|c|c|c|c|c|}
\hline & 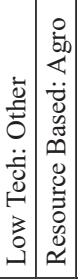 & 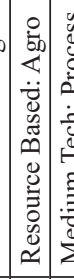 & 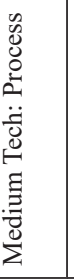 & 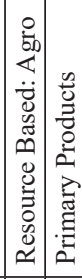 & 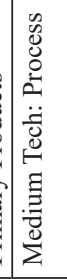 & 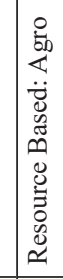 & 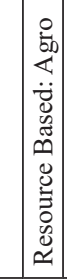 & 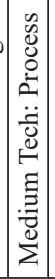 & 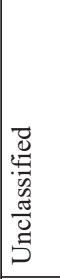 & 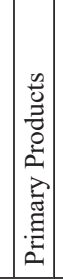 & . & 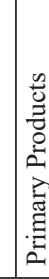 & 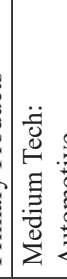 & & & & & 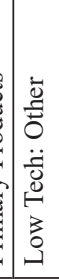 \\
\hline & 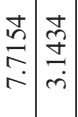 & 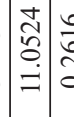 & 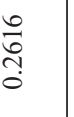 & 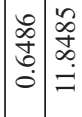 & $\frac{\infty}{2}$ & 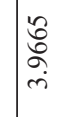 & ن. & & 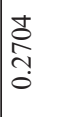 & $\mid$ & & 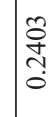 & 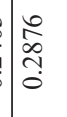 & & & & & {$\left[\begin{array}{l}\tilde{y} \\
\multirow{y}{n}{} \\
0 \\
0\end{array}\right.$} \\
\hline
\end{tabular}

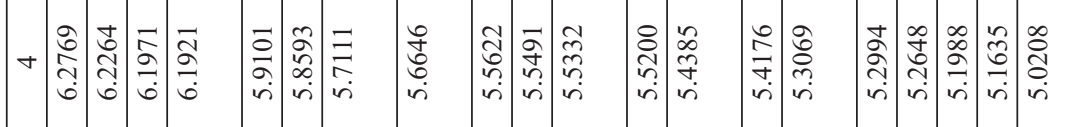

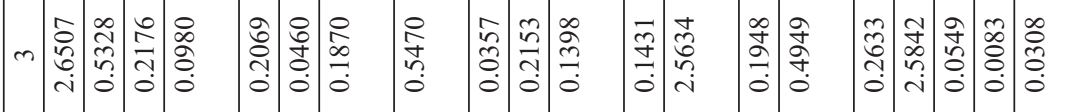




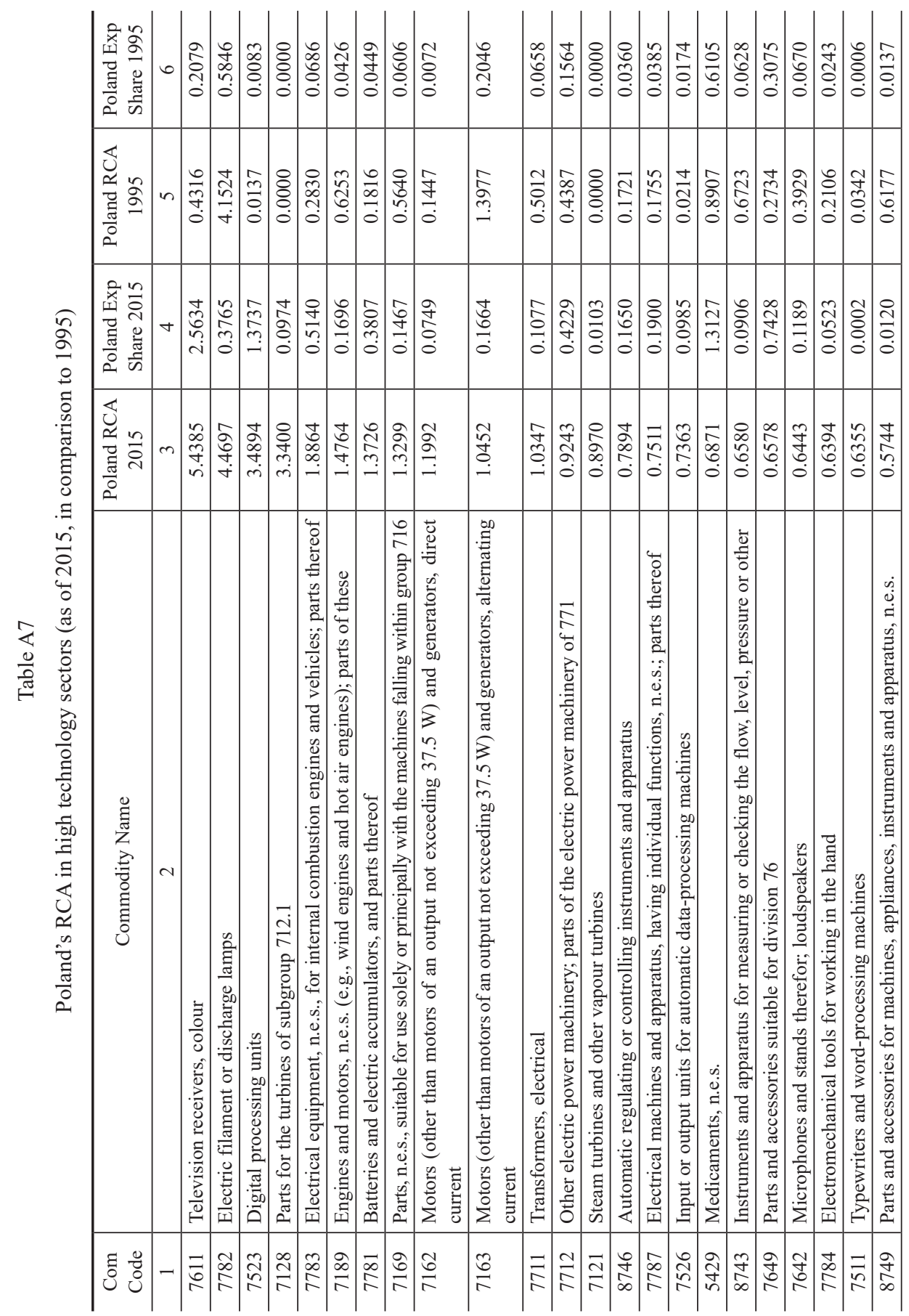




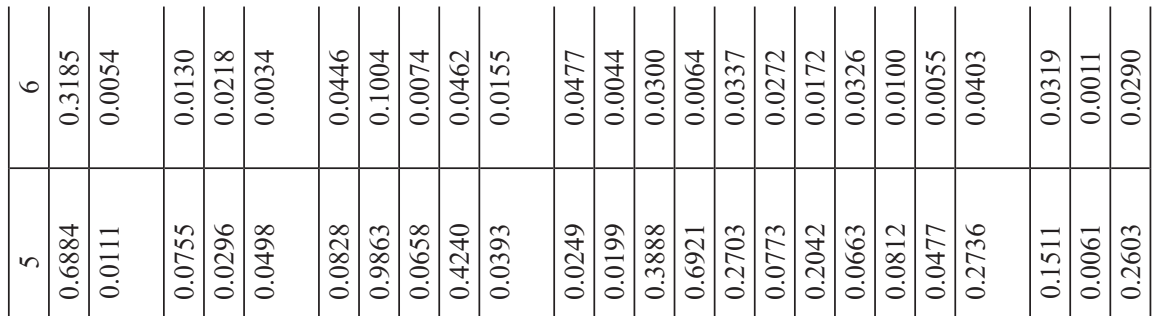

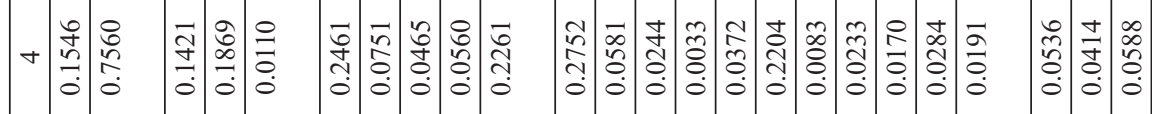

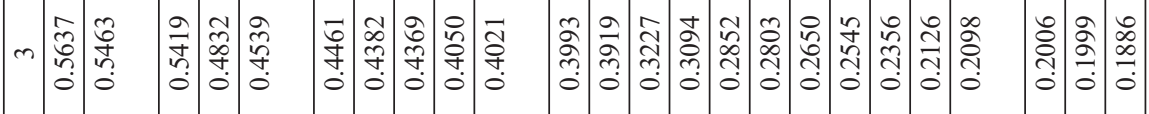

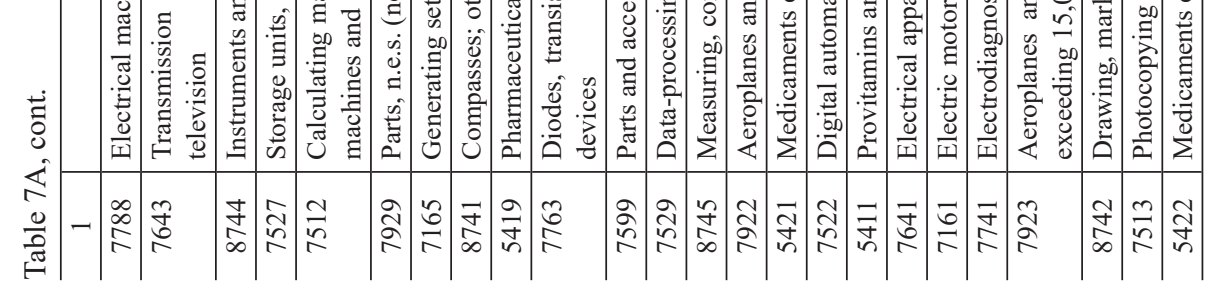




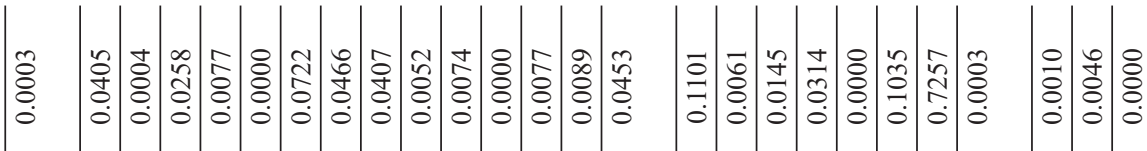

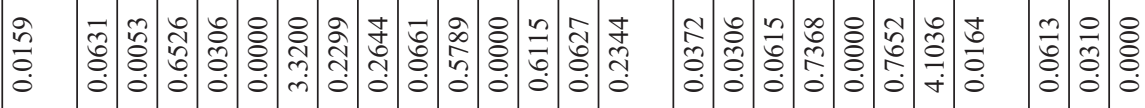

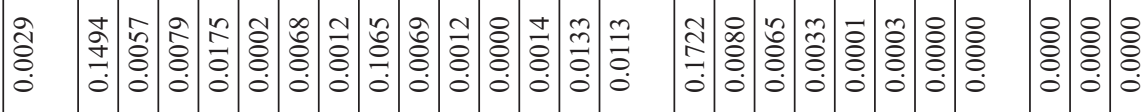

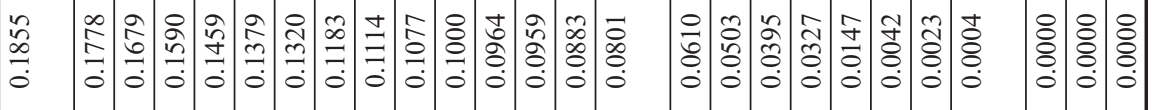

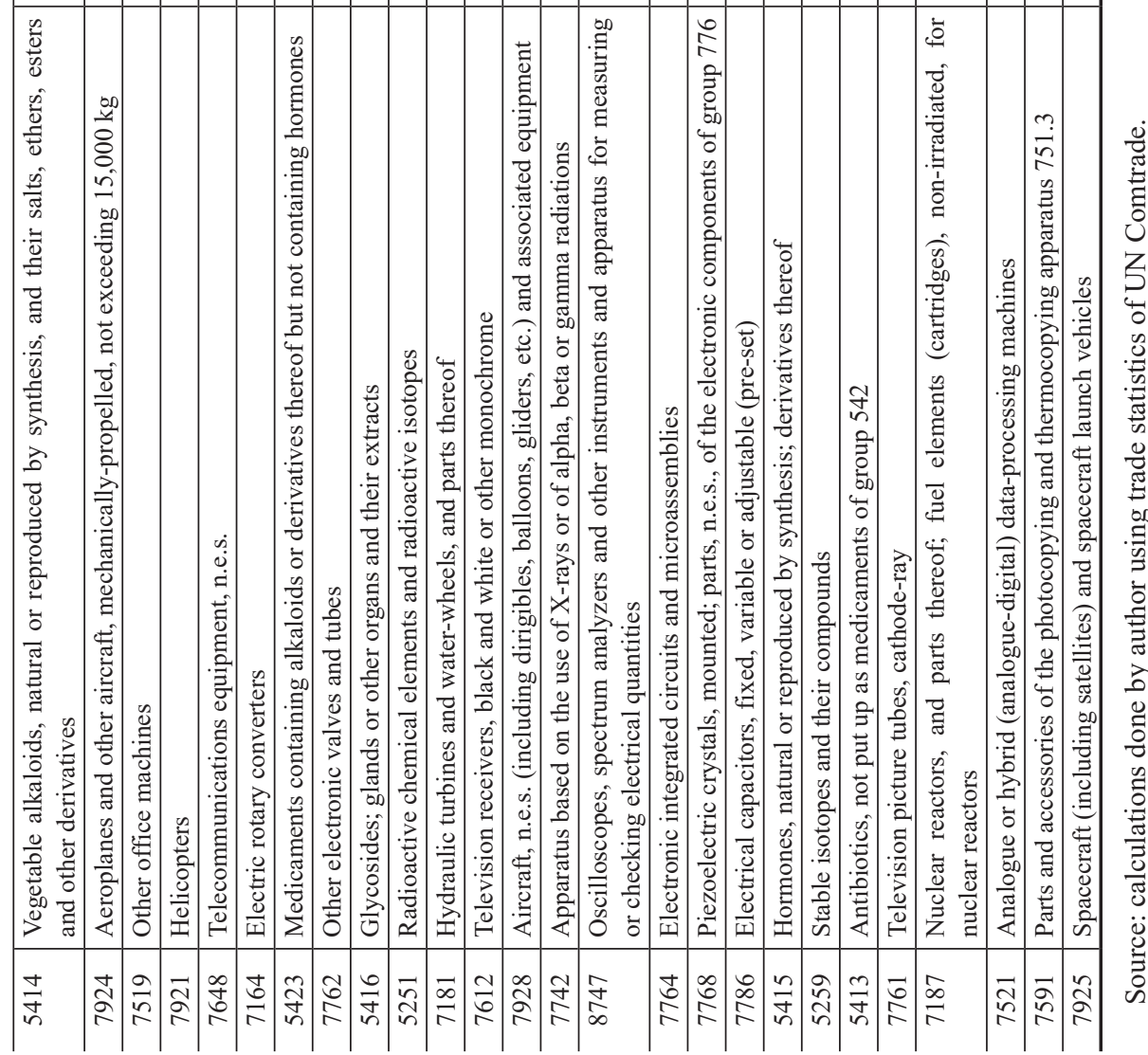




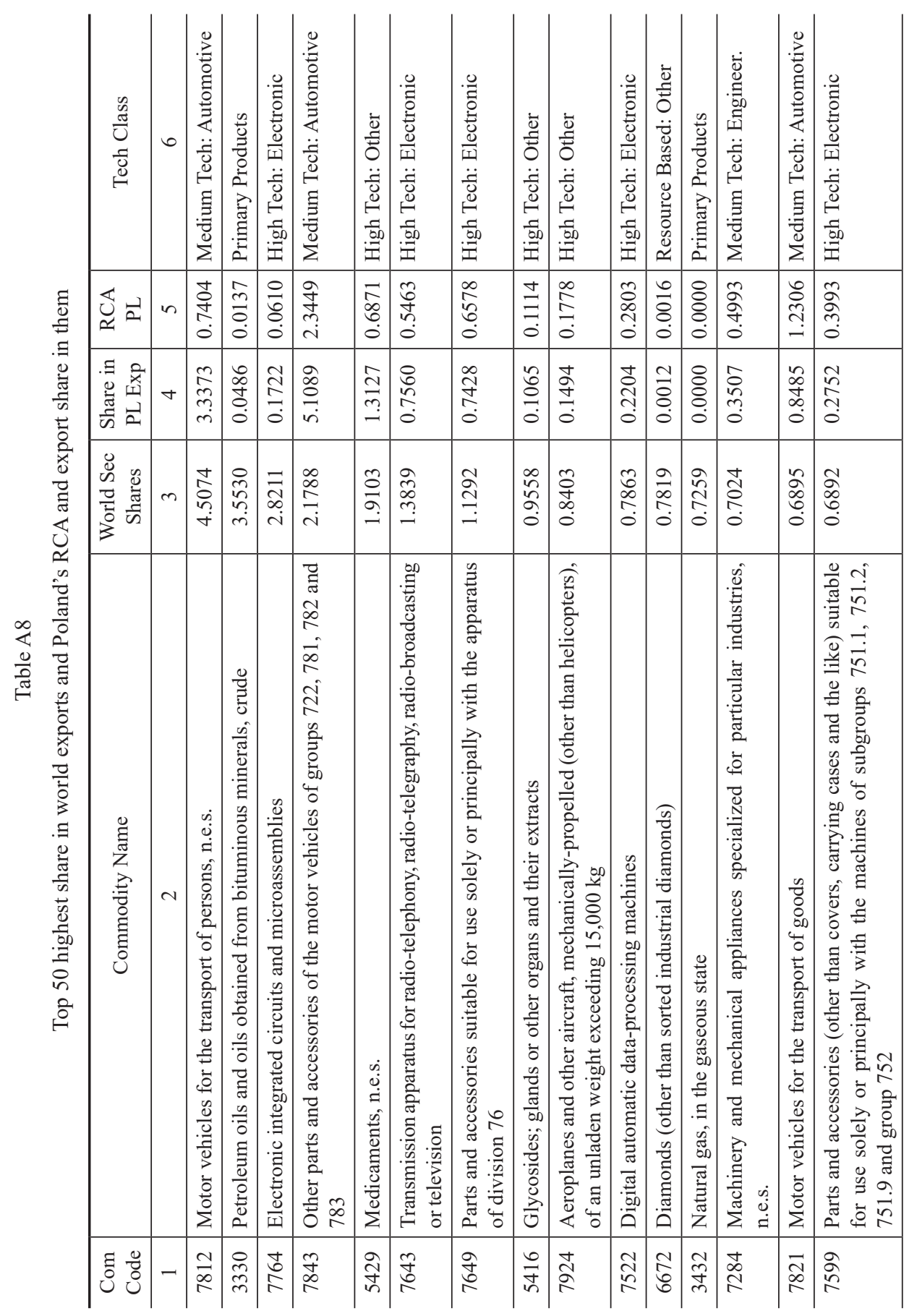




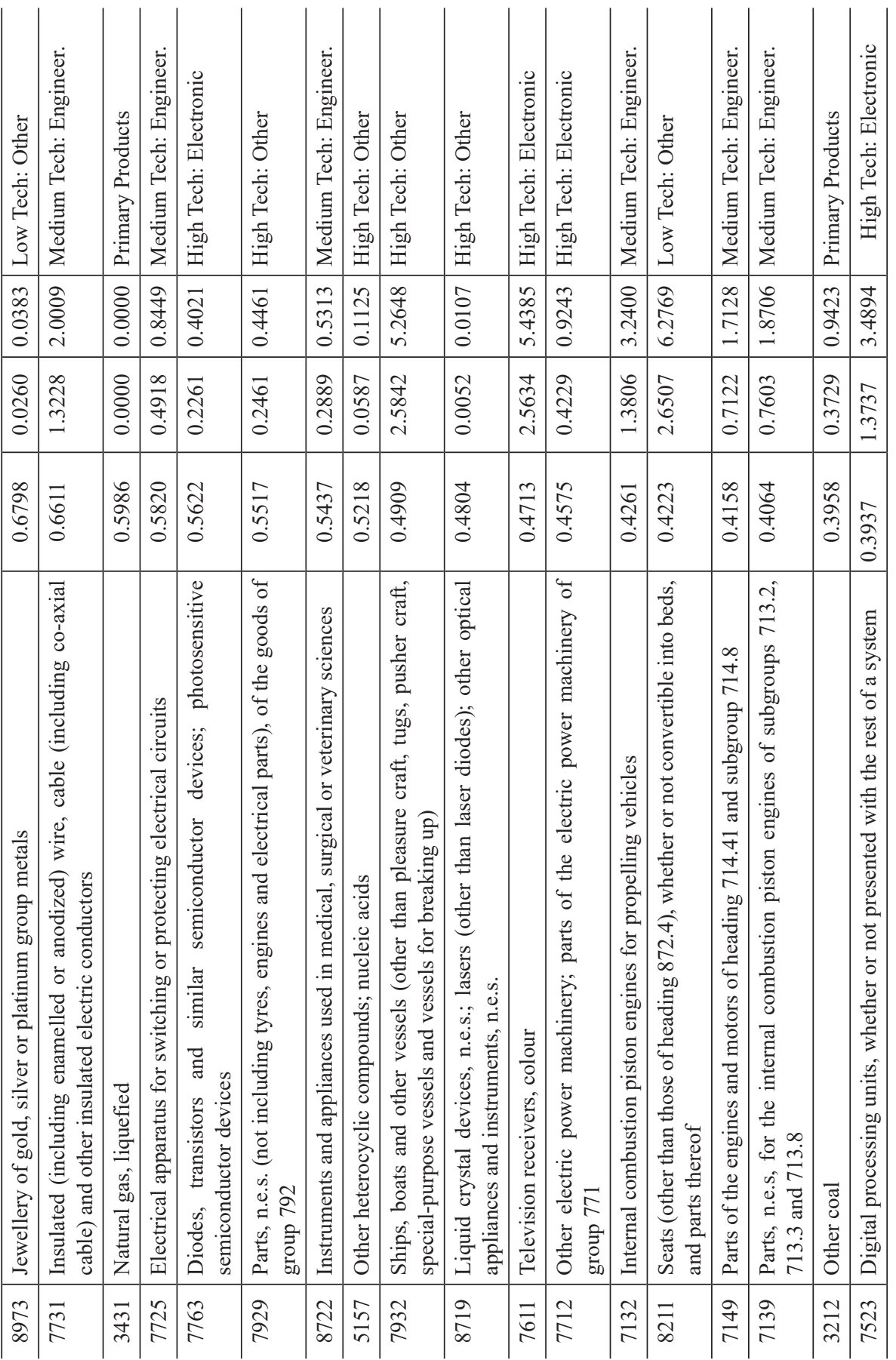




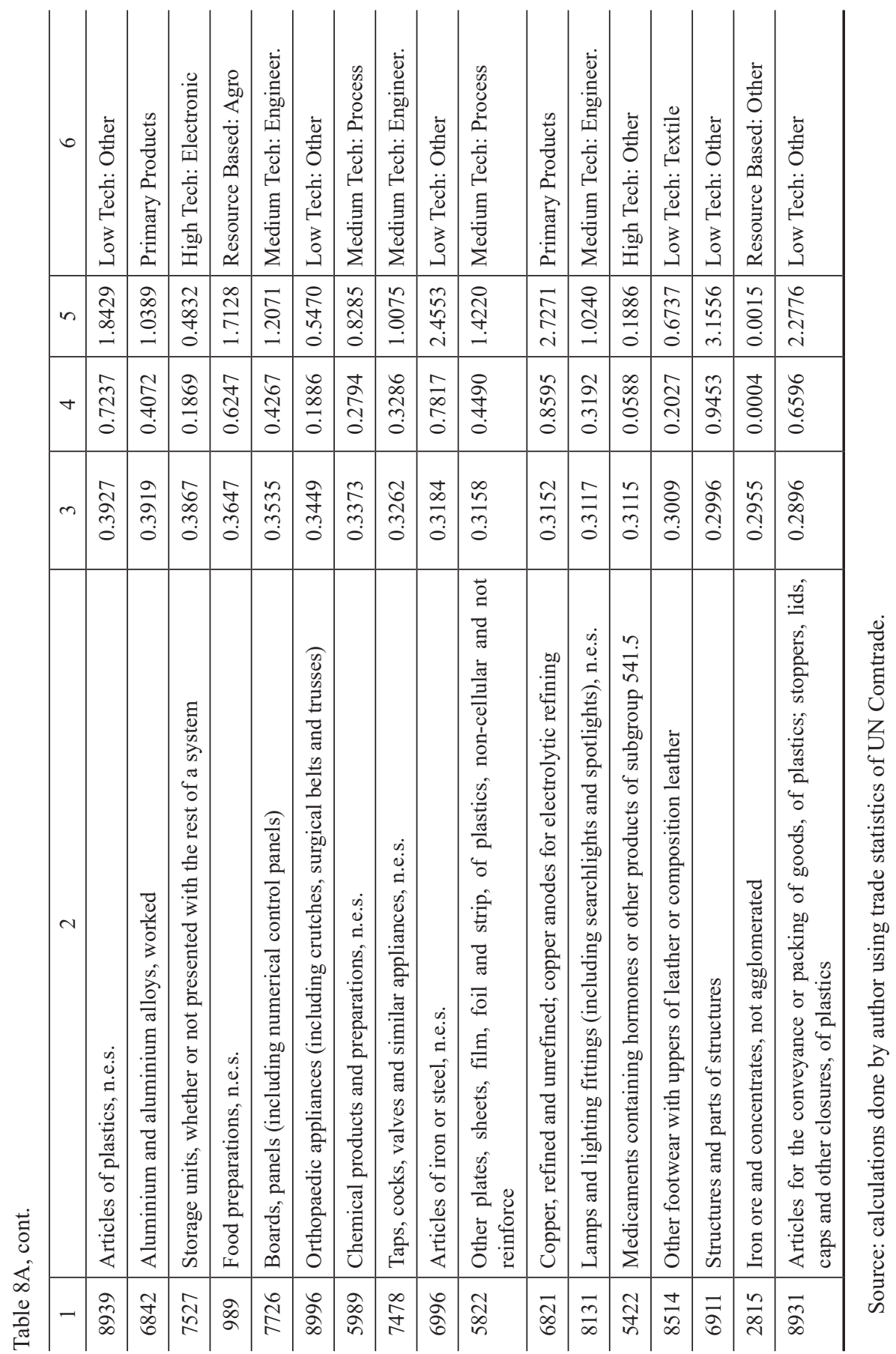




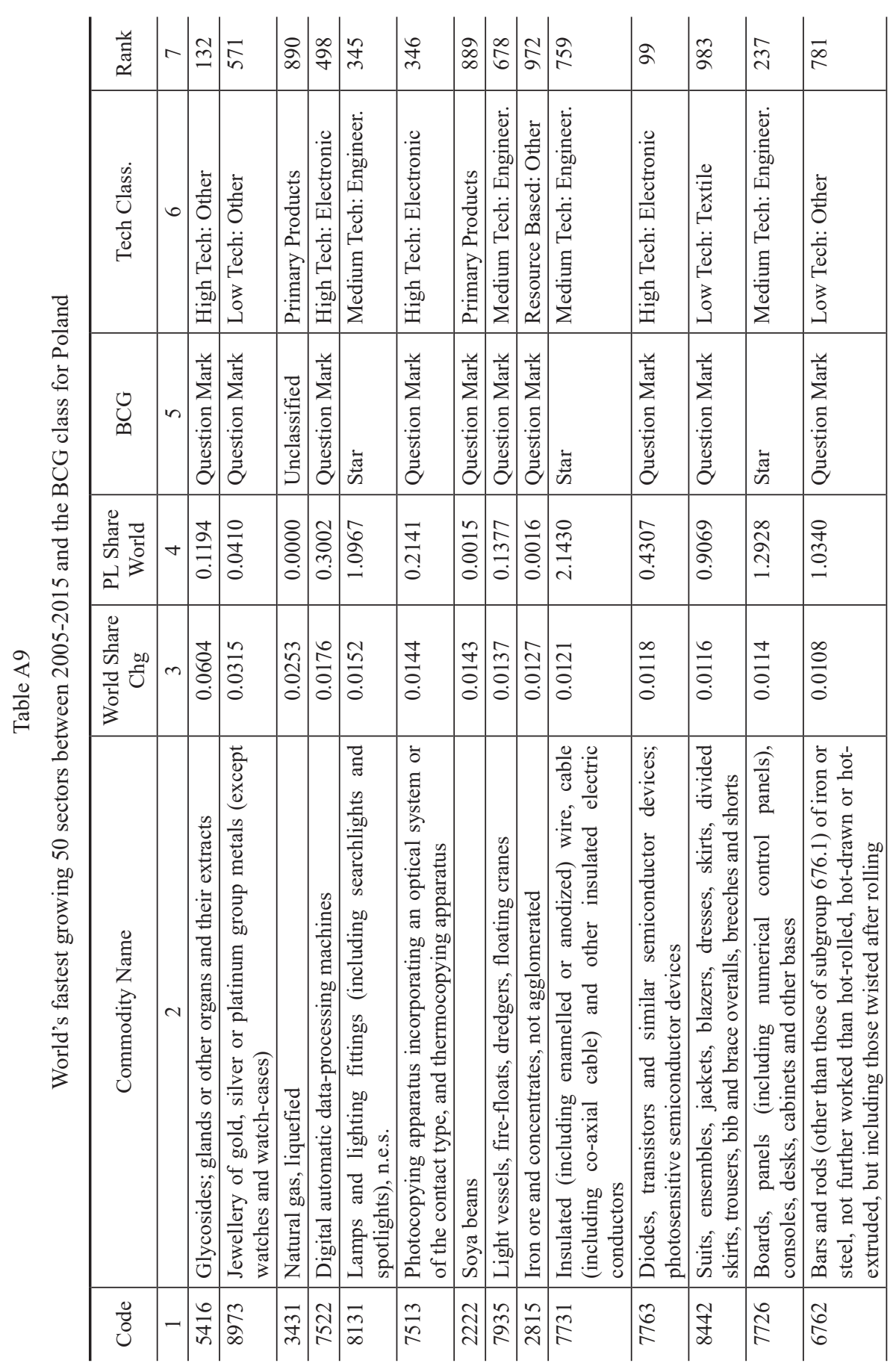




\begin{tabular}{|c|c|c|c|c|c|c|c|c|c|c|c|c|c|c|c|c|}
\hline & $\stackrel{\infty}{m}$ & \begin{tabular}{l}
$\infty$ \\
\hdashline \\
0
\end{tabular} & 이 & $\frac{\partial}{2}$ & $\stackrel{\widetilde{\sigma}}{\sigma}$ & 字 & $=$ & $\vec{\infty}$ & 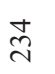 & in & $\stackrel{\infty}{m}$ & $\underset{m}{\mathbb{N}}$ & : & $\stackrel{\otimes}{\infty}$ & & స్రి \\
\hline 6 & 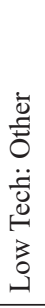 & 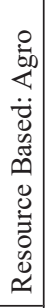 & 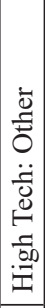 & 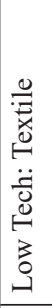 & 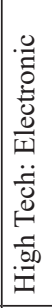 & 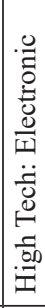 & 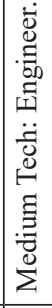 & 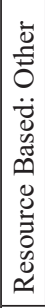 & 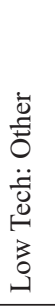 & 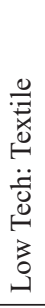 & 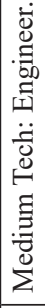 & 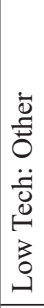 & 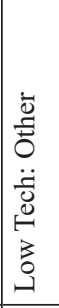 & 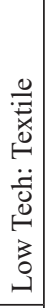 & & 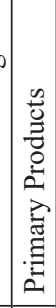 \\
\hline 绾 & 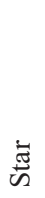 & 志 & 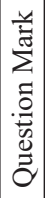 & 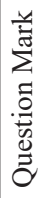 & 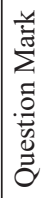 & 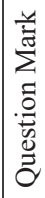 & 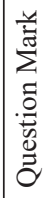 & 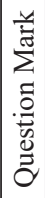 & 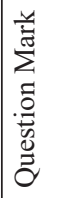 & 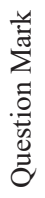 & 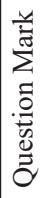 & 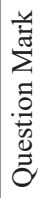 & 䓌 & 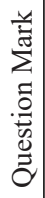 & & 离 \\
\hline t & $\overline{\vec{\infty}}$ & $\begin{array}{l}\stackrel{m}{f} \\
\stackrel{\infty}{\infty} \\
\stackrel{-}{-}\end{array}$ & $\begin{array}{l}2 \\
\vdots \\
0 \\
0 \\
0\end{array}$ & $\begin{array}{l}\underset{\Delta}{\Delta} \\
\infty \\
0 \\
0\end{array}$ & $\begin{array}{l}\stackrel{\partial}{\circ} \\
\stackrel{\partial}{o}\end{array}$ & 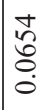 & $\begin{array}{l}\text { 守 } \\
\tilde{n} \\
0\end{array}$ & ه & $\begin{array}{l}\infty \\
0 \\
\infty \\
n \\
0 \\
0\end{array}$ & 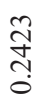 & 8 & 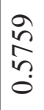 & 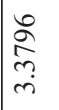 & \begin{tabular}{l}
$n$ \\
\multirow{1}{0}{} \\
$n$ \\
0 \\
0
\end{tabular} & & 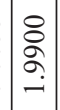 \\
\hline & 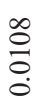 & \begin{tabular}{|l|}
$\stackrel{0}{0}$ \\
$\vdots$ \\
0 \\
0
\end{tabular} & $\begin{array}{l}\text { t) } \\
\stackrel{0}{0} \\
0 \\
0\end{array}$ & $\stackrel{\overrightarrow{0}}{\circ}$ & 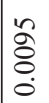 & 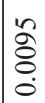 & 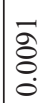 & $\begin{array}{l}0 \\
\stackrel{0}{0} \\
\stackrel{0}{0}\end{array}$ & 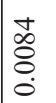 & $\bar{\alpha}$ & 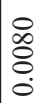 & \begin{tabular}{l}
$\infty$ \\
\multirow{8}{0}{} \\
0 \\
0
\end{tabular} & $\begin{array}{l}0 \\
\stackrel{0}{0} \\
0 \\
0\end{array}$ & $\stackrel{0}{0}$ & & $\hat{\varepsilon}$ \\
\hline
\end{tabular}

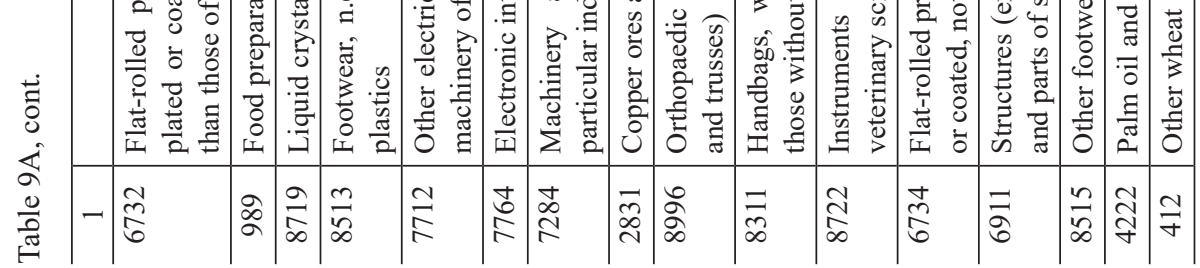




\begin{tabular}{|c|c|c|c|c|c|c|c|c|c|c|c|c|c|c|c|c|c|c|c|}
\hline$\underset{\sim}{\infty}$ & $\stackrel{\infty}{2}$ & $\stackrel{\cong}{=}$ & $\underset{\infty}{2}$ & $\frac{m}{i n}$ & $\frac{0}{\infty}$ & ปี & $\Xi$ & $\frac{m}{\infty}$ & $\frac{1}{6}$ & $\tilde{n}$ & ฮิ & $\stackrel{\infty}{\widetilde{\alpha}}$ & $\stackrel{0}{0}$ & $\stackrel{\sim}{*}$ & $\underset{\gamma}{\stackrel{\gamma}{\gamma}}$ & $\ddot{\mathscr{0}}$ & 宗 & 点 & $\underset{\widehat{\sigma}}{\mathbb{V}}$ \\
\hline 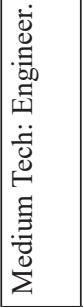 & 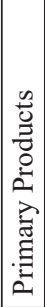 & 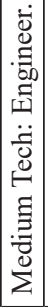 & 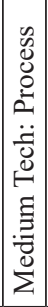 & 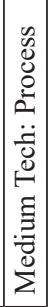 & 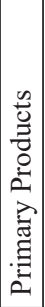 & 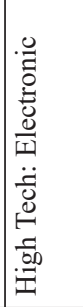 & 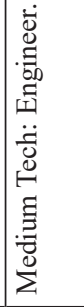 & 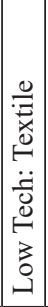 & 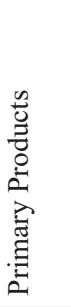 & 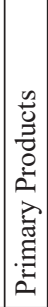 & 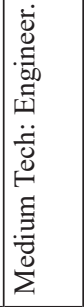 & 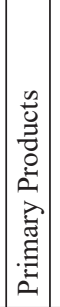 & 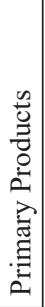 & 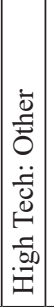 & 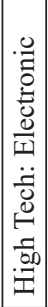 & 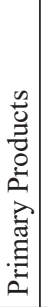 & 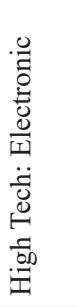 & 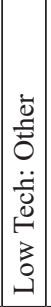 & 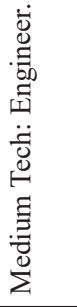 \\
\hline 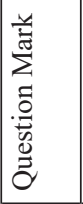 & 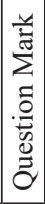 & $\begin{array}{l}\vec{\Xi} \\
\dot{\omega}\end{array}$ & 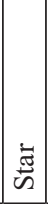 & 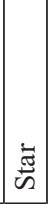 & 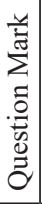 & 壳 & 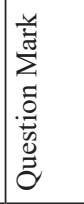 & 离 & 壳 & 恋 & 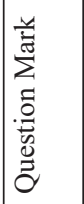 & 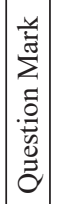 & 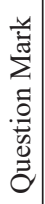 & 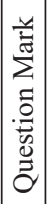 & 竘 & 恋 & 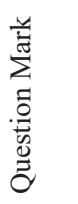 & 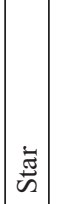 & 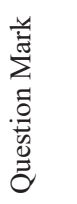 \\
\hline 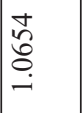 & $\begin{array}{l}0 \\
0 \\
0 \\
0 \\
0\end{array}$ & 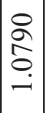 & $\mid \begin{array}{c}\mathcal{N} \\
\stackrel{N}{4} \\
\\
-\end{array}$ & $\begin{array}{l}0 \\
\stackrel{0}{0} \\
\dot{7} \\
i \\
i\end{array}$ & $\begin{array}{l}\infty \\
\stackrel{N}{f} \\
\stackrel{+}{\sigma}\end{array}$ & 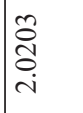 & $\begin{array}{l}\mathscr{n} \\
\infty \\
\tilde{m} \\
\tilde{0}\end{array}$ & $\begin{array}{l}= \\
\stackrel{\vec{n}}{\sim} \\
\stackrel{2}{n}\end{array}$ & 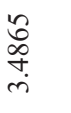 & 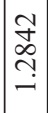 & \begin{tabular}{l}
$n$ \\
\multirow{2}{*}{} \\
0 \\
0 \\
0
\end{tabular} & $\mid \begin{array}{l} \pm \\
0 \\
0 \\
0 \\
0\end{array}$ & $\begin{array}{l}0 \\
0 \\
0 \\
0 \\
0 \\
0\end{array}$ & $\mid \begin{array}{l}1 \\
0 \\
\infty \\
n \\
0\end{array}$ & $\mid \begin{array}{l}\stackrel{8}{8} \\
\stackrel{P}{+} \\
-\end{array}$ & \begin{tabular}{c}
$g$ \\
\hdashline \\
\hdashline \\
-
\end{tabular} & $\begin{array}{l}\stackrel{8}{0} \\
\text { o. } \\
\stackrel{0}{0}\end{array}$ & $\mid \begin{array}{l}\infty \\
\stackrel{\infty}{S} \\
\stackrel{-}{-}\end{array}$ & $\frac{\tilde{I}}{\stackrel{\Xi}{0}}$ \\
\hline 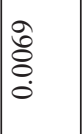 & $\mid \begin{array}{l}0 \\
\dot{0} \\
\dot{0} \\
\dot{0}\end{array}$ & $\mid \begin{array}{l}\infty \\
0 \\
0 \\
0 \\
0 \\
0\end{array}$ & $\mid \begin{array}{l}6 \\
8 \\
8 \\
0 \\
0\end{array}$ & $\mid \begin{array}{l}\infty \\
2 \\
8 \\
0 \\
0 \\
0\end{array}$ & $\mid \begin{array}{l}n \\
\tilde{o} \\
0 \\
0 \\
0\end{array}$ & $\mid \begin{array}{l}n \\
\tilde{o} \\
\vdots \\
0 \\
0\end{array}$ & 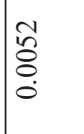 & 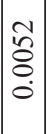 & 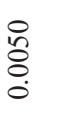 & $\begin{array}{l}\text { f } \\
\stackrel{8}{0} \\
\dot{0}\end{array}$ & 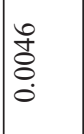 & $\left|\begin{array}{l}0 \\
0 \\
0 \\
0 \\
0\end{array}\right|$ & $\mid \begin{array}{l}0 \\
0 \\
0 \\
0 \\
0\end{array}$ & $\left|\begin{array}{l} \\
\dot{0} \\
0 \\
0\end{array}\right|$ & 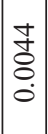 & $\begin{array}{l}\tilde{f} \\
\stackrel{2}{8} \\
0 \\
0\end{array}$ & $\begin{array}{l}\text { f } \\
\stackrel{8}{8} \\
\stackrel{0}{0}\end{array}$ & 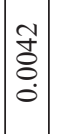 & $\begin{array}{l}\text { I } \\
\stackrel{8}{8} \\
\stackrel{0}{0}\end{array}$ \\
\hline 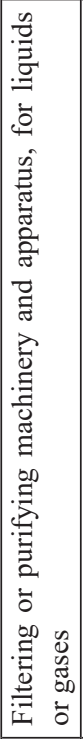 & 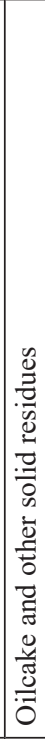 & 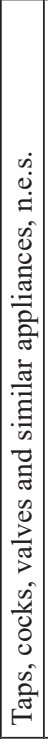 & 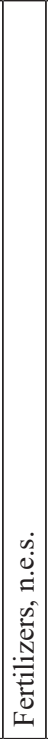 & 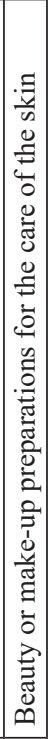 & 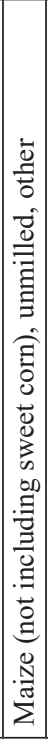 & 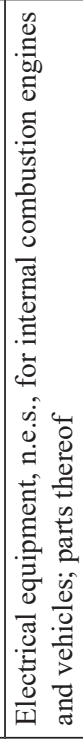 & 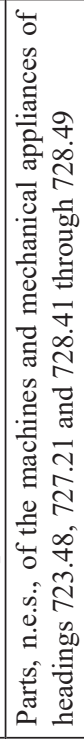 & \begin{tabular}{|l|}
0 \\
$\tilde{w}$ \\
$\tilde{b}$ \\
0 \\
$\dot{\omega}$ \\
\end{tabular} & 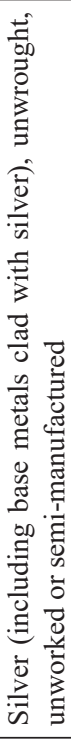 & 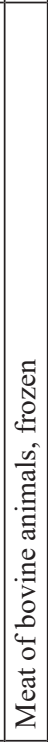 & 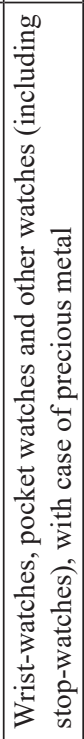 & 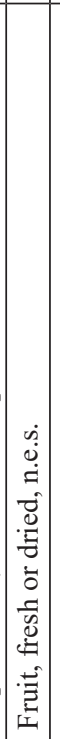 & 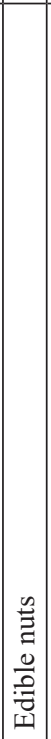 & 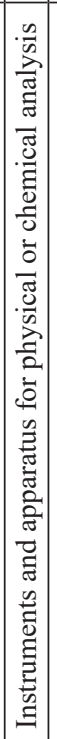 & 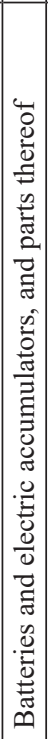 & 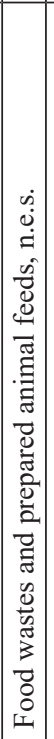 & 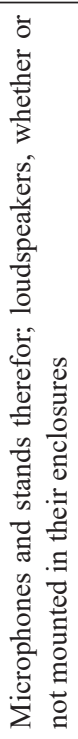 & 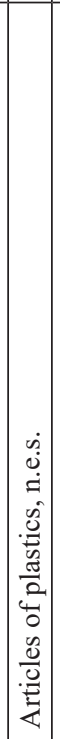 & 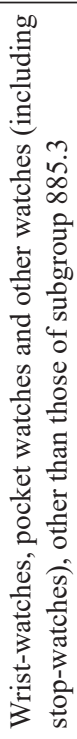 \\
\hline li & $\frac{m}{\infty}$ & $\frac{\infty}{\stackrel{\infty}{⿱ 亠}}$ & $\mid \begin{array}{l}\stackrel{\widehat{े}}{\mathbf{b}} \\
\stackrel{n}{n}\end{array}$ & $m$ & 12 & $\stackrel{\infty}{\infty}$ & $\ddot{\infty}$ & 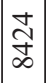 & $\vec{\infty}$ & $\simeq$ & $\begin{array}{l}\hat{n} \\
\infty \\
\infty\end{array}$ & $\begin{array}{l}2 \\
\text { in }\end{array}$ & $\stackrel{\hat{n}}{i}$ & $\underset{\infty}{\frac{7}{\infty}}$ & $\begin{array}{l}\vec{\infty} \\
\stackrel{2}{*}\end{array}$ & $\frac{\infty}{\infty}$ & $\underset{2}{2}$ & $\tilde{\check{\infty}}$ & $\infty$ \\
\hline
\end{tabular}




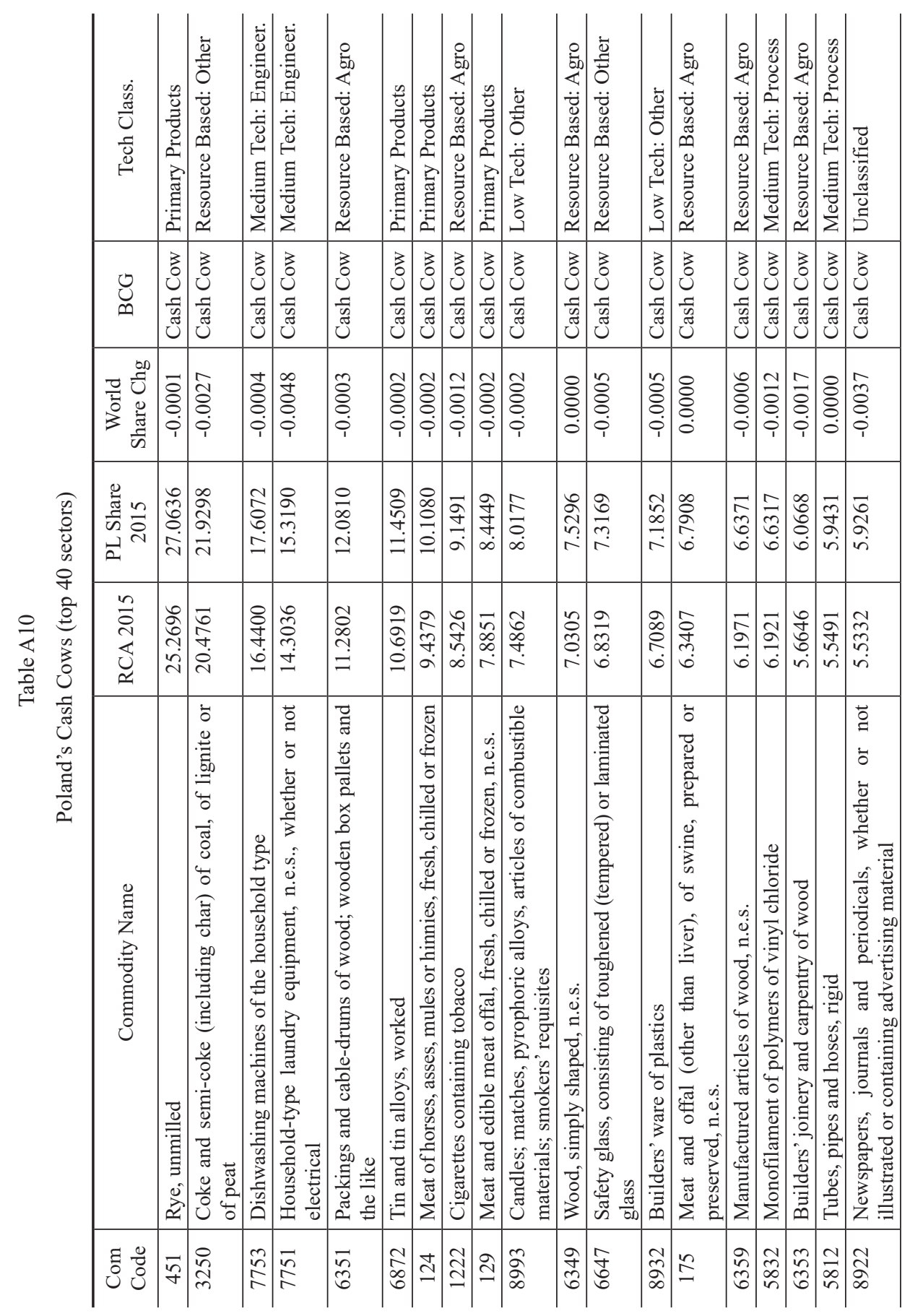




\begin{tabular}{|c|c|c|c|c|c|c|c|c|c|c|c|c|c|c|c|c|c|c|c|c|}
\hline 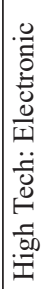 & 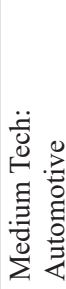 & 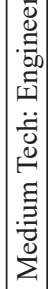 & $\begin{array}{c}0 \\
0 \\
0 \\
\dot{0} \\
\dot{0} \\
0 \\
0 \\
0 \\
0 \\
0 \\
\vdots \\
0 \\
0 \\
\approx \\
\simeq\end{array}$ & 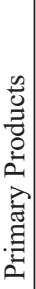 & 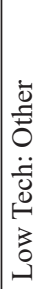 & 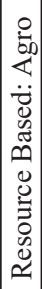 & 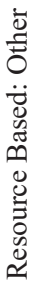 & 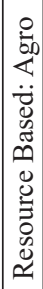 & 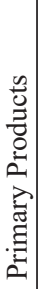 & 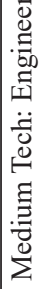 & 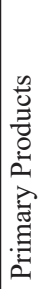 & 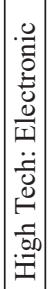 & 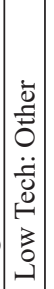 & 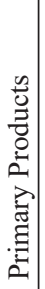 & 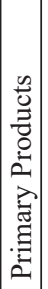 & 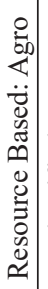 & 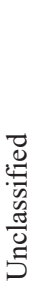 & 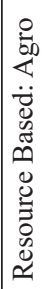 & 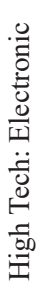 & 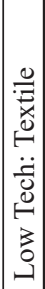 \\
\hline $\begin{array}{l}3 \\
0 \\
\frac{3}{\tilde{g}} \\
\tilde{g}\end{array}$ & 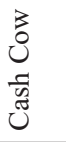 & $\begin{array}{c}3 \\
0 \\
0 \\
-1 \\
5 \\
0 \\
0 \\
0\end{array}$ & 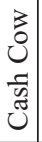 & $\begin{array}{l}3 \\
0 \\
0 \\
0\end{array}$ & $\mid \begin{array}{l}3 \\
0 \\
0 \\
-5 \\
0 \\
0 \\
0\end{array}$ & $\mid \begin{array}{c}3 \\
0 \\
ن \\
-\frac{1}{n} \\
\tilde{n} \\
0\end{array}$ & $\begin{array}{l}0 \\
\frac{1}{\pi} \\
\tilde{E}\end{array}$ & $\begin{array}{l}3 \\
0 \\
ن \\
-\tilde{n} \\
\tilde{n} \\
0\end{array}$ & $\begin{array}{l}3 \\
0 \\
\tilde{u} \\
\tilde{u} \\
\tilde{\Xi}\end{array}$ & $\begin{array}{l}3 \\
0 \\
0 \\
-1 \\
\tilde{n} \\
\tilde{J}\end{array}$ & $\begin{array}{l}3 \\
0 \\
0 \\
\frac{3}{n} \\
\tilde{J} \\
0\end{array}$ & $\mid \begin{array}{c}3 \\
0 \\
ن \\
\frac{1}{n} \\
\tilde{n} \\
0\end{array}$ & $\left|\begin{array}{l}3 \\
0 \\
0 \\
-\tilde{n} \\
\tilde{n} \\
0\end{array}\right|$ & $\mid \begin{array}{c}3 \\
0 \\
ن \\
\frac{1}{5} \\
\tilde{c} \\
0\end{array}$ & $\left|\begin{array}{l}3 \\
0 \\
0 \\
\frac{3}{5} \\
\tilde{J}\end{array}\right|$ & $\begin{array}{l}3 \\
0 \\
u \\
\frac{3}{n} \\
\tilde{J}\end{array}$ & $\begin{array}{l}3 \\
0 \\
\tilde{u} \\
\tilde{n} \\
\tilde{\Xi}\end{array}$ & 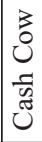 & 步 & \begin{tabular}{|l}
$\tilde{T}$ \\
$\tilde{T}$ \\
$\tilde{z}$ \\
$\tilde{U}$
\end{tabular} \\
\hline $\bar{z}$ & $\begin{array}{l}\overrightarrow{8} \\
8 \\
\dot{8} \\
\dot{1}\end{array}$ & $\begin{array}{l}1 \\
0 \\
0 \\
0 \\
0\end{array}$ & 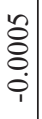 & $\frac{8}{8}$ & ố & ธి & & 苂 & 8 & छे & \& & $\begin{array}{l}0 \\
\stackrel{+}{8} \\
8 \\
\dot{1}\end{array}$ & $\mid \begin{array}{c}0 \\
\hat{8} \\
\dot{0} \\
1\end{array}$ & के & 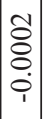 & Ş & $\begin{array}{l}\stackrel{8}{2} \\
\stackrel{8}{8} \\
\dot{0}\end{array}$ & $\begin{array}{l}0 \\
0 \\
8 \\
0 \\
\dot{8}\end{array}$ & $\begin{array}{l}0 \\
0 \\
\end{array}$ & \\
\hline
\end{tabular}

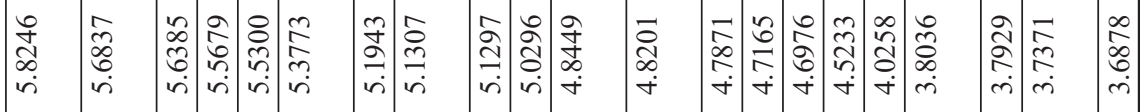

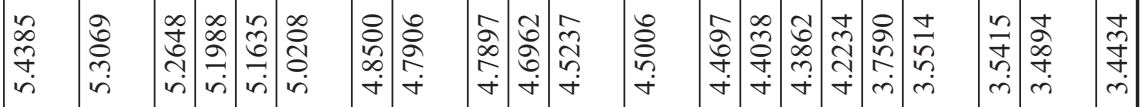

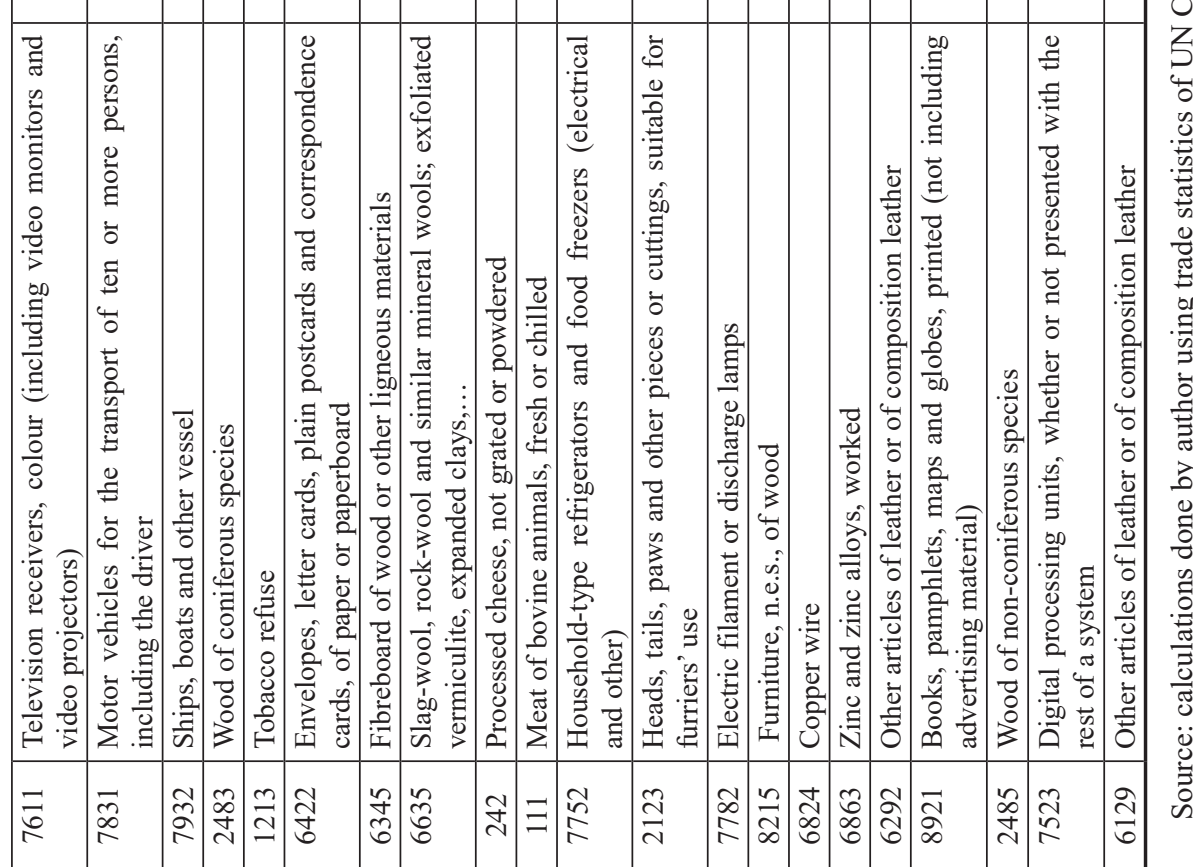




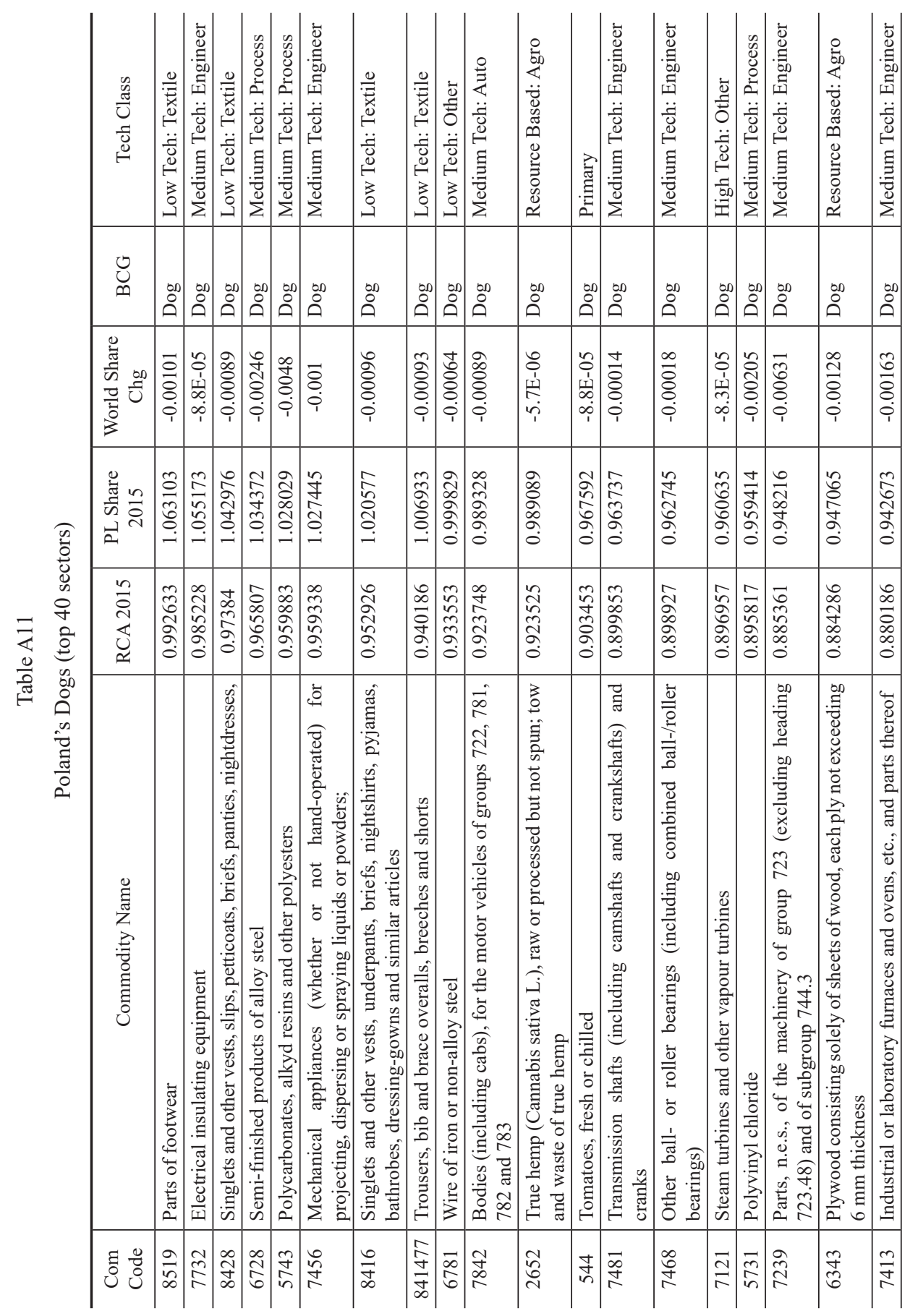




\begin{tabular}{|c|c|c|c|c|c|c|c|c|c|c|c|c|c|c|c|c|c|c|c|c|c|}
\hline \multirow{7}{*}{ 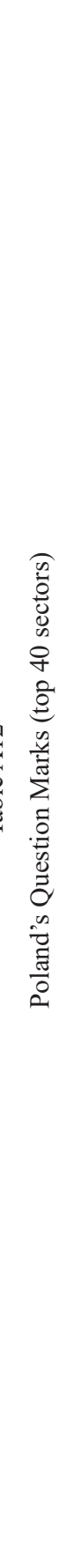 } & 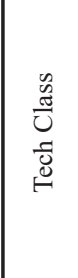 & 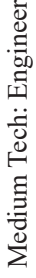 & 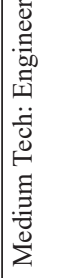 & 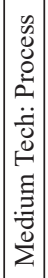 & 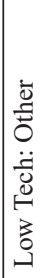 & 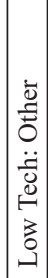 & 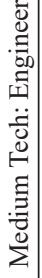 & 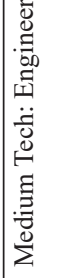 & 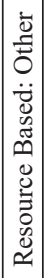 & $\begin{array}{l}\text { 壳 } \\
\text { : }\end{array}$ & 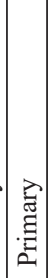 & 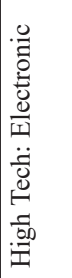 & 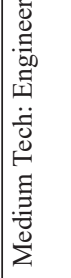 & 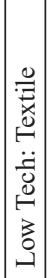 & 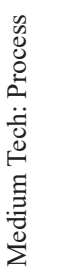 & 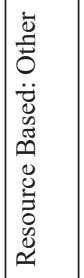 & 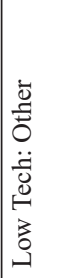 & 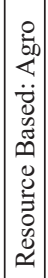 & 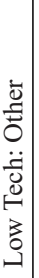 & 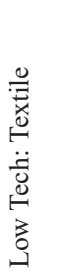 & 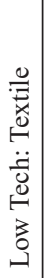 \\
\hline & U్ల & 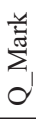 & 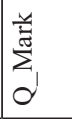 & 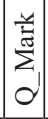 & $\begin{array}{l}\frac{y}{z} \\
\vdots \\
\vdots \\
0\end{array}$ & 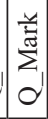 & 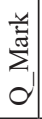 & 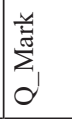 & 妾 & 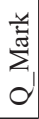 & $\begin{array}{l}\frac{y}{u} \\
\sum \\
d\end{array}$ & 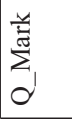 & 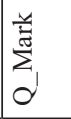 & 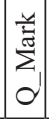 & $\begin{array}{l}\stackrel{y}{\vec{J}} \\
\sum_{0}\end{array}$ & 旁 & 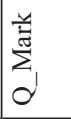 & $\begin{array}{c}-4 \\
\vdots \\
\vdots \\
0\end{array}$ & 立 & 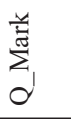 & $\sum_{1}^{\pi}$ \\
\hline & 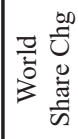 & 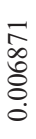 & $\begin{array}{l}\stackrel{1}{2} \\
\stackrel{2}{8} \\
\dot{8} \\
\dot{0}\end{array}$ & $\mid \begin{array}{l}0 \\
\infty \\
0 \\
8 \\
0 \\
0\end{array}$ & 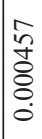 & $\mid \begin{array}{l}m \\
\infty \\
0 \\
0 \\
0 \\
0\end{array}$ & $\begin{array}{l}9 \\
\dot{0} \\
0 \\
8 \\
0 \\
0\end{array}$ & 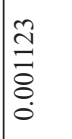 & $\mid \begin{array}{c}0 \\
\stackrel{1}{2} \\
\widehat{\widehat{\sigma}} \\
0 \\
0\end{array}$ & $\begin{array}{l}n \\
\frac{1}{5} \\
\vdots \\
0 \\
0\end{array}$ & 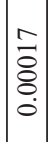 & 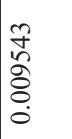 & $\begin{array}{l}n \\
\tilde{n} \\
\swarrow \delta \\
\delta \\
0 \\
0\end{array}$ & $\mid \begin{array}{l}2 \\
\hat{0} \\
0 \\
8 \\
0 \\
0\end{array}$ & 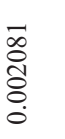 & 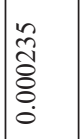 & 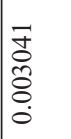 & 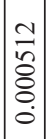 & 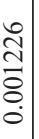 & $\begin{array}{l}\frac{2}{2} \\
\frac{1}{2} \\
0 \\
0 \\
0\end{array}$ & $\begin{array}{c}0 \\
\stackrel{2}{0} \\
\vdots \\
0 \\
0\end{array}$ \\
\hline & 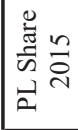 & 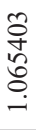 & 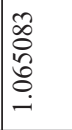 & 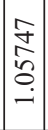 & 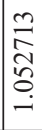 & $\begin{array}{c}\hat{n} \\
\hat{o} \\
\tilde{y} \\
0 \\
-i \\
\end{array}$ & 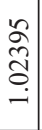 & 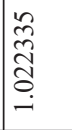 & $\begin{array}{c}\infty \\
0 \\
\infty \\
0 \\
- \\
-\end{array}$ & $\begin{array}{l}0 \\
\stackrel{0}{\sigma} \\
\stackrel{8}{-}\end{array}$ & $\begin{array}{l}\hat{N} \\
\hat{\sigma} \\
\sigma \\
\sigma \\
0\end{array}$ & $\begin{array}{l}n \\
2 \\
\infty \\
\vdots \\
0\end{array}$ & $\begin{array}{l}\hat{n} \\
\overline{0} \\
\vdots \\
0 \\
0\end{array}$ & 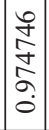 & $\begin{array}{l}\text { Jे } \\
\text { o. }\end{array}$ & 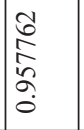 & 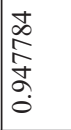 & 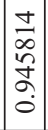 & $\begin{array}{l}\stackrel{+}{2} \\
\tilde{n} \\
\tilde{\sigma} \\
0\end{array}$ & $\frac{o}{\hat{\sigma}}$ & 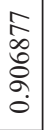 \\
\hline & 芯 & \begin{tabular}{l}
$\vec{\infty}$ \\
\multirow{\sigma}{\sigma}{} \\
$\vdots$ \\
$\vdots$
\end{tabular} & 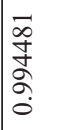 & $\mid \begin{array}{l}m \\
0 \\
0 \\
\infty \\
o \\
0 \\
0\end{array}$ & 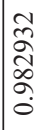 & 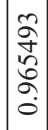 & $\begin{array}{l}n \\
\hat{8} \\
0 \\
2 \\
\vdots \\
0\end{array}$ & $\begin{array}{l}\hat{0} \\
\vdots \\
\vdots \\
o \\
0\end{array}$ & 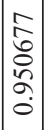 & 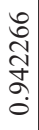 & 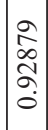 & 菑 & $\frac{\mathfrak{n}}{\stackrel{q}{7}}$ & 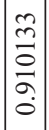 & 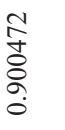 & 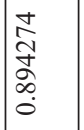 & 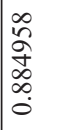 & 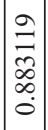 & 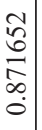 & $\begin{array}{l}\stackrel{1}{0} \\
\\
\dot{b} \\
0 \\
0\end{array}$ & 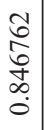 \\
\hline & 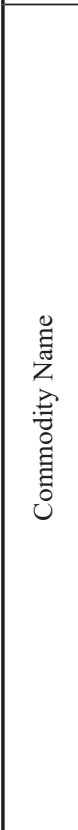 & 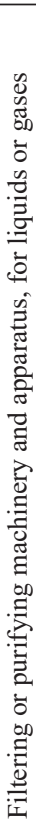 & 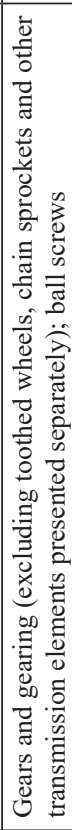 & 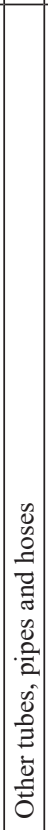 & 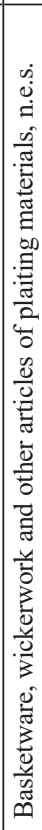 & 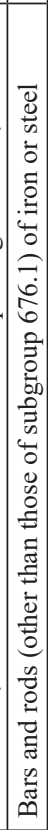 & 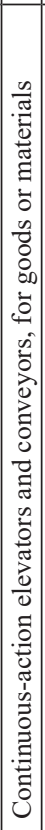 & 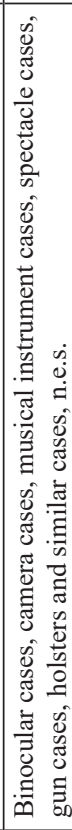 & 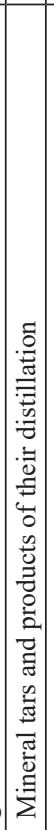 & 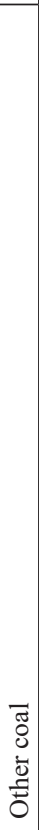 & 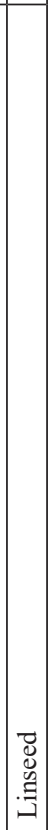 & 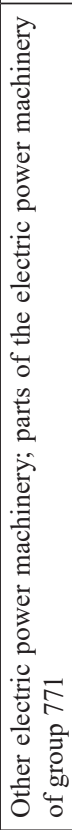 & 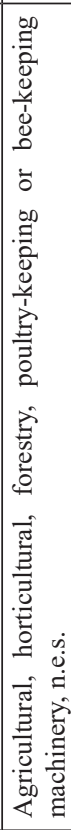 & 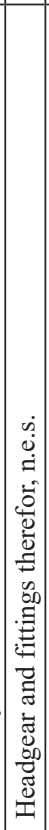 & 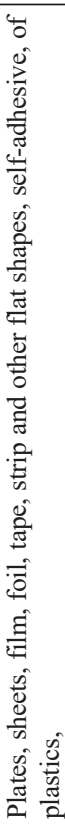 & 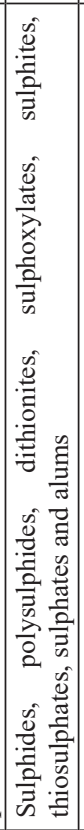 & 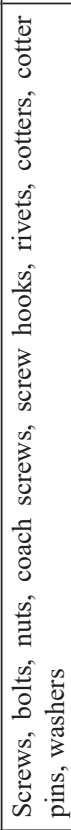 & 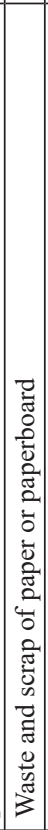 & 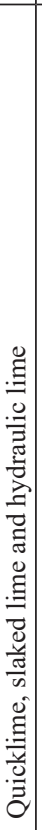 & 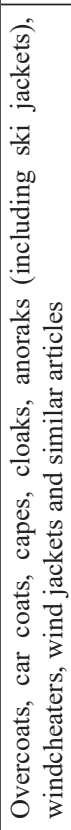 & 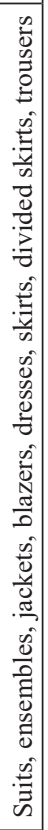 \\
\hline & نี & & $\infty_{\infty}^{+}$ & $\left|\begin{array}{l}0 \\
\infty \\
\infty \\
n\end{array}\right|$ & 18 & 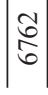 & 列 & 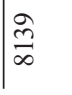 & $\left|\begin{array}{c}\tilde{N} \\
\tilde{m}\end{array}\right|$ & $\mid$ & 志 & $\stackrel{ }{i}$ & 12 & $\begin{array}{l}+ \\
\infty \\
\infty \\
\infty\end{array}$ & & 志 & I & $\vec{\sim}$ & 6 & $\infty$ & $\underset{\infty}{+}$ \\
\hline
\end{tabular}




\begin{tabular}{|c|c|c|c|c|c|c|c|c|c|c|c|c|c|c|c|c|c|c|c|}
\hline & 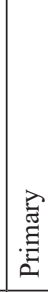 & 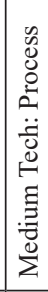 & 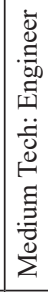 & 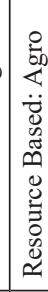 & 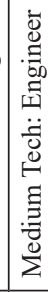 & 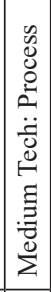 & 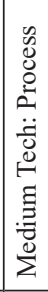 & 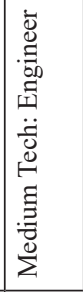 & 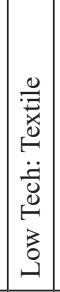 & 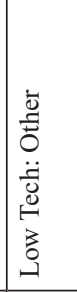 & 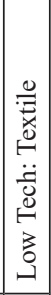 & 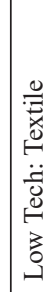 & 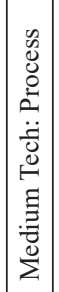 & 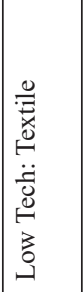 & 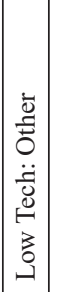 & 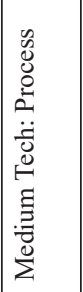 & 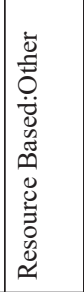 & 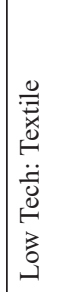 & 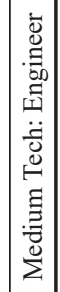 \\
\hline$\Sigma$ & 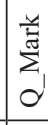 & 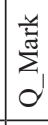 & 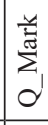 & $\frac{y}{\bar{Z}}$ & 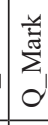 & 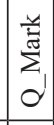 & $\begin{array}{l}\frac{y}{u} \\
\sum \\
d \\
d\end{array}$ & 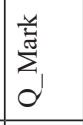 & 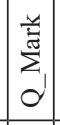 & 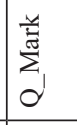 & 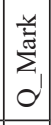 & $\frac{y}{\vdots}$ & 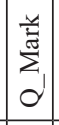 & 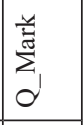 & $\begin{array}{c}\frac{y}{\vec{z}} \\
\sum \\
\alpha\end{array}$ & 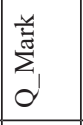 & $\sum_{j}^{\frac{y}{J}}$ & $\sum_{d}^{\frac{y}{\pi}}$ & 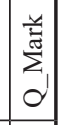 \\
\hline & 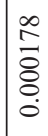 & 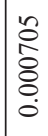 & 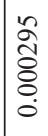 & $\begin{array}{l}\tilde{0} \\
\tilde{\Omega} \\
\delta \\
0 \\
0\end{array}$ & $\begin{array}{l}\tilde{n} \\
\tilde{\delta} \\
8 \\
0 \\
0\end{array}$ & $\begin{array}{l}n \\
0 \\
1 \\
1 \\
0 \\
\infty \\
i\end{array}$ & 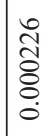 & $\begin{array}{l}\hat{\tilde{g}} \\
\stackrel{8}{8} \\
\dot{8} \\
\dot{0}\end{array}$ & 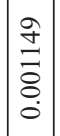 & $\begin{array}{l}\bar{\Xi} \\
\frac{n}{8} \\
\vdots \\
0\end{array}$ & $\mid \begin{array}{c}\sigma \\
\delta \\
\delta \\
\vdots \\
\dot{\sigma}\end{array}$ & 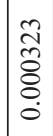 & $\begin{array}{l}\frac{m}{m} \\
\frac{n}{8} \\
\dot{0} \\
\dot{0}\end{array} \mid$ & $\begin{array}{l}n \\
2 \\
2 \\
\delta \\
8 \\
0\end{array}$ & $\left|\begin{array}{l}0 \\
0 \\
0 \\
8 \\
0 \\
0\end{array}\right|$ & 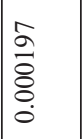 & ڤે & 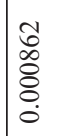 & \begin{tabular}{c}
$\infty$ \\
$\stackrel{\infty}{n}$ \\
\hdashline \\
0 \\
0
\end{tabular} \\
\hline$\theta$ & $\begin{array}{l}\hat{n} \\
\hat{\sigma} \\
\hat{\alpha} \\
\dot{0}\end{array}$ & $\begin{array}{l}\mathfrak{2} \\
\mathbb{N} \\
\infty \\
\infty \\
0 \\
0\end{array}$ & $\begin{array}{l}\text { पे } \\
\text { Oे } \\
0 \\
\infty \\
0 \\
0\end{array}$ & 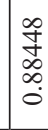 & $\begin{array}{l}\stackrel{a}{f} \\
\infty \\
\infty \\
\infty \\
0 \\
0\end{array}$ & $\begin{array}{l}0 \\
\dot{0} \\
0 \\
0 \\
0 \\
0 \\
0\end{array}$ & 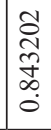 & 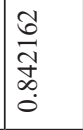 & $\begin{array}{c}\vec{\infty} \\
\infty \\
\vec{\infty} \\
\infty \\
0\end{array}$ & \begin{tabular}{l}
0 \\
\multirow{1}{*}{} \\
$\infty$ \\
$\tilde{I}$ \\
0 \\
0
\end{tabular} & $\begin{array}{l}\vec{n} \\
\stackrel{n}{\delta} \\
0 \\
0 \\
0\end{array}$ & $\begin{array}{l}\infty \\
\stackrel{\infty}{\sigma} \\
\underset{J}{J} \\
\infty \\
0 \\
\end{array}$ & 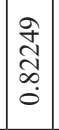 & $\begin{array}{l}\stackrel{\infty}{n} \\
\stackrel{\sim}{\approx} \\
\infty \\
0 \\
0\end{array}$ & $\left|\begin{array}{c}\infty \\
0 \\
0 \\
0 \\
\infty \\
0 \\
0\end{array}\right|$ & $\begin{array}{l}+ \\
\stackrel{\infty}{\sigma} \\
\stackrel{\alpha}{\infty} \\
\dot{0}\end{array}$ & $\begin{array}{l}\infty \\
\infty \\
0 \\
0\end{array}$ & $\begin{array}{l}0 \\
0 \\
0 \\
0 \\
0\end{array}$ & 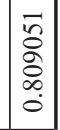 \\
\hline & 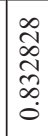 & \begin{tabular}{l}
$n$ \\
\multirow{1}{*}{} \\
$\infty$ \\
$\infty$ \\
0 \\
0
\end{tabular} & 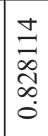 & $\begin{array}{l}\sigma \\
\infty \\
\infty \\
\approx \\
\infty \\
0 \\
0\end{array}$ & 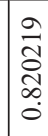 & $\begin{array}{l}2 \\
\infty \\
0 \\
0 \\
\infty \\
0 \\
0\end{array}$ & $\begin{array}{l}\infty \\
\stackrel{\infty}{0} \\
\infty \\
\stackrel{\infty}{0} \\
0\end{array}$ & $\begin{array}{l}\hat{n} \\
\hat{\infty} \\
\infty \\
0 \\
0\end{array}$ & 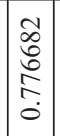 & 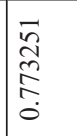 & \begin{tabular}{|l|}
$\mid \infty$ \\
0 \\
0 \\
$\stackrel{2}{8}$ \\
$\hat{0}$ \\
0
\end{tabular} & 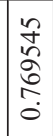 & $\begin{array}{l}a \\
2 \\
2 \\
0 \\
0 \\
0\end{array}$ & \begin{tabular}{l}
$\frac{2}{2}$ \\
\multirow{6}{0}{} \\
$\stackrel{0}{0}$
\end{tabular} & $\begin{array}{l}0 \\
0 \\
0 \\
0 \\
0 \\
0 \\
0\end{array}$ & $\begin{array}{l}\frac{0}{2} \\
\stackrel{a}{0} \\
\stackrel{0}{0}\end{array}$ & 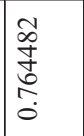 & 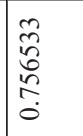 & $\begin{array}{l}\overrightarrow{\tilde{y}} \\
\tilde{n} \\
\tilde{n} \\
\tilde{\sigma}\end{array}$ \\
\hline 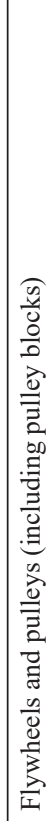 & 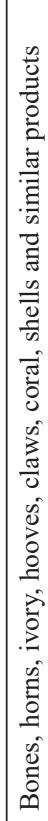 & 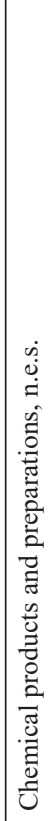 & 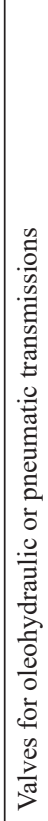 & 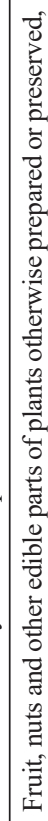 & 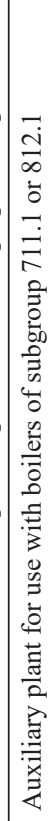 & 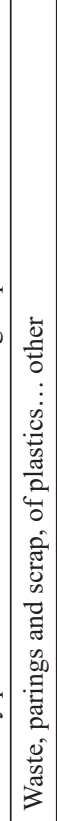 & 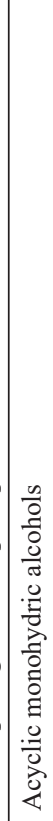 & 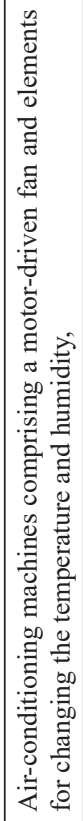 & 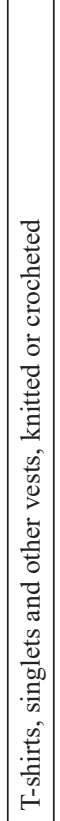 & 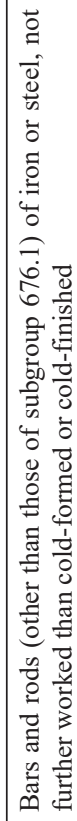 & 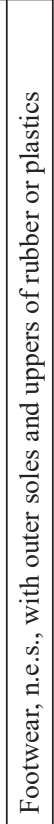 & 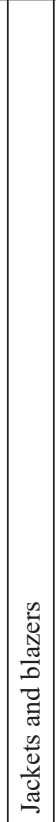 & 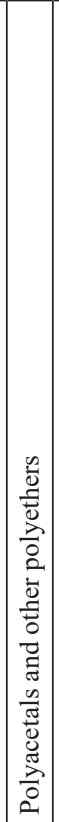 & 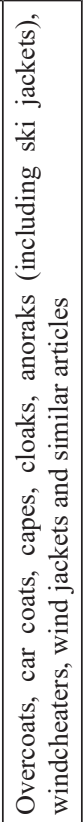 & 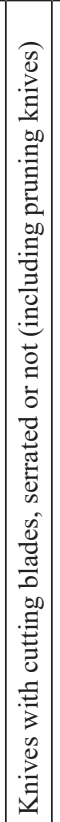 & 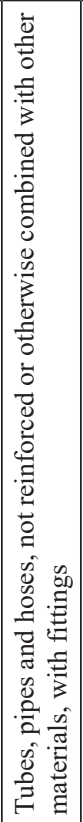 & 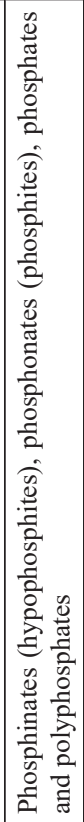 & 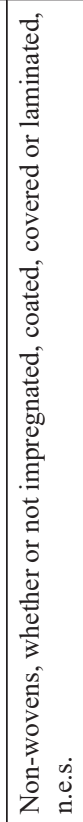 & 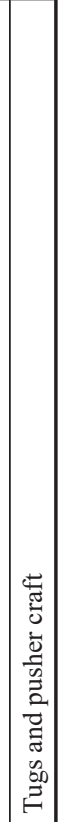 \\
\hline$\infty$ & $\overline{\vec{\sim}}$ & $\begin{array}{l}\infty \\
\text { in }\end{array}$ & $\underset{⿱}{\stackrel{2}{I}}$ & $\stackrel{\infty}{\infty}$ & $\stackrel{ }{ }$ & 六 & $\vec{\sim}$ & $\frac{7}{7}$ & 志 & $\begin{array}{l}0 \\
6 \\
6\end{array}$ & $\frac{m}{2}$ & 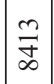 & in & J & $\begin{array}{l}\infty \\
0 \\
8\end{array}$ & & in & $\frac{2}{\hat{b}}$ & $\hat{2}$ \\
\hline
\end{tabular}




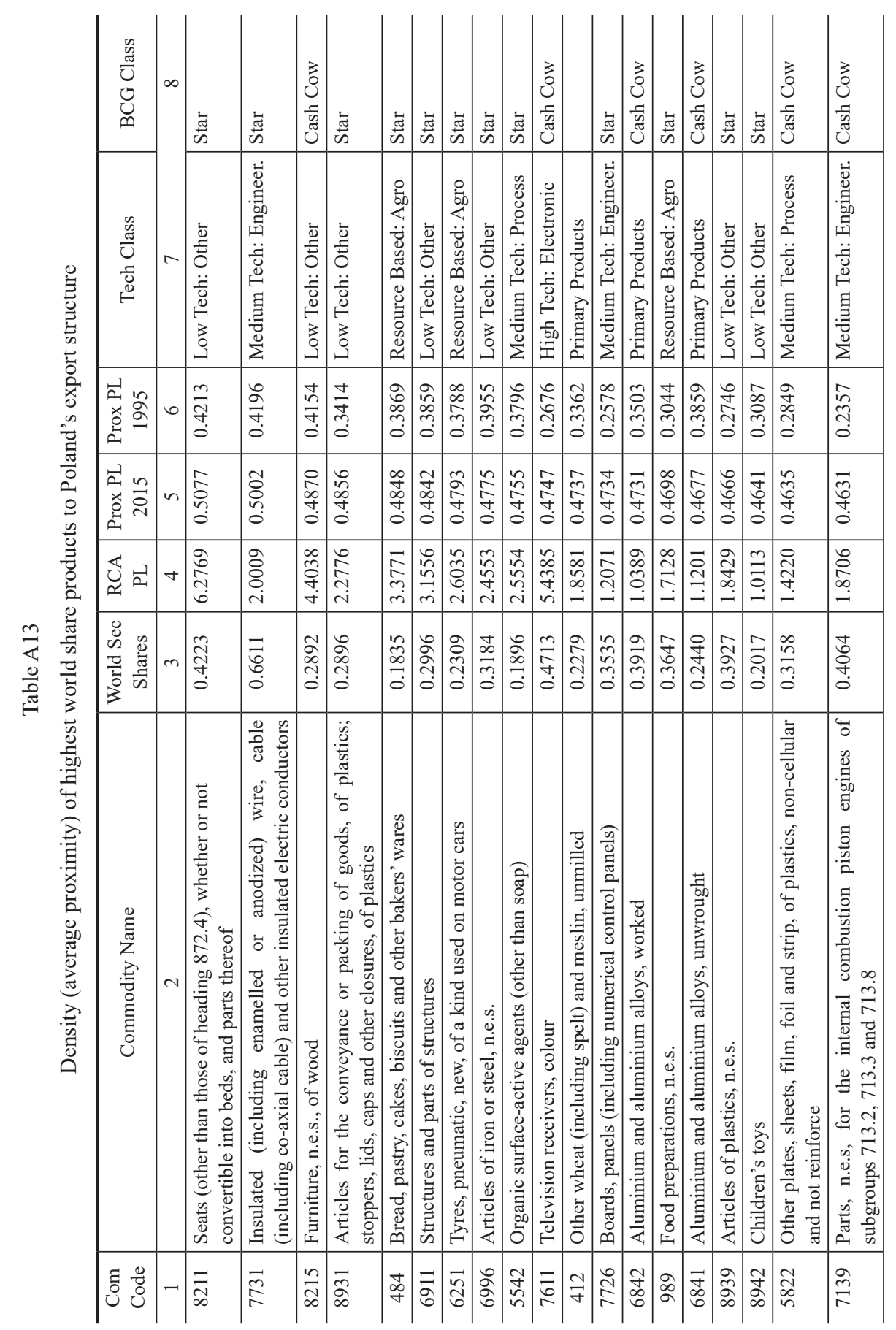




\begin{tabular}{|c|c|c|c|c|c|c|c|c|c|c|c|c|c|c|c|c|c|c|c|c|}
\hline 节 & \begin{tabular}{|c|}
3 \\
0 \\
0 \\
0 \\
$\tilde{z}$ \\
0
\end{tabular} & 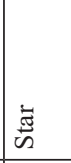 & $\begin{array}{l}\tilde{\Xi} \\
\tilde{H}\end{array}$ & & 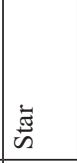 & 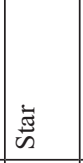 & 壳 & \begin{tabular}{|c|} 
\\
0 \\
0 \\
-5 \\
$\tilde{z}$ \\
$\tilde{J}$ \\
\end{tabular} & $\begin{array}{l}3 \\
0 \\
0 \\
-1 \\
\tilde{n} \\
\tilde{z}\end{array}$ & 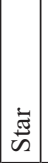 & 志 & 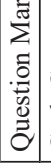 & 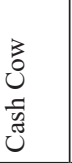 & 离 & $\mid \begin{array}{l}\infty \\
0 \\
0\end{array}$ & $\stackrel{0}{\circ}$ & & & & 忢 \\
\hline 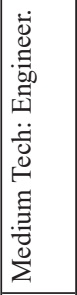 & 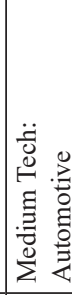 & 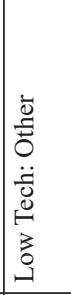 & 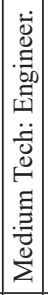 & 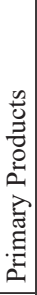 & 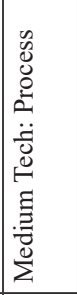 & 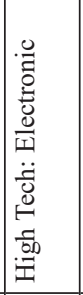 & 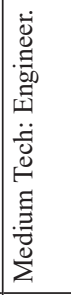 & 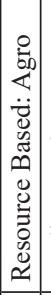 & 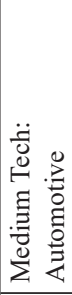 & 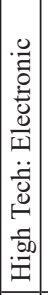 & 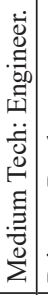 & 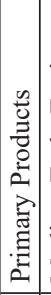 & 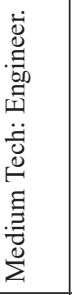 & 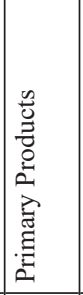 & 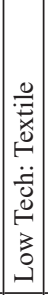 & 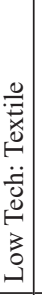 & 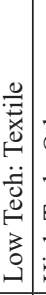 & 它 & 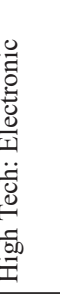 & 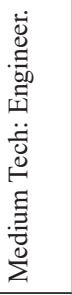 \\
\hline$\frac{\bar{y}}{\bar{y}}$ & 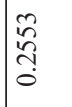 & 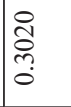 & $\mid \begin{array}{l}\infty \\
0 \\
0 \\
\tilde{n} \\
0\end{array}$ & $\begin{array}{c}\tilde{1} \\
\tilde{\infty} \\
\vdots \\
0 \\
0\end{array}$ & 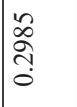 & 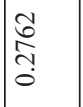 & 光 & 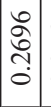 & 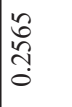 & 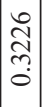 & 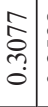 & 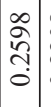 & 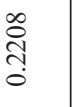 & $\begin{array}{l}\tilde{N} \\
\infty \\
\infty \\
0 \\
0\end{array}$ & $\begin{array}{c}\overrightarrow{7} \\
\stackrel{5}{+} \\
\stackrel{0}{0}\end{array}$ & 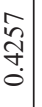 & $\begin{array}{l}\hat{\infty} \\
\text { aे } \\
\text { aे }\end{array}$ & $\begin{array}{l}0 \\
0 \\
b \\
\vdots \\
0\end{array}$ & & $\begin{array}{l}\stackrel{N}{\tilde{J}} \\
\stackrel{\sim}{0}\end{array}$ \\
\hline$\frac{1}{0}$ & 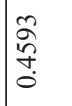 & $\begin{array}{l}n \\
n \\
n \\
0 \\
0\end{array}$ & 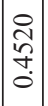 & \begin{tabular}{l}
$\stackrel{0}{2}$ \\
\multirow{+}{+}{} \\
$\dot{0}$
\end{tabular} & $\begin{array}{l}\infty \\
\stackrel{\infty}{+} \\
\stackrel{0}{+}\end{array}$ & 㔬 & 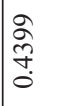 & $\left|\begin{array}{c}\stackrel{0}{0} \\
\stackrel{f}{f} \\
\stackrel{0}{0}\end{array}\right|$ & 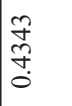 & $\begin{array}{c}\hat{\tilde{ల}} \\
\tilde{\tilde{\sigma}} \\
\tilde{0}\end{array}$ & 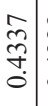 & $\begin{array}{l}\tilde{J} \\
\tilde{f} \\
\stackrel{0}{0}\end{array}$ & $\begin{array}{l}\vec{\rho} \\
\stackrel{\overbrace{}}{\circ} \\
\stackrel{0}{0}\end{array}$ & 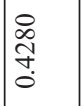 & 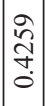 & \begin{tabular}{l}
$\stackrel{f}{ \pm}$ \\
\multirow{2}{*}{} \\
$\stackrel{0}{0}$
\end{tabular} & 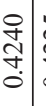 & 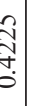 & & $\frac{\infty}{\stackrel{\infty}{7}} \underset{0}{0}$ \\
\hline 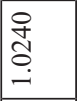 & 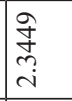 & 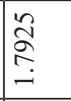 & $\begin{array}{l}\tilde{\partial} \\
\stackrel{2}{i}\end{array}$ & $\begin{array}{l}0 \\
: \\
0 \\
\dot{0}\end{array}$ & 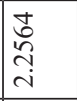 & 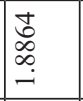 & 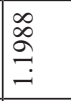 & \begin{tabular}{|c|}
$\vec{n}$ \\
$\hat{n}$ \\
\\
\end{tabular} & 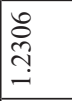 & 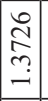 & $\begin{array}{l}0 \\
\tilde{8} \\
0 \\
\end{array}$ & $\begin{array}{l}n \\
n \\
n \\
o \\
0\end{array}$ & $\begin{array}{l}\infty \\
\text { ơ } \\
\text { Oे } \\
\end{array}$ & $\begin{array}{l}\vec{i} \\
\stackrel{i}{i} \\
\text { in }\end{array}$ & 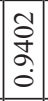 & $\begin{array}{l}\hat{\tilde{\imath}} \\
\dot{0} \\
0\end{array}$ & $\begin{array}{l}\widehat{\Upsilon} \\
\stackrel{2}{*} \\
0\end{array}$ & $\begin{array}{l}\mathbb{1} \\
0 \\
0 \\
0 \\
0 \\
\end{array}$ & & 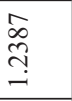 \\
\hline$=$ & 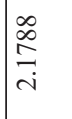 & 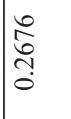 & 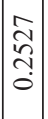 & $\begin{array}{l}+ \\
+ \\
0 \\
0 \\
0\end{array}$ & 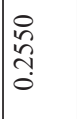 & 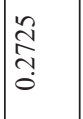 & $\frac{n}{2}$ & $\left|\begin{array}{c}0 \\
+ \\
\infty \\
0 \\
0\end{array}\right|$ & $\begin{array}{l}2 \\
2 \\
\infty \\
0 \\
0\end{array}$ & $\mid \begin{array}{l}\tilde{n} \\
\hat{N} \\
\tilde{n}\end{array}$ & 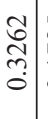 & 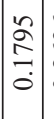 & 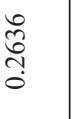 & $\frac{\tilde{n}}{\text { ñ }}$ & $\mid \begin{array}{l}\infty \\
\stackrel{2}{0} \\
\stackrel{0}{0}\end{array}$ & 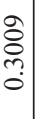 & 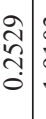 & $\frac{6}{6}$ & & 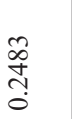 \\
\hline 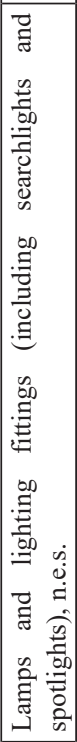 & 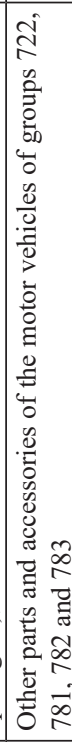 & 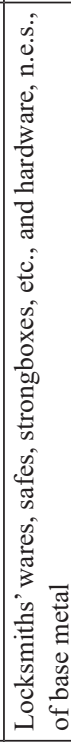 & 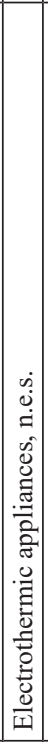 & 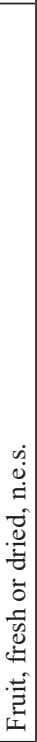 & 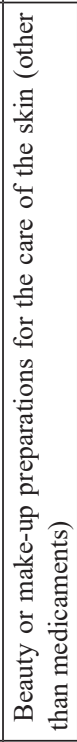 & 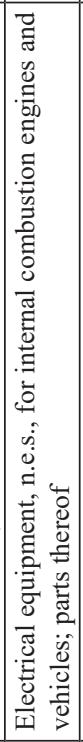 & 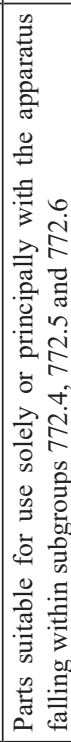 & 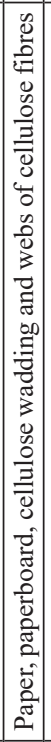 & 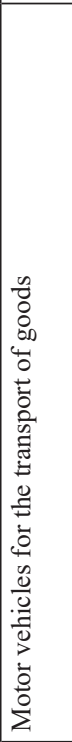 & 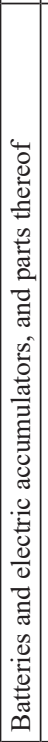 & 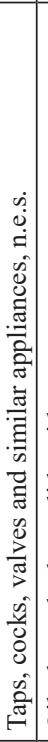 & 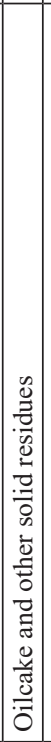 & 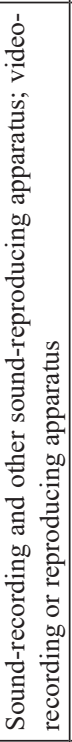 & 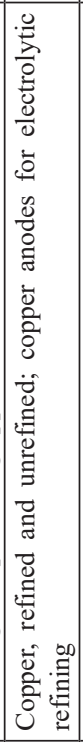 & 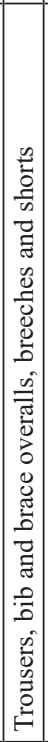 & 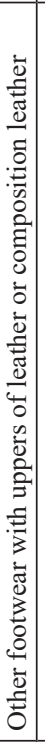 & 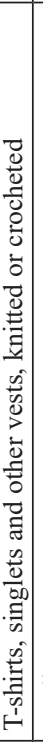 & 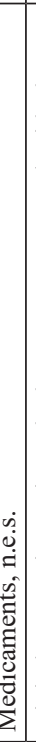 & 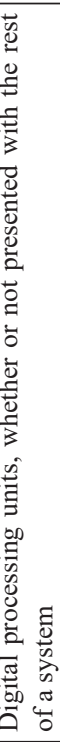 & 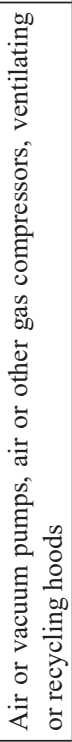 \\
\hline $\bar{\Omega}$ & $\stackrel{9}{+}$ & $\bar{\Omega}$ & $\mid \begin{array}{l}\infty \\
\stackrel{2}{\curvearrowright} \\
\hat{n}\end{array}$ & 2 & $m$ & $\infty$ & & 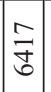 & $\therefore$ & 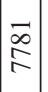 & 寺 & $\frac{m}{\infty}$ & & $\overrightarrow{\widetilde{d}}$ & $\begin{array}{l} \pm \\
⿱ 亠 乂 \\
\infty\end{array}$ & & in & & & $\overline{\stackrel{g}{q}}$ \\
\hline
\end{tabular}




\begin{tabular}{|c|c|c|c|c|c|c|c|c|c|c|c|c|c|c|c|c|c|c|c|c|}
\hline & 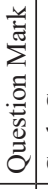 & 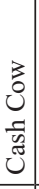 & $\begin{array}{l}\infty 0 \\
0^{\circ} \\
\end{array}$ & $\begin{array}{l}00 \\
\circ \\
\end{array}$ & 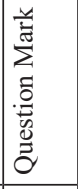 & 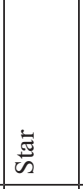 & $\begin{array}{l}\infty 00 \\
0 \\
\end{array}$ & $\begin{array}{l}3 \\
0 \\
0 \\
-7 \\
\tilde{n} \\
\tilde{z} \\
0\end{array}$ & $\begin{array}{l}00 \\
\stackrel{2}{0} \\
\end{array}$ & $\begin{array}{l}\infty 0 \\
\stackrel{0}{0}\end{array}$ & 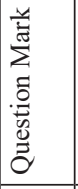 & \begin{tabular}{|l|}
$\vec{\Xi}$ \\
$\ddot{\omega}$
\end{tabular} & 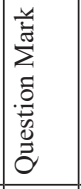 & 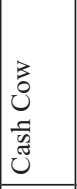 & \begin{tabular}{|c|}
00 \\
0 \\
0
\end{tabular} & \begin{tabular}{|l|} 
\\
00 \\
0 \\
0
\end{tabular} & & $\stackrel{\mathscr{g}}{\tilde{a}}$ & 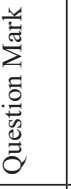 & \\
\hline & 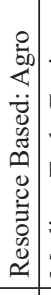 & 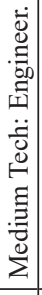 & 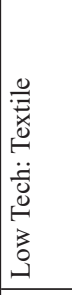 & 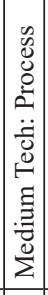 & 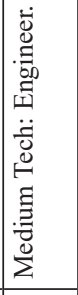 & 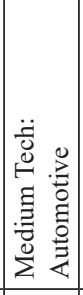 & 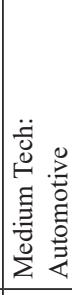 & 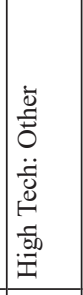 & 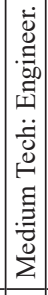 & 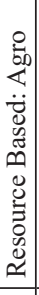 & 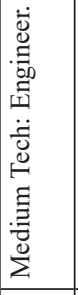 & 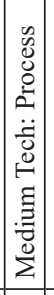 & 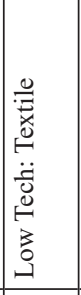 & 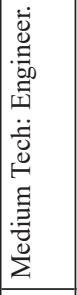 & 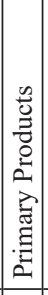 & 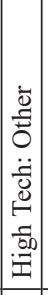 & 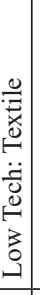 & 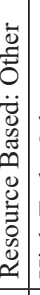 & 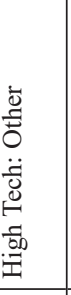 & \\
\hline 0 & 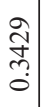 & 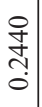 & $\underset{\stackrel{F}{\sim}}{\stackrel{f}{+}}$ & 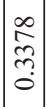 & 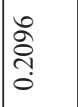 & $\begin{array}{c}\infty \\
\sim \\
\sim\end{array}$ & $\mid \begin{array}{l}\tilde{n} \\
\tilde{n} \\
n\end{array}$ & రీ & ָ̊. & $\begin{array}{l}\hat{n} \\
\tilde{0} \\
\vdots \\
0\end{array}$ & i & 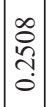 & $\frac{8}{7}$ & a & $\mid \begin{array}{c} \pm \\
\infty \\
\tilde{n} \\
0\end{array}$ & 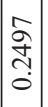 & 6 & $\begin{array}{l}\stackrel{8}{\pi} \\
\text { ?] } \\
0\end{array}$ & & \\
\hline$n$ & $\mid \begin{array}{c}\mathcal{J} \\
\stackrel{f}{f} \\
0\end{array}$ & $\begin{array}{l}0 \\
\\
\overrightarrow{7} \\
0\end{array}$ & 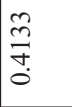 & 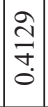 & $\mid$\begin{tabular}{l}
2 \\
\multirow{\sigma}{\sigma}{} \\
$\dot{0}$
\end{tabular} & 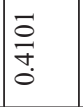 & $\approx$ & $y$ & $\mid \begin{array}{l}2 \\
\vdots \\
\vdots \\
0 \\
0\end{array}$ & 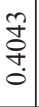 & ồ & 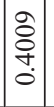 & 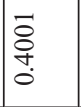 & & $\mid \begin{array}{l}0 \\
\infty \\
\infty \\
\tilde{0} \\
0\end{array}$ & $\mid \begin{array}{l}\infty \\
0 \\
\infty \\
\tilde{0} \\
0\end{array}$ & $\tilde{n}$ & $\begin{array}{l}\hat{\tilde{m}} \\
\infty \\
\tilde{0} \\
0\end{array}$ & & \\
\hline 寸 & \begin{tabular}{l}
$\vec{n}$ \\
\multirow{2}{0}{} \\
$\stackrel{0}{*}$
\end{tabular} & 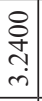 & $\begin{array}{l}\hat{2} \\
2 \\
\hat{2} \\
0\end{array}$ & $\begin{array}{c}2 \\
\stackrel{0}{0} \\
\infty \\
\dot{0} \\
\end{array}$ & 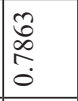 & 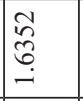 & \begin{tabular}{l}
$\stackrel{+}{+}$ \\
\multirow{I}{*}{} \\
0
\end{tabular} & 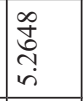 & $\begin{array}{l}7 \\
\infty \\
0 \\
0\end{array}$ & $\begin{array}{l}0 \\
+ \\
0 \\
0 \\
\dot{0}\end{array}$ & $\frac{\infty}{2}$ & \begin{tabular}{|c|} 
\\
0 \\
0 \\
0 \\
- \\
\end{tabular} & $\begin{array}{l}\infty \\
\infty \\
\infty \\
\infty\end{array}$ & & \begin{tabular}{|c|}
$\hat{m}$ \\
$\stackrel{0}{0}$ \\
$\dot{0}$
\end{tabular} & 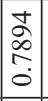 & $\underline{z}$ & $\begin{array}{l}8 \\
8 \\
0 \\
0\end{array}$ & & \\
\hline$n$ & 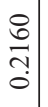 & $\begin{array}{c}\overrightarrow{0} \\
\stackrel{+}{+} \\
\stackrel{0}{0}\end{array}$ & 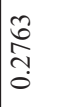 & 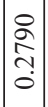 & 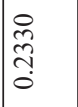 & $\frac{2}{\sim}$ & 竞 & 7 & $\mid \begin{array}{c}\stackrel{1}{ } \\
\infty \\
0 \\
0 \\
0\end{array}$ & 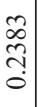 & 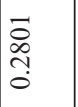 & $\mid \begin{array}{c}2 \\
\stackrel{\alpha}{0} \\
\stackrel{0}{0}\end{array}$ & 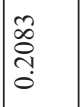 & & $\mid \begin{array}{c}0 \\
n \\
n \\
n \\
m\end{array}$ & $\mid \begin{array}{c}\overrightarrow{0} \\
\hat{\tilde{े}} \\
\hat{0}\end{array}$ & $\begin{array}{l}\vec{n} \\
\stackrel{0}{0}\end{array}$ & 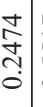 & & \\
\hline $\mathrm{N}$ & 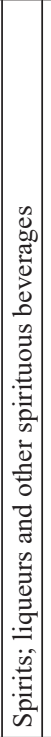 & 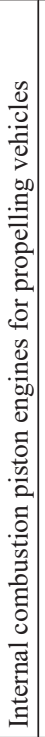 & 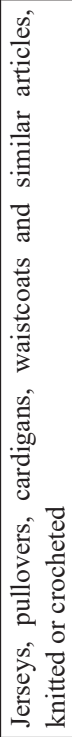 & 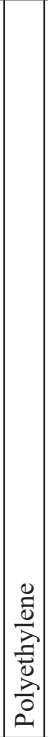 & 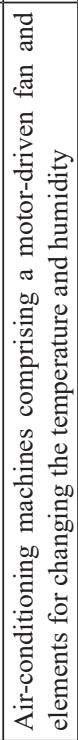 & 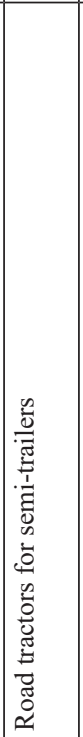 & 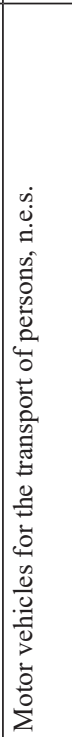 & 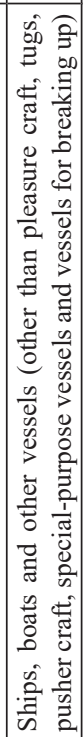 & 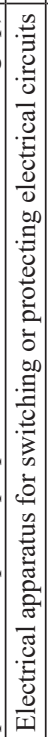 & 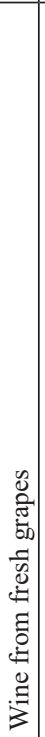 & 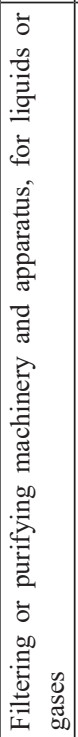 & 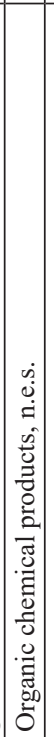 & 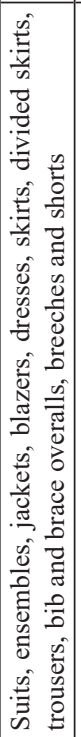 & 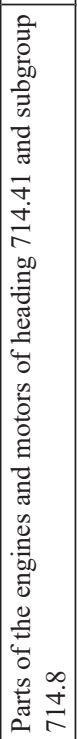 & 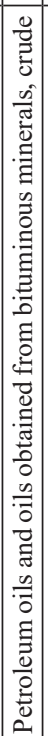 & 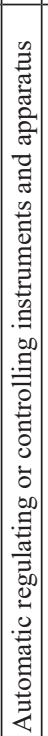 & 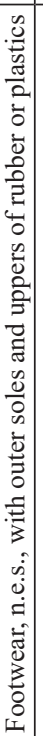 & 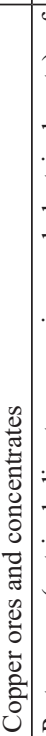 & 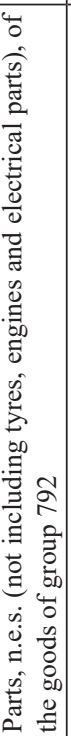 & \\
\hline & $\vec{\sim}$ & & 2 & $\bar{\nabla}$ & $\frac{4}{7}$ & & $\approx$ & જิ & a & & ल) & $\begin{array}{l}0 \\
\infty \\
0 \\
i n\end{array}$ & & & 隹 & $\frac{⿱}{d}$ & & $\bar{c}$ & & \\
\hline
\end{tabular}


ESCAPE FROM MIDDLE INCOME TRAP...

\begin{tabular}{|c|c|c|c|c|c|c|c|c|c|c|c|c|c|c|c|c|c|c|c|c|c|}
\hline $\begin{array}{l}\vec{v} \\
0 \\
0 \\
0\end{array}$ & 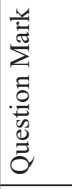 & 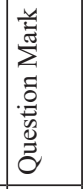 & 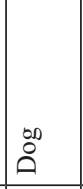 & 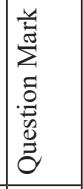 & 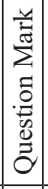 & & 0 & 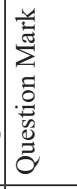 & $\stackrel{6}{0}^{60}$ & $\mid \begin{array}{c}\infty 0 \\
0\end{array}$ & ○ & 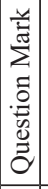 & & 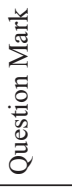 & 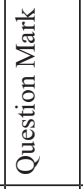 & 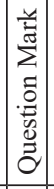 & $\begin{array}{c} \\
8 \\
0 \\
0 \\
0\end{array}$ & & 80 & 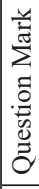 & 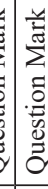 \\
\hline & 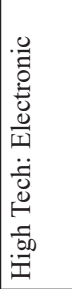 & 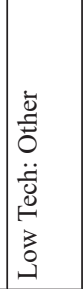 & 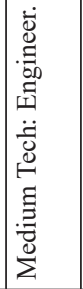 & 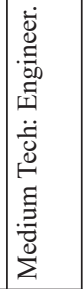 & 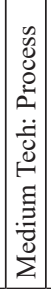 & 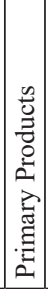 & 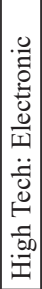 & 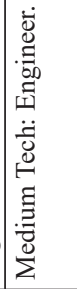 & 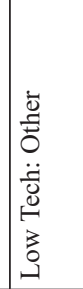 & 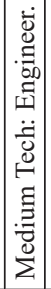 & 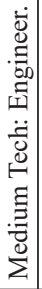 & 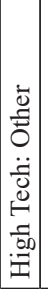 & 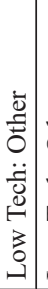 & 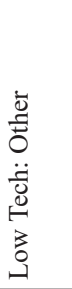 & 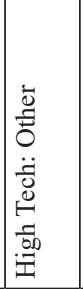 & 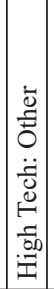 & 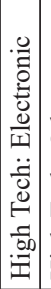 & 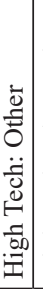 & 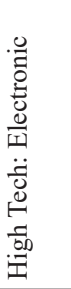 & 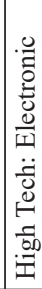 & . \\
\hline 0 & 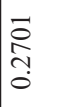 & $\tilde{2}$ & થે & กิ & $\begin{array}{l}\tilde{n} \\
\vdots \\
\vdots \\
0 \\
\vdots\end{array}$ & $\mid \begin{array}{l}\stackrel{0}{2} \\
\hat{n} \\
0 \\
0\end{array}$ & 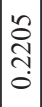 & 苂 & $\cong$ & $\underset{\mathbb{Z}}{\mathbb{J}}$ & 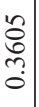 & $\begin{array}{l}\tilde{n} \\
\hat{\tilde{y}} \\
\hat{0}\end{array}$ & $\stackrel{\infty}{N}$ & 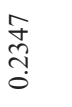 & 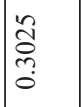 & 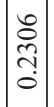 & \begin{tabular}{l}
2 \\
$\infty$ \\
$\infty$ \\
\hdashline \\
0
\end{tabular} & $\triangle$ & $\frac{\tilde{N}}{\tilde{n}}$ & 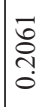 & \\
\hline $\begin{array}{l}0 \\
\infty \\
0 \\
0\end{array} \mid$ & 1 & 8 & : & ?. & 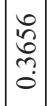 & $\mid \begin{array}{l}\tilde{N} \\
\tilde{0} \\
0 \\
0 \\
0\end{array}$ & 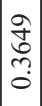 & $\begin{array}{l}2 \\
2 \\
n \\
\tilde{o} \\
0\end{array}$ & $\begin{array}{l}\infty \\
n \\
n\end{array}$ & 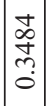 & 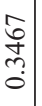 & 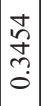 & $\begin{array}{l}8 \\
0 \\
\text { d }\end{array}$ & & 1 & $\mid \begin{array}{c}\tilde{c} \\
\infty \\
\tilde{\omega} \\
\tilde{0}\end{array}$ & $\underset{\hat{n}}{\hat{n}}$ & 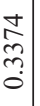 & 0 & $\begin{array}{l}\bar{m} \\
\text { ले } \\
0\end{array}$ & $?$ \\
\hline $\begin{array}{l}0 \\
\vdots \\
0 \\
0\end{array}$ & & 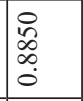 & & in & \begin{tabular}{|c|}
0 \\
0 \\
0 \\
0 \\
0 \\
0
\end{tabular} & $\begin{array}{l} \\
8 \\
0 \\
0 \\
0\end{array}$ & $\begin{array}{l}n \\
\tilde{6} \\
n \\
0 \\
0\end{array}$ & ב & $\begin{array}{l}\alpha \\
y \\
y\end{array}$ & 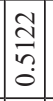 & $\begin{array}{l}4 \\
0 \\
\infty \\
\infty \\
0 \\
0\end{array}$ & $\begin{array}{l} \pm \\
\exists \\
\\
\end{array}$ & & & & 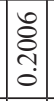 & \begin{tabular}{|c|} 
\\
$\tilde{2}$ \\
$\infty$ \\
0 \\
0 \\
\end{tabular} & & 0 & 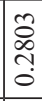 & \\
\hline$\left|\begin{array}{c}0 \\
\infty \\
\\
0\end{array}\right|$ & 4 & 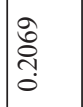 & $\bar{\Omega}$ & $\stackrel{\text { fn }}{n}$ & $\mid \begin{array}{c}m \\
\hat{n} \\
\mathfrak{0} \\
0\end{array}$ & 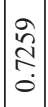 & 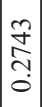 & 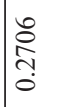 & $\frac{5}{2}$ & $\mid \begin{array}{c}\infty \\
0 \\
0 \\
0\end{array}$ & $\begin{array}{l}0 \\
0 \\
\stackrel{1}{0} \\
0\end{array}$ & $\begin{array}{l}\infty \\
\tilde{2} \\
\hat{\sigma} \\
0\end{array} \mid$ & $\stackrel{\infty}{\widehat{\sigma}}$ & & & $\begin{array}{l}\overrightarrow{\hat{\sigma}} \\
\text { స̦ } \\
0\end{array}$ & $\left|\begin{array}{l}\hat{D} \\
\infty \\
\tilde{0}\end{array}\right|$ & $\dot{q}$ & $\stackrel{\infty}{\rightarrow}$ & $\begin{array}{l}0 \\
\stackrel{0}{0} \\
\vdots \\
0\end{array}$ & \\
\hline 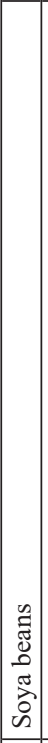 & 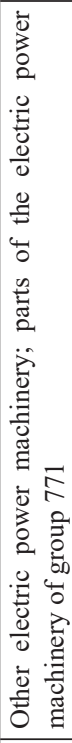 & 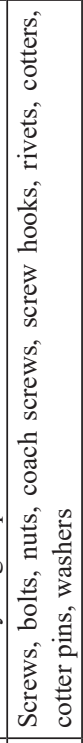 & 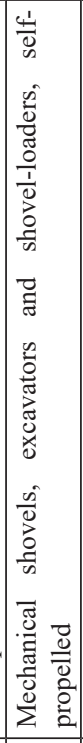 & 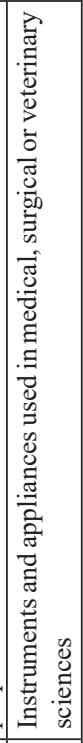 & 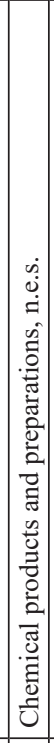 & 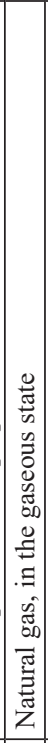 & 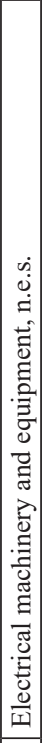 & 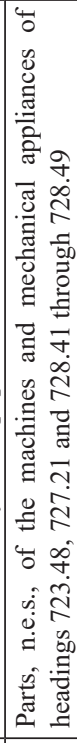 & 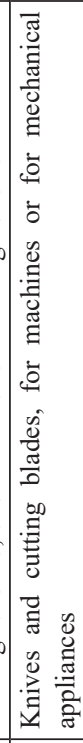 & 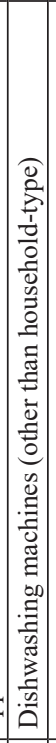 & 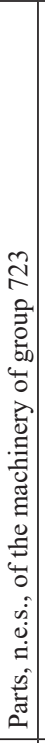 & 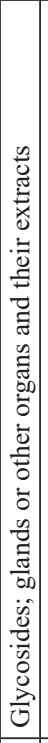 & 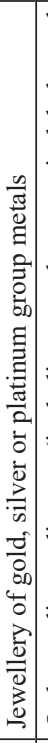 & 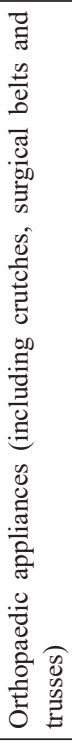 & 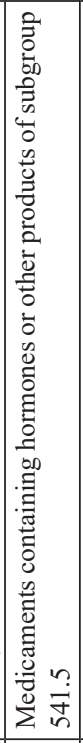 & 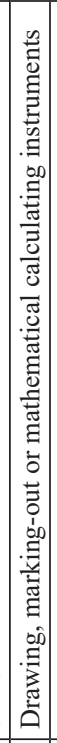 & 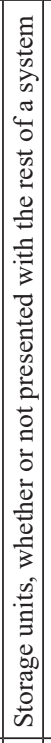 & 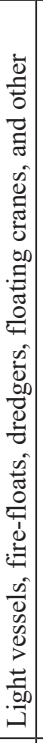 & 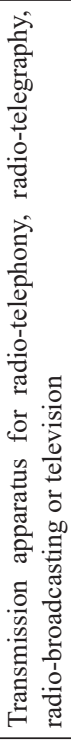 & 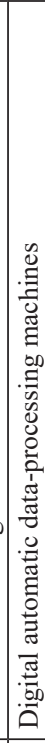 & 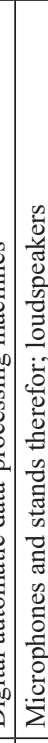 \\
\hline & & I & & d & $\begin{array}{l}\stackrel{2}{2} \\
\text { in }\end{array}$ & $\mid \begin{array}{c}1 \\
\tilde{f} \\
\tilde{m}\end{array}$ & & & & $\approx$ & & 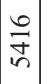 & & & & ㄱ & î & & & j & \\
\hline
\end{tabular}




\begin{tabular}{|c|c|c|c|c|c|c|c|c|c|c|c|c|c|c|c|c|c|c|}
\hline$\infty$ & $\begin{array}{l}\infty \\
0^{\infty} \\
\end{array}$ & 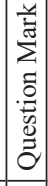 & 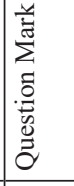 & $\begin{array}{l}\text { bo } \\
. \\
.\end{array}$ & 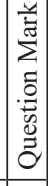 & 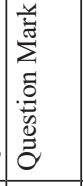 & $\begin{array}{l}00 \\
0 \\
0 \\
\end{array}$ & $\begin{array}{l}00 \\
0 \\
0\end{array}$ & ڤ̊ & 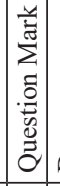 & \begin{tabular}{|c|}
0 \\
0 \\
$\circ$ \\
\end{tabular} & . & $\begin{array}{l}\infty \\
. \\
\end{array}$ & 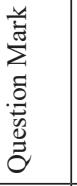 & & 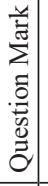 & 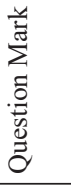 & 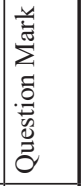 \\
\hline$r$ & 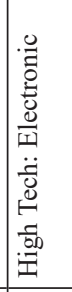 & 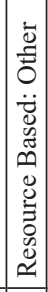 & 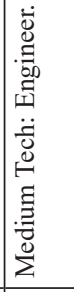 & 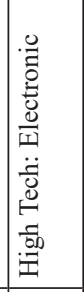 & 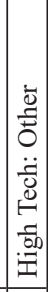 & 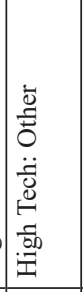 & 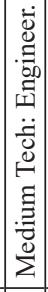 & 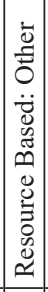 & 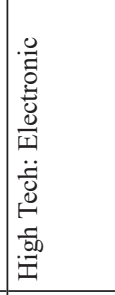 & 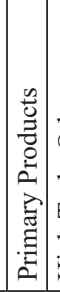 & 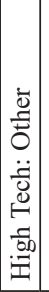 & 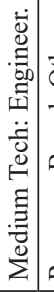 & 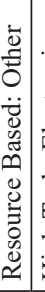 & 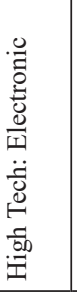 & 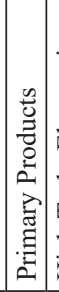 & 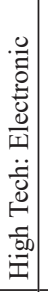 & 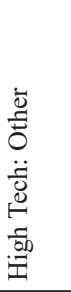 & 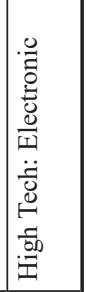 \\
\hline 6 & 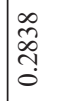 & 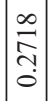 & 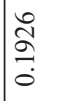 & $\frac{\circ}{\stackrel{0}{N}}$ & $\begin{array}{l}\tilde{\delta} \\
\stackrel{\emptyset}{0} \\
\dot{0}\end{array}$ & 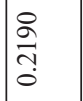 & 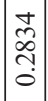 & 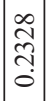 & 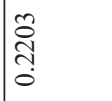 & 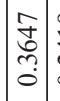 & 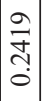 & 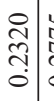 & 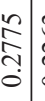 & 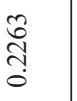 & $\begin{array}{l}\tilde{0} \\
\tilde{n} \\
0 \\
0\end{array}$ & $\begin{array}{l}\text { 岁 } \\
\hat{\sigma} \\
\stackrel{0}{0}\end{array}$ & 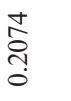 & 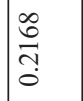 \\
\hline in & $\begin{array}{l}\stackrel{+}{N} \\
\stackrel{0}{0}\end{array}$ & $\begin{array}{l}\tilde{\hat{A}} \\
\stackrel{0}{0}\end{array}$ & $\begin{array}{l}\tilde{N} \\
\tilde{\sim} \\
\tilde{0}\end{array}$ & $\frac{m}{\tilde{m}}$ & $\begin{array}{l}\stackrel{0}{0} \\
\vec{n} \\
0 \\
0\end{array}$ & $\frac{m}{\stackrel{m}{m}}$ & 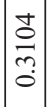 & 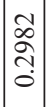 & 홍 & $\mid \begin{array}{l}\hat{\alpha} \\
\dot{\alpha} \\
\hat{0} \\
\dot{0}\end{array}$ & 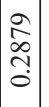 & 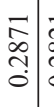 & 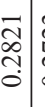 & 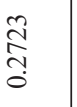 & $\mid \begin{array}{l}\tilde{0} \\
\hat{0} \\
\hat{0} \\
0\end{array}$ & $\begin{array}{l} \pm \\
0 \\
n \\
i \\
0\end{array}$ & 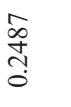 & \begin{tabular}{l}
3 \\
\multirow{6}{0}{} \\
$\tilde{y}$ \\
$\tilde{0}$
\end{tabular} \\
\hline$\nabla$ & $\begin{array}{l}\infty \\
2 \\
6 \\
0 \\
0\end{array}$ & \begin{tabular}{|l|} 
\\
\\
8 \\
0 \\
0
\end{tabular} & $\begin{array}{l}\mathfrak{\alpha} \\
\stackrel{\alpha}{\sigma}\end{array}$ & $\begin{array}{l}\vec{\Xi} \\
\stackrel{n}{0} \\
0\end{array}$ & 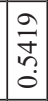 & 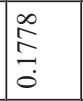 & $\begin{array}{l}\hat{0} \\
\vdots \\
0 \\
0\end{array}$ & \begin{tabular}{|l|} 
\\
\\
8 \\
0 \\
0
\end{tabular} & $\begin{array}{l}\hat{2} \\
\hat{\sigma} \\
\hat{\sigma}\end{array}$ & \begin{tabular}{l}
$\tilde{y}$ \\
\multirow{2}{0}{} \\
$\dot{0}$
\end{tabular} & $\begin{array}{c}\cong \\
\Xi \\
\vdots \\
0\end{array}$ & \begin{tabular}{l|l}
$\vec{t}$ & \\
$\dot{0}$ & \\
$\dot{0}$ &
\end{tabular} & 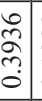 & 8 & \begin{tabular}{|l|} 
\\
\\
$\vdots$ \\
0 \\
$\vdots$
\end{tabular} & \begin{tabular}{|c|} 
\\
\hdashline \\
0 \\
$\circ$ \\
0
\end{tabular} & $\begin{array}{l}\hat{0} \\
0 \\
0 \\
0\end{array}$ & $\begin{array}{l}\vec{\sigma} \\
\text { ơ } \\
\text {. }\end{array}$ \\
\hline$m$ & 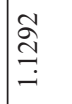 & $\begin{array}{l}n \\
\tilde{2} \\
\hat{\jmath} \\
\vdots\end{array}$ & 売 & 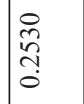 & 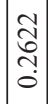 & 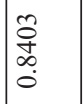 & $\mid$\begin{tabular}{l|}
0 \\
$\overrightarrow{0}$ \\
$\stackrel{0}{0}$ \\
$\stackrel{0}{0}$
\end{tabular} & $\mid \begin{array}{c}\stackrel{0}{a} \\
\infty \\
\stackrel{0}{0}\end{array}$ & 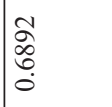 & $\mid \begin{array}{l}\infty \\
2 \\
\tilde{2} \\
\tilde{0}\end{array}$ & $\begin{array}{l}\frac{\infty}{\sim} \\
\stackrel{\sim}{n} \\
0\end{array}$ & 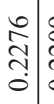 & 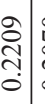 & 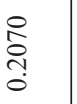 & $\mid \begin{array}{l}0 \\
\infty \\
0 \\
0 \\
0 \\
0\end{array}$ & $\begin{array}{c}= \\
\bar{\lambda} \\
\infty \\
i\end{array} \mid$ & $\begin{array}{l}+ \\
\stackrel{0}{\infty} \\
\stackrel{\infty}{+} \\
0\end{array}$ & 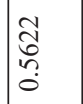 \\
\hline$N$ & 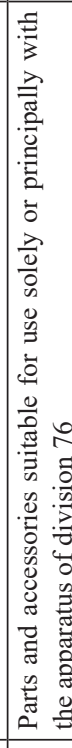 & 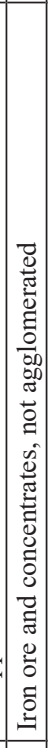 & 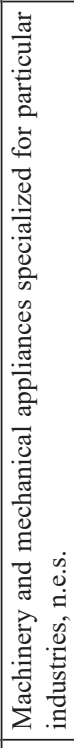 & 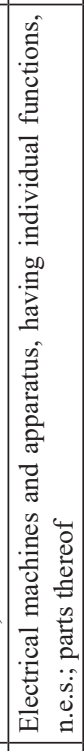 & 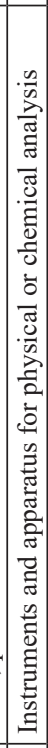 & 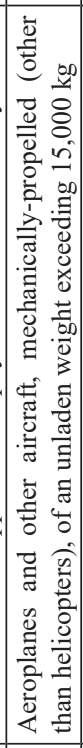 & 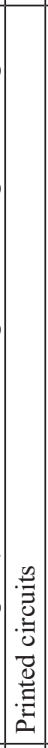 & 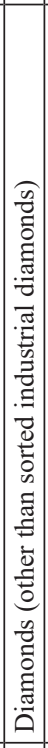 & 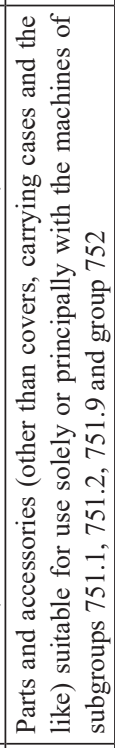 & 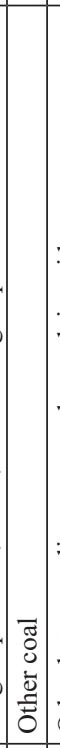 & 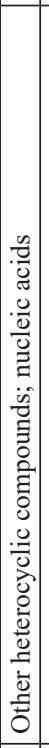 & 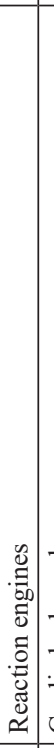 & 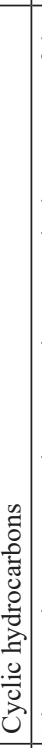 & 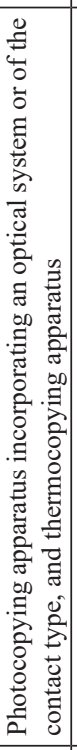 & 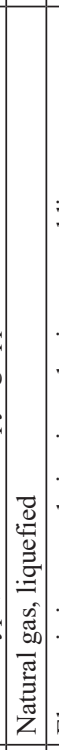 & 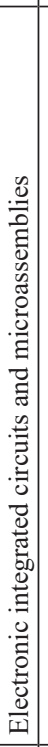 & 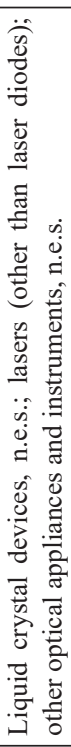 & 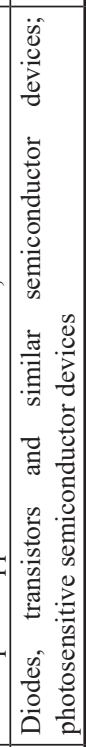 \\
\hline & g) & $\left|\begin{array}{c}n \\
\infty \\
\sim \\
\sim\end{array}\right|$ & $\stackrel{+}{\stackrel{D}{N}}$ & $\infty$ & $\underset{\infty}{\frac{7}{\infty}}$ & 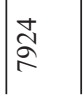 & $\mid \begin{array}{c}\mathbb{N} \\
\stackrel{N}{\approx}\end{array}$ & 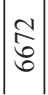 & 을 & $\frac{\sim}{\pi}$ & $\left|\begin{array}{c}n \\
i n \\
i n\end{array}\right|$ & $\frac{g}{\sim}$ & $\frac{N}{\bar{n}}$ & $m$ & $\overrightarrow{\tilde{m}}$ & 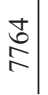 & $\frac{a}{\infty}$ & $\begin{array}{l}\tilde{6} \\
\curvearrowright\end{array}$ \\
\hline
\end{tabular}


Total: $\$ 21.3 \mathrm{~B}$

Graph A1. Poland's export structure in product space (1995)

https://atlas.media.mit.edu/en/visualize/network/sitc/export/pol/all/show/1995/

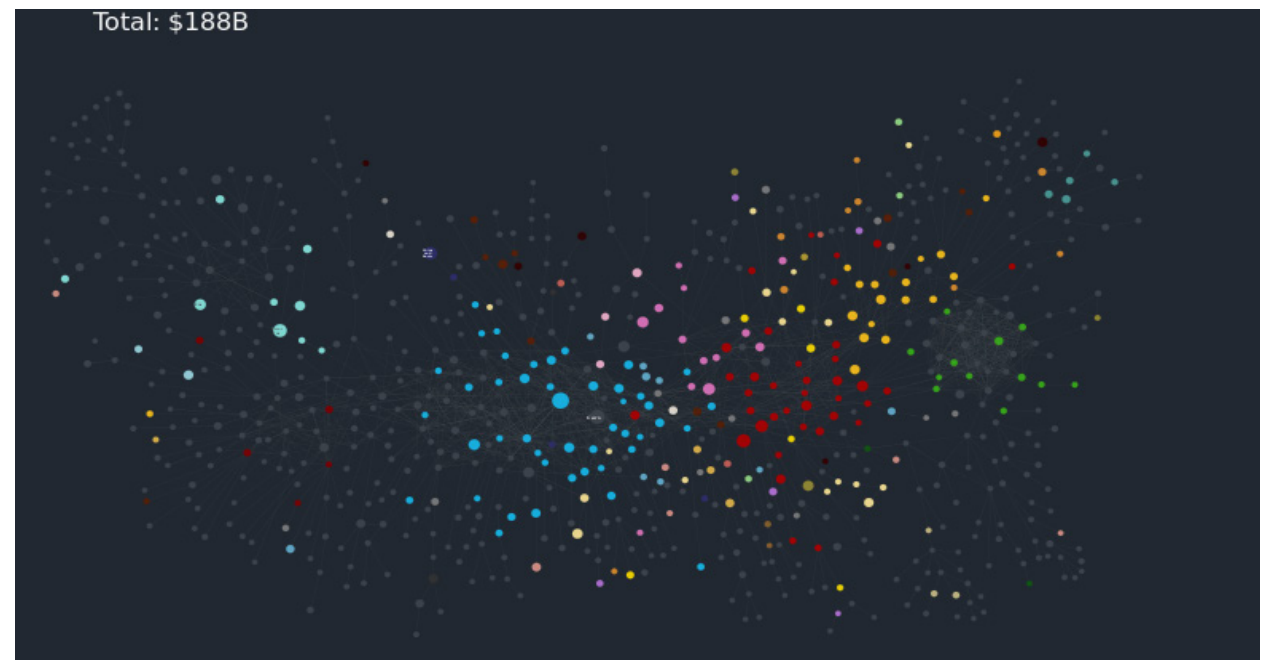

Graph A2. Poland's Export Structure in Product Space (2015)

https://atlas.media.mit.edu/en/visualize/network/sitc/export/pol/all/show/2015/ 


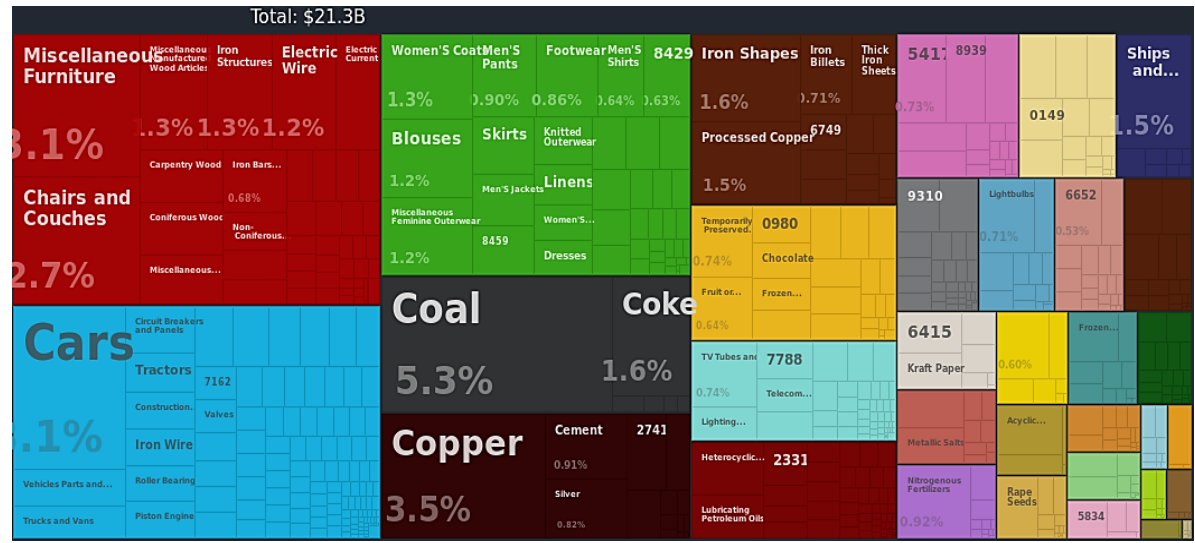

Graph A3. Tree map of Poland's export structure (1995)

https://atlas.media.mit.edu/en/visualize/tree_map/sitc/export/pol/all/show/1995/

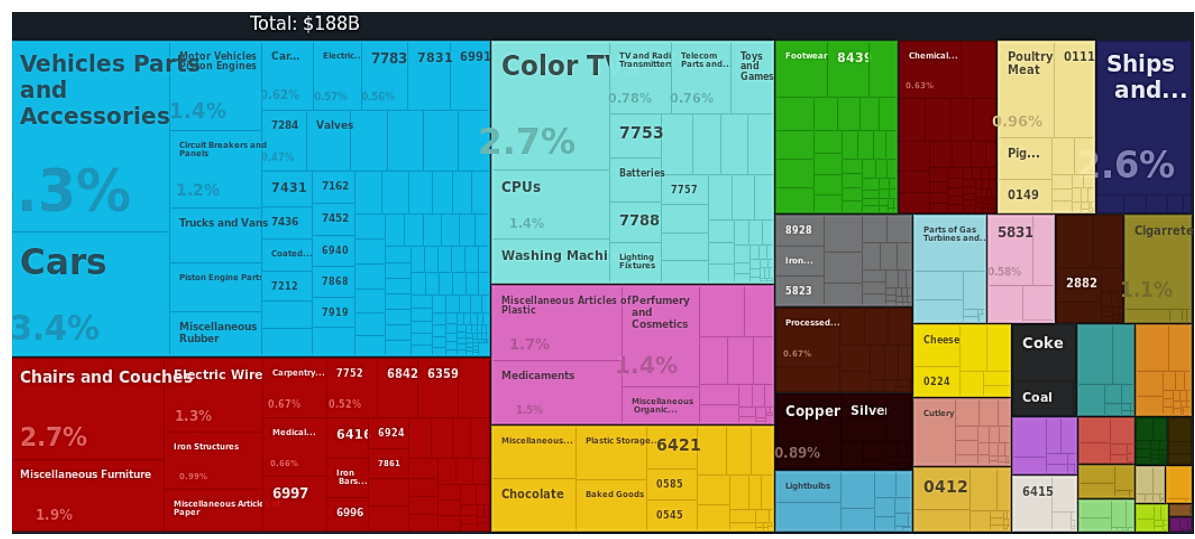

Graph A4. Tree map of Poland's export structure (2015)

https://atlas.media.mit.edu/en/visualize/tree_map/sitc/export/pol/all/show/2015/ 